\title{
Parasitism and contaminants: relationships and underlying mechanisms for a model endohelminth-bird association
}

\author{
by \\ Stacey Adele Robinson
}

\begin{abstract}
A thesis submitted to the Faculty of Graduate and Postdoctoral Affairs in partial fulfillment of the requirements for the degree of
\end{abstract}

\author{
Doctor of Philosophy \\ in \\ Biology \\ Carleton University \\ Ottawa, Ontario \\ (C) 2011
}

Stacey Adele Robinson 
Library and Archives

Canada

Published Heritage

Branch

395 Wellington Street

Ottawa ON K1A 0N4

Canada
Bibliothèque et

Archives Canada

Direction du

Patrimoine de l'édition

395 , rue Wellington

Ottawa ON K1A ON4

Canada
Your file Votre référence

ISBN: 978-0-494-81580-9

Our file Notre référence

ISBN: $978-0-494-81580-9$
NOTICE:

The author has granted a nonexclusive license allowing Library and Archives Canada to reproduce, publish, archive, preserve, conserve, communicate to the public by telecommunication or on the Internet, loan, distribute and sell theses worldwide, for commercial or noncommercial purposes, in microform, paper, electronic and/or any other formats.

The author retains copyright ownership and moral rights in this thesis. Neither the thesis nor substantial extracts from it may be printed or otherwise reproduced without the author's permission.
AVIS:

L'auteur a accordé une licence non exclusive permettant à la Bibliothèque et Archives Canada de reproduire, publier, archiver, sauvegarder, conserver, transmettre au public par télécommunication ou par l'Internet, prêter, distribuer et vendre des thèses partout dans le monde, à des fins commerciales ou autres, sur support microforme, papier, électronique et/ou autres formats.

L'auteur conserve la propriété du droit d'auteur et des droits moraux qui protège cette thèse. $\mathrm{Ni}$ la thèse ni des extraits substantiels de celle-ci ne doivent être imprimés ou autrement reproduits sans son autorisation.
In compliance with the Canadian Privacy Act some supporting forms may have been removed from this thesis.

While these forms may be included in the document page count, their removal does not represent any loss of content from the thesis.
Conformément à la loi canadienne sur la protection de la vie privée, quelques formulaires secondaires ont été enlevés de cette thèse.

Bien que ces formulaires aient inclus dans la pagination, il n'y aura aucun contenu manquant. 


\begin{abstract}
Organisms are subjected to multiple stressors; however, their occurrence or impacts often have been studied separately. Interactions between stressors must be considered to understand fully their impacts on organisms. Herein. I explore whether endoparasites (helminths) and mercury concentrations are related and determine the factors influencing any such relationships, in double-crested cormorants Phalacrocorax auritus. Cormorants offer a model system well-suited to such investigations because they are top consumers and exposed to these two stressors via the prey fish they consume.

Cormorants showed sex differences in parasitism (Contracaecum spp. and Drepanocephalus spathans) and in mercury concentration, where males had greater burdens of both. However, the males responsible for the sex difference in parasitism were different from the males responsible for the sex difference in mercury concentration. Therefore. I investigated reasons for these two patterns.

I did not find support for reduced immune function in males; a conventional hypothesis for sex differences in parasitism. Instead, I found evidence, in both adults and nestlings, that the sex difference was most likely influenced by sex differences in exposure to infective parasitic stages from sex differences in diet inferred from stable carbon isotope values in breast muscle.

For the independent sex differences in Contracaecum spp. and mercury concentration, I determined whether the parasites sequestered mercury in their own tissues and thus affected the bioaccumulation of mercury by the host. Although Contracaecum spp. bioaccumulated methylmercury by feeding on host tissues this
\end{abstract}


bioaccumulation could not alone explain the magnitude of difference in mercury concentration between low and high mercury concentration males.

I then explored a novel physiological mechanism for the lower concentration of mercury in females compared to males. I found eridence that suggests males and females might differ in their capabilities to demethylate and/or excrete methylmercury from the liver and that egg depuration is not likely the only explanation for sex differences in mercury levels.

In summary, males had greater burdens of endoparasites and mercury: however, rarely did the same males have high burdens of both. I suggest that future studies need to consider inter-sex differences in feeding ecology when examining contaminant-parasite associations in free-ranging organisms. 


\section{Preface}

\section{Co-authorship Statement}

My contributions to the research described in this thesis were: (1) I proposed and developed the research questions in partnership with Drs. M. R. Forbes and C. E. Hebert, and was primarily responsible for the design of the projects used to address these questions: (2) I was primarily responsible for carrying out all the lab work (e.g., necropsy and tissue collections) and mercury and selenium analyses described, and for the field work carried out at Pigeon Island in 2009 (see Chapter 5). I informally supervised a summer lab assistant (L. Hermsen) who helped to process cormorants collected from Lake Erie in 2008 and Lake Ontario in 2009. Dr. J. D. McLaughlin identified the parasite specimens. The stable isotope analyses of cormorant breast muscle and parasite tissue (see Chapters 3-6) were carried out by, or under the direction of, Paul Middlestead. G. G. Hatch Stable Isotope Laboratory, University of Ottawa; (3) I analysed all of the data; and (4) I wrote all first drafts of the chapters/manuscripts.

I used the integrated thesis format and therefore each data chapter was formatted as an independent research article that has either been published in or was submitted to a peer-reviewed journal when this thesis was completed. There is some repetition in introductions and discussions: however I have cross-referenced between chapters to reduce repetition in the methods sections. As indicated above, I always played a major role in the design of the research and in the preparation and writing of each chapter/manuscript. However, I must acknowledge the constructive guidance and advice from my co-authors. My supervisors, Drs. M. R. Forbes and C. E. Hebert contributed 
their theoretical, statistical and grammatical knowledge to each of my six chapter/manuscript drafts listed below. Dr. J. D. McLaughlin was a great asset in identifying parasite species and for providing necropsy training. He also contributed grammatical expertise to the drafts of chapters/manuscripts two, four and five. Lastly, Dr.

A. M. Scheuhammer provided guidance on metal analyses and statistical and grammatical expertise on the drafts for chapter/manuscript six.

I have permission from each publisher to reproduce published manuscripts in my thesis. I have also received permission from each of my co-authors to use the collaborative work in this thesis. A specific chapter that has been published elsewhere must be cited using the journal citation information provided below. However, to reference my thesis as a whole or an unpublished chapter, I recommend using the following citation:

Robinson, S. A. 2011. Parasitism and contaminants: relationships and underlying mechanisms for a model endohelminth-bird association. PhD Thesis, Carleton University. Ottawa, Ontario, Canada.

\section{Chapters - Manuscript status at time of thesis completion}

2 - Robinson, S. A., Forbes, M. R., Hebert. C. E. and McLaughlin. J. D. 2008. Malebiased parasitism by common helminths is not explained by sex differences in body size or spleen mass of breeding cormorants Phalacrocorax auritus. Journal of Avian Biology 39: 272-276. Publisher: John Wiley \& Sons, Inc. 
3- Robinson, S. A., Forbes, M. R. and Hebert, C. E. 2009. Parasitism, mercury contamination, and stable isotopes in fish-eating double-crested cormorants: no support for the co-ingestion hypothesis. Canadian Journal of Zoology 87: 740747. Publisher: NRC Research Press.

4- Robinson, S. A., Forbes, M. R., Hebert. C. E. and McLaughlin, J. D. 2010. Male biased parasitism in cormorants and relationships with foraging ecology on Lake Erie. Canada. Waterbirds 33: 307-313. Publisher: Waterbird Society

5- Robinson, S. A., Forbes, M. R., Hebert. C. E. and McLaughlin, J. D. Sex differences in nematode parasitism and stable isotope signatures, but not total mercury concentration, occur at the chick stage in double-crested cormorants Phalacrocorax aurthis. Journal of Avian Biology (Submitted January 2011). Publisher: John Wiley \& Sons, Inc.

6- Robinson, S. A., Forbes, M. R. and Hebert, C. E. 2010. Mercury in parasitic nematodes and trematodes in double-crested cormorant hosts: Bioaccumulation in the face of sequestration by nematodes. Science of the Total Environment 408: 5439-5444. Publisher: Elsevier.

7- Robinson, S. A.. Forbes, M. R., Hebert, C. E. and Scheuhammer, A. M. 2010. Evidence for sex differences in mercury dynamics in double-crested cormorants. Environmental Science and Technology 45: 1213-1218. Publisher: American Chemical Society. 


\section{Acknowledgements}

I have enjoyed my entire experience as a graduate student at Carleton University. My supervisors, Drs. Mark R. Forbes and Craig E. Hebert provided excellent support, guidance and encouragement throughout my graduate career. Mark and Craig have been fantastic supervisors. Their patience, kindness and genuine interest in seeing me succeed have meant a great deal to me. Mark's strong enthusiasm for data and encouragement to publish was motivating and infectious. Craig has been particularly helpful in organizing the acquisition of samples where he would personally transport, in the back of a van, hundreds of dead birds from Brighton, Leamington and Kingston, Ontario to Ottawa, Ontario. Although my work did not involve much time in the field. Craig was able to include me on other projects. Perhaps the most memorable is travelling by helicopter to a small island at the edge of the Niagara Falls for the collection of herring gull eggs with Chip Weseloh. I will never forget it. Thank you, Craig and Chip.

I would also like to thank my thesis committee members, Drs. Susan Bertram and Tony Gaston. Both Sue and Tony have provided valuable advice throughout the progression of my thesis. Sue always had a smile on her face and a word of encouragement when I would meet her in the hallways of Nesbitt. Tony provided me with the opportunity to teach Nunavut Arctic College students. in Iqaluit, how to collect tissue samples for contaminant analysis. I greatly appreciated this opportunity to experience a bit of the Great Canadian North and to pass on my necropsy knowledge to others. I would also like to thank my B.Sc. Honours supervisor, Dr. Scott Ramsay from Wilfrid Laurier University. I absolutely loved working in the forests at the University of 
Northern British Columbia collecting data on chigger parasitism on white-throated sparrows with Scott. I am very grateful that Scott encouraged me to continue on to graduate school with Mark Forbes.

The people in the Forbes lab have been great colleagues. Previous students, Tonia Robb, Mark Mallory, Yemisi Dare, Paul Smith and Isabel Buttler provided comments on my projects, presentations and writing over the past five years. Tonia took me under her wing and helped me get settled in as a graduate student at Carleton. She not only helped me with the official thesis related areas, but also taught me that graduate school is not all about work, that socializing with others at the pub over a beer is very important. Mark Mallory has been a great resource and friend. He welcomed me into his home when I was visiting Iqaluit and has provided his expert advice on drafts of this thesis. Current members of the Forbes lab (Gregory Bulte, Sam Iverson, Wayne Knee, Julia Mlynarek, Laura Nagel and Will Shim) were also helpful in discussions of my research during the 'weekly' Forbes lab meetings.

I was very fortunate to have access to the facilities at Environment Canada's National Wildlife Research Centre (NWRC). The personnel working in the Specimen Bank (Masresha Asrat, Lisa Hermsen, Robyn Lima, Christine McClelland, Rosalyn McNeil, Guy Savard, and Karen Timm) were wonderful people to work with over the years. They all welcomed me into their lab and offered assistance whenever it was needed. I also worked in the Metals Lab at NWRC and greatly appreciated all the time and effort that Della Bond and Ewa Neugebauer invested into training me for the various metal analyses that were used in this thesis. 
I must recognize the extra effort of Ontario Ministry of National Resources. Parks Canada and Environment Canada personnel involved in the cormorant cull programs on Lake Ontario and Lake Erie (specifically Tammy Dobbie, David Moore, Don Tyerman, and their teams). They collected hundreds of dead birds for me, for that I am very grateful (as odd as that sounds). I must thank the many others that I never even met that were involved in collecting my samples. I would also like to thank Kim Williams, Lorraine Robinson and Gordon McArthur for their assistance in collecting samples of cormorant nestlings at Pigeon Island. Dan McLaughlin has been a pleasure to learn from and work with. He has identified the parasites I collected from cormorants and taught me how to identify parasites myself. Dan has helped me grow as a parasitologist.

A big thank you is warranted to my friends and family for their support and encouragement. I have met a great number of wonderful people at Carleton University. My dear friend Stacey Lee-Jenkins ( $\mathrm{S} \perp$ and I'm S2) has been a great friend since the first day of graduate school. Stacey has always been a great support system and available to discuss research or life-related problems. My parents (Wayne and Lorraine Robinson) have been truly supportive of my academic career. They have listened to my many presentations and proofread my various scholarship applications. My mothers' involvement in animal research and her excitement for scientific research had a significant influence on my career path. I have been blessed with a mother that enjoys science as much as I do and who will join me in the field even when it results in being covered in guano and regurgitated fish. I would also like to thank my grandparents (Ray and Fay Robinson) for nurturing my interest in birds. At last, but definitely not least, my 
husband Nick Smith. I thank Nick for his unwaivering support of my extended education. even when it meant we were over $500 \mathrm{~km}$ apart for over four years. Nick is my best friend and partner; my PhD experience would not have been as enjoyable without his support and encouragement.

Funding for this research came from a National Sciences and Engineering Research Council (NSERC) Grant to M. R. Forbes and from Environment Canada's Ecotoxicology and Wildlife Health Program. I also want to thank NSERC for funding me personally through a Canadian Graduate Scholarship. 


\section{Table of Contents}

$\begin{array}{ll}\text { Abstract } & \text { ii }\end{array}$

Preface iv

Acknowledgements vii

Table of Contents

List of Tables xiv

List of Figures xvi

List of Appendices xviii

CHAPTER ONE General Introduction $\quad 1$

CHAPTER TWO Greater burdens of common helminths in males is not 10 explained by sex differences in body size or spleen mass of breeding cormorants Phalacrocorax atritus

Abstract

$\begin{array}{ll}\text { Introduction } & 12\end{array}$

$\begin{array}{ll}\text { Methods } & 13\end{array}$

$\begin{array}{ll}\text { Results } & 16\end{array}$

$\begin{array}{ll}\text { Discussion } & 23\end{array}$

CHAPTER THREE Parasitism, mercury contamination and stable isotopes in 28 fish-eating cormorants: no support for the co-ingestion hypothesis

$\begin{array}{ll}\text { Abstract } & 29 \\ \text { Introduction } & 30 \\ \text { Methods } & 32 \\ \text { Results } & 35 \\ \text { Discussion } & 43\end{array}$ 
Table of Contents Continued

CHAPTER FOUR Sex differences in parasitism in cormorants and 51 relationships with foraging ecology on Lake Erie, Canada

Abstract

Introduction

Methods

Results

Discussion

CHAPTER FIVE Sex differences in nematode parasitism and stable isotope 70 signatures, but not total mercury concentration, occur at the chick stage in double-crested cormorants Phalacrocorax auritus

$\begin{array}{lc}\text { Abstract } & 71 \\ \text { Introduction } & 72 \\ \text { Methods } & 75 \\ \text { Results } & 78 \\ \text { Discussion } & 83\end{array}$

CHAPTER SIX Mercury in parasitic nematodes and trematodes and their 90 double-crested cormorant hosts: bioaccumulation in the face of sequestration by nematodes

Abstract

Introduction

Methods

Results

Discussion 


\section{Table of Contents Continued}

CHAPTER SEVEN Evidence for sex differences in mercury dynamics in double-crested cormorants

Abstract

Introduction

115

Methods

118

Results

121

Discussion

CHAPTER EIGHT General Discussion

Literature Cited 


\section{List of Tables}

Table

Title

Page

2.1 Prevalence of helminths in male and female cormorants. also reported) of helminths in cormorants, categorized by host sex. with associating relationships with body mass, and foraging ecology with the sexes of cormorants analysed together and separately.

4.1 Median abundance and median intensity with $25 \%$ and $75 \%$ interquartile ranges (IQR) of trematodes and nematodes in male and female cormorants.

4.2 Correlations between parasitism and foraging ecology $\left(\delta^{13} \mathrm{C}\right.$ and

$\delta^{15} \mathrm{~N}$ values) with the sexes of cormorants analysed together and separately.

5.1 Prevalence, median abundance and median intensity of

Contracaecum spp. in male and female nestling cormorants. 


\section{List of Tables Continued}

Table

Title

Page

6.1

Median total mercury ( $\mathrm{TotHg}$ ) concentrations for male and

100

female cormorant breast muscle, male and female nematode

tissue and trematode tissue. Median ratios of methylmercury

( $\mathrm{MeHg}$ ) to total mercury and median percentage of total mercury

concentration that is methylmercury $(\% \mathrm{MeHg})$ for male and

female nematode tissue and trematode tissue.

6.2

Stable carbon $\left(\delta^{13} \mathrm{C}\right)$ and nitrogen isotope $\left(\delta^{15} \mathrm{~N}\right)$ values for male

105

and female cormorants and their female nematodes and

trematodes.

7.I Examples of studies that have found significant differences in

mercury concentration between adult male and female birds. 


\section{List of Figures}

Figure

Title

Page

2.1 Body mass of male and female cormorants plotted versus

19

an index of structural size (principal component 1 scores

from an analysis of morphometric data-see text for details).

2.2 Spleen mass plotted in relationship to body mass for male and

female cormorants.

2.3 Relationships between abundance of Contracaecum spp. and

Drepanocephahts spathans in male and female cormorants.

3.1 Relationships between abundance of Contracaecum spp. and

mercury concentration for male and female cormorants.

$\delta^{13} \mathrm{C}$ values in male and female cormorants.

3.3 Relationships between $\delta^{15} \mathrm{~N}$ and $\delta^{13} \mathrm{C}$ values for male and

female cormorants.

4.1 No correlation between the abundance of Drepanocephalus

spathans and Contracaecum spp. in male and female cormorants. male and female cormorants.

4.3 Negative correlation between $\delta^{13} \mathrm{C}$ values (in breast muscle) and abundance of Contracaecum spp. in male and female cormorants. 


\section{List of Figures Continued}

Figure

Title

Page

5.1 Correlations between abundance of Contracaecum spp. and

82

$\delta^{13} \mathrm{C}$ values in breast muscle of male and female cormorant nestlings.

6.1 Positive correlation between male and female cormorant total mercury concentration in breast muscle and the total mercury concentration in their male and female

Contracaecum spp.

7.1 Relationships between $\log _{10}$ inorganic mercury ( $\mathrm{IoHg}$ ) concentration and methylmercury concentration in liver tissue of male and female cormorants.

7.2 Relationships between proportion of total mercury that is methylmercury $(\% \mathrm{MeHg})$ and total mercury concentration in liver tissue of male and female cormorants. 


\section{List of Appendices}

Appendix

Title

Page

A

Operational definitions of terms bolded in the text.

193

xviii 
Chapter 1

\section{CHAPTER ONE}

General Introduction 


\section{General Introduction}

Organisms are typically and perhaps even predictably exposed to multiple stressors $^{1}$ in their environment (Sih et al. 2004). A stressor is an external factor that might limit an organism`s rate of resource acquisition, growth and/or reproduction (Grime 1989). Often. the distribution and effects of stressors are studied in isolation of one another and particular hypotheses are generated to explain patterns observed between stressors and physiological or life history traits of organisms and variation in those patterns. It is crucial to study how stressors co-occur and interact to understand fully the negative effects or potential for negative effects of stressors on organisms.

Parasites are stressors to their hosts. By definition, parasites use their hosts' resources for their own growth and/or reproduction and thereby invariably impose a negative effect on their hosts (Price 1980). For example. certain helminths parasitising birds have been associated with increased morbidity (Rausch 1983). There is also considerable evidence of parasite-associated reductions in body condition, metabolic rate. clutch size, breeding success and survival of avian hosts (Keymer et al. 1991; Delahay et al. 1995; Connors \& Nickol 1991; Hudson 1986; Saumier et al. 1986; Minchella \& Scott 1991; Hudson et al. 1992). The pathogenicity of avian helminth infections often depends on the intensity of parasitism (Holmes \& Price 1986).

Environmental contaminants also can be stressors and their release into the environment is often linked to human activities. There are many types of environmental contaminants including groups such as persistent organic pollutants (e.g.,

${ }^{1}$ See Appendix A for the operational definition of this term and for subsequent terms that are bolded. 
organochlorines) and trace metals (e.g.. mercury). Both of these groups are of concern from environmental and toxicological viewpoints because both groups biomagnify through ecosystems, resulting in top consumers, like fish-eating birds, being exposed to the highest levels (Scheuhammer 1987; Fisk et al. 2005). Mercury is of particular concern because global emissions continue to increase (Pacyna et al. 2006) while other 'legacy’ persistent organic pollutants (e.g., dichloro-diphenyl-trichloroethane (DDT), polychlorinated biphenyls (PCBs)) appear to be diminishing in North America as a result of environmental policies to reduce production and use (Braune et al. 2005; Braune 2007).

My thesis work centers on parasitism in relationship to mercury contamination in a free-ranging bird species. As much as two thirds of the available mercury in the environment is estimated to come from anthropogenic sources, such as coal combustion and waste incineration, whereas the remaining one third is from natural sources, such as soil erosion, rock weathering, and volcanic eruptions (Mason et al. 1994; Pacyna \& Pacyna 2002). Although mercury is present in nature, anthropogenic sources are responsible for dramatically increased global emissions (Pacyna \& Pacyna 2002; Pacyna et al. 2006). It is of particular concern in aquatic ecosystems where methylmercury is produced (Weiner et al. 2003). Methylmercury is the most toxic chemical form of mercury and is readily assimilated from the diet and accumulated in piscivorous wildlife (Weiner et al. 2003). Methylmercury is harmful to the central nervous system of a variety of vertebrates, including birds (Wolfe et al. 1998; Scheuhammer et al. 2007). Acute exposure to methylmercury can adversely affect adult survival: however, chronic 
exposure can cause sublethal effects in birds, such as reduced reproductive success, altered behaviour and teratogenic effects (Scheuhammer 1987). Toxicity generally increases with increasing methylmercury concentrations (Weiner et al. 2003), but threshold levels causing adverse effects differ among species.

As mentioned. multiple stressors often are studied separately in part due to the interests of researchers in specific disciplines, such as evolutionary ecology versus applied ecotoxicology. A common pattern for parasitism in mammals and free-ranging birds of interest to evolutionary ecologists is a sex difference where males tend to be more often infected and have greater parasitemia (prevalence, abundance, intensity) than do females (Poulin 1996; Schalk \& Forbes 1997). A similar pattern of interest to ecotoxicologists is found for mercury concentrations, where male birds tend to have higher concentrations than do females (Burger 2007). These two particular patterns are studied separately, have their own set of explanations and often are published in very different journals; however, both parasites and mercury occur together in top consumers, such as aquatic birds. Their apparent similar distributions might suggest one is dependent on the other or that certain subsets of individuals (e.g., old males) have higher susceptibility or exposure to these two stressors.

Below, I detail my investigation into relationships, if any, between parasites and mercury contamination in a model piscivorous species: the double-crested cormorant Phalacrocorax auritus (Lesson 1831). The double-crested cormorant is a useful model system to study contaminant-parasite associations because they are top consumers within aquatic ecosystems. They consume predominantly fish (Hatch \& Weseloh 1999), which 
means they are exposed to concentrated methylmercury (Weiner et al. 2003).

Furthermore, they are definitive hosts to a variety of indirect life cycle helminth species for which fishes are the intermediate hosts (Hatch \& Weseloh 1999). Therefore, cormorants should be exposed to both mercury and parasites via the prey they consume. Cormorants are also sensitive to the effects of contaminants. In the 1960 s and early 1970s, drastic declines in cormorant populations were associated with high exposure to contaminants that negatively affected egg shell thickness, embryo survival, and reproductive recruitment into the population (Weseloh et al. 1983; Price \& Weseloh 1986). Since the banning of organochlorines, such as DDT, and the increase in food supply principally on their wintering areas, cormorant populations on the Great Lakes have increased exponentially (Weseloh et al. 1995). Populations have reached such high levels that provincial and federal government agencies have been culling adult cormorants and oiling eggs for several years. I was able to obtain the "culled" samples necessary to conduct the many studies described herein. Cormorants therefore offered an excellent opportunity to study relationships between parasites and mercury in a freeranging and migratory bird population. My studies also serve as a baseline approach for other investigations into similar relationships among stressors in other free-ranging wildlife.

In my first data chapter (Chapter 2). I described helminth parasitism in breeding cormorants from a colony on Lake Ontario. I determined if cormorants follow the general pattern observed of sex differences in parasitism where male mammals and birds have greater parasite burdens than females (Poulin 1996; Schalk \& Forbes 1997). I explored 
whether sex differences in parasitism could be explained by sex differences in body mass, body size or proxies of immune function. I end with an alternative hypothesis to explain sex differences in parasitism based on parasite exposure: one explanation which is not often invoked (Forbes 2007).

In Chapter 3, I investigated the association between parasitism and mercury concentration and I explored the "exposure" hypothesis for what appeared to be independent levels of parasitism and mercury concentration within male and female cormorants. Degrees of endoparasitism and methylmercury burden have been positively correlated in free-ranging birds (Wayland et al. 2001; Sagerup et al. 2009). The underlying hypothesis for such investigations is that methylmercury reduces immunity, thereby resulting in a higher degree of parasitism (e.g., Luebke et al. 1994; Boroskova et al. 1995). However, alternative explanations such as co-ingestion should be addressed to further inform and test hypotheses about relationships between methylmercury and parasitism that might occur either within or between sexes. I used breast muscle stable isotope signatures (carbon and nitrogen) as a measure of foraging ecology to determine the extent to which parasites and methylmercury were co-ingested in male and female cormorants.

In Chapter 4, I further explored whether males and females were differentially exposed to Contracaecum spp. using a second sample of cormorants collected at a different site in a subsequent year. My rationale here was to test the generality of any novel patterns observed in the birds from Lake Ontario. The second sample came from Lake Erie where the fish community is more diverse than in Lake Ontario (Coon 1999). I 
determined the generality of my finding that male cormorants have greater abundance of parasites. The pattern of males having more parasites was reproducible and thus enabled a second test of the explanation for such sex differences in parasitism being due to sex differences in foraging ecology.

In Chapter 5, I studied cormorant nestlings from Lake Ontario to test further the supposition of sex difference in parasitism by nematodes (Chapters 3 and 4 ) being due to sex differences in foraging ecology. Nestlings offer a unique opportunity for study, where influence of age, lifetime exposure and prey item consumption are known or are relatively homogenous between sexes. Therefore. by studying nestlings I could control for some of the factors that were thought to influence levels of parasites and mercury concentration in adults. More specifically, I tested for sex differences in parasitism by Contracaecum spp.. in body mass, body size, and provisioning ecology (inferred from stable carbon and nitrogen analysis). I did not expect to find sex differences in parasites because I did not expect nestlings to differ in provisioning ecology. I also examined sex differences in mercury concentration, but did not expect a difference because sex differences are most likely associated with sex-specıfic characteristics of adults (e.g., egg laying; but see Chapter 7).

For chapters 6 and 7, I further explored the possible explanations for sex differences in mercury concentration. Male cormorants had greater mercury concentrations than females; however, the males responsible for the sex difference in parasitism were different from the males responsible for the sex difference in mercury concentration (see Chapter 2). I therefore explored whether the parasites themselves 
might be affecting the bioaccumulation of mercury by the host. In fish. helminths (mainly acanthocephalans and cestodes) have been found to reduce their hosts' levels of certain heavy metals (Sures \& Siddall 1999: Sures et al. 2003). In both the Lake Ontario and Lake Erie samples. I found that cormorants rarely had concurrently high abundance of nematodes and high concentrations of mercury. In fact, the males that had high burdens of nematodes and high burdens of mercury were different; thus, different male cormorants were responsible for the two patterns of males having higher mercury burdens and higher parasitism than females. I explored whether it was possible that mercury accumulated in nematode tissue and not in the bird tissues, and thus could explain, for example the magnitude of difference in mercury concentration between males showing low versus high mercury concentrations.

In chapter 7. I investigated a novel hypothesis for differences in methylmercury dynamics within males and females. The most common explanation for a sex difference in mercury in adult birds is that females depurate mercury to their eggs (Braune \& Gaskin 1987; Lewis et al. 1993); however, experimental studies have not found that the amount of mercury depurated to eggs can completely explain the difference between males and females (Monteiro \& Furness 2001). I proposed an alternative explanation where females have a greater physiological capability to demethylate and/or excrete mercury from their livers and thus reduce their overall accumulation compared to males. In studies that have examined sex differences in mercury concentration in birds, there was sometimes a general statement that physiological differences pertaining to methylmercury metabolism 
must exist between males and females (see Monteiro and Furness 2001); however, I am the first to propose and explore a mechanism for the physiological difference.

Finally, in my general discussion (Chapter 8) I summarize the key findings of each of my data chapters and how the information has contributed to the understanding of contaminant-parasite relationships. I also discuss future directions based on the results of this work. 
Chapter 2

\section{CHAPTER TWO}

Greater burdens of common helminths in males is not explained by sex differences in body size or spleen mass of breeding cormorants Phalacrocorax auritus

This chapter formed the basis for the following publication and was reproduced with permission from the publisher, (C) 2008 John Wiley \& Sons, Inc:

Robinson, S. A.. Forbes, M. R., Hebert, C. E. and McLaughlin, J. D. 2008. Male-biased parasitism by common helminths is not explained by sex differences in body size or spleen mass of breeding cormorants Phalacrocorax auritus. Journal of Avian Biology 39: $272-276$. 


\section{Abstract}

In vertebrates, males often are more parasitised than conspecific females. This difference in parasitism might result from sex differences in parasite exposure and/or susceptibility to infection. Such information is important for testing hypotheses about allocation of resources to life histories of males and females and for testing hypotheses about factors thought to influence parasite fitness and parasite dynamics. I tested whether doublecrested cormorants Phalacrocorax auritus (Lesson 1831) exhibit sex differences in parasitism by gut helminths. The prevalence of nematode Contracaecum spp. and trematode Drepanocephahıs spathans (Dietz 1909) infections was $\sim 90 \%$ and $39 \%$, respectively. Cestode, primarily Paradilepis caballeroi (Rysavy \& Macko 1973) and acanthocephalan Andracantha gravida (Alegret 1941) infections were less common $(<10$ \%). Male and female cormorants did not differ in prevalence of infection by any helminth species. However, males had twice the abundance and intensity of Contracaecum spp. infections and twice the intensity of $D$. spathans infections than found in females. For common parasites, degree of parasitism was also unrelated to body size or mass in either sex. Males and females did not differ in spleen mass and spleen mass was unrelated to abundance of common parasites. No significant relationship was observed between abundance of trematodes and nematodes. At present, the greater burden of nematodes and trematodes in male cormorants, are independent patterns that remain unexplained, but are most likely attributable to sex differences in exposure and/or immunological differences not yet assessed. 


\section{Introduction}

Spatial, temporal and demographic variation in parasitism often occurs within host species (Lajeunesse \& Forbes 2002: Krasnov et al. 2005). In many species of vertebrates, males are more heavily parasitised than are females (Poulin 1996; Zuk \& McKean 1996; Schalk \& Forbes 1997; Klein 2004, but see McCurdy et al. 1998). Greater burdens of parasites in male mammals are thought to occur because of sex differences in life history strategies between males and females. That is, males are thought to invest more energy and resources into growth and less into immunity than do females (Moore \& Wilson 2002). Furthermore, sex differences in parasitism are associated with sexual size dimorphism in mammals: species with larger males typically show greater burdens of parasites in males (Moore \& Wilson 2002).

There are other reasons why sexual size dimorphism might relate to sex differences in parasitism. For birds, sex differences in foraging (Lewis et al. 2002) should influence exposure to parasites transmitted through food. When sex differences in parasitism are found in nature, particularly in males, sex-related differences in immunity are usually invoked as determinants and less is made of potential sex differences in exposure (Forbes 2007). What is important, however, is the net difference between the sexes in their exposure and/or susceptibility profiles.

The objectives of this study were threefold. First. I tested for sex differences in parasitism in breeding double-crested cormorants Phalacrocorax auritus (Lesson 1831; hereafter cormorants) and assessed its occurrence for common versus rarer parasites (and all species considered together). I then tested whether such sex differences, when they 
occurred, might be explained by absolute differences in body size and spleen mass, or relative spleen mass after controlling for body size. The avian spleen is responsible for producing $\mathrm{B}$ - and $\mathrm{T}$ - cells involved in humoral and cell-mediated immune responses (John 1994a, b, 1995). Finally, I tested whether abundances of parasites were correlated to determine if sex differences in parasitism by more than one species of parasite might be due to inclusion of particular individuals in samples.

\section{Methods}

\section{Study species}

Double-crested cormorants are colonial breeding, fish-eating, aquatic birds that inhabit coasts and inland bodies of water across North America, including the Great Lakes (Hatch \& Weseloh 1999). Cormorants are monogamous and share in incubation duties and feeding of young. Adult male cormorants are heavier and structurally larger than females (Glahn \& McCoy 1995).

\section{Samples and sampling protocol}

My sample of cormorants was collected as part of a culling program. I obtained 263 cormorants shot by the Ontario Ministry of Natural Resources (OMNR) during May 2006 at Presqu'ile Provincial Park. Brighton, Ontario, Canada $\left(43^{\circ} 60^{\circ} \mathrm{N}, 77^{\circ} 43^{\prime} \mathrm{W}\right)$.

OMNR personnel excised gastrointestinal tracts from 137 cormorants in the field. and individually bagged and froze these tracts at $-40^{\circ} \mathrm{C}$. Another 126 birds were frozen intact. National Wildlife Research Centre personnel processed all birds and 
gastrointestinal tracts, which were kept frozen until dissection (following Forbes et al. 1999: Shutler et al. 1999).

I thawed birds and weighed them to $\pm 0.1 \mathrm{~g}$, measured wing chord, bill height. head length, and tarsus length (all to $\pm 0.01 \mathrm{~mm}$ ), and sexed them by gonadal inspection. The spleen was excised, any attached connective tissue removed, and weighed to $\pm 0.1 \mathrm{~g}$. Those specimens with intact digestive tracts (proventriculus, stomach and intestine to cloacal region) were examined for helminths. Gastrointestinal tracts were opened lengthwise, examined under a dissecting microscope and parasites were collected with forceps, washed with physiological saline, counted, and stored for subsequent indentification. JDM and SAR identified all specimens. Voucher specimens will be deposited with the Canadian Museum of Nature.

I assessed infection levels of helminths as prevalence, abundance and intensity (following Bush et al. 1997). Prevalence was defined as the percentage of hosts infected with one or more individuals of a single species or taxon. Abundance was the number of parasites of a particular species in a single host and mean abundance for a particular parasite was based on both infected and uninfected hosts. Intensity was the number of individuals of a helminth species in a single infected host and mean intensity was based only on infected hosts. I also defined species richness as the number of species of helminths per bird.

I tested whether prevalence, abundance, intensity of the total helminth load, that of each helminth species, and species richness differed between male and female cormorants. I used $\chi^{2}$ tests for prevalence analyses. The abundance and intensity data 
were not normally distributed even after transformation (according to Shapiro-Wilk test) and therefore I used non-parametric Wilcoxon tests (Zar 1999). I also used Wilcoxon tests for species richness comparisons. Median values were reported with their corresponding $25 \%$ and $75 \%$ interquartile ranges (IQR) and mean values were reported with their standard errors.

I also assessed the level of sexual size dimorphism for intact cormorants in my sample $(n=126)$. I used both fresh mass and an index of structural size based on principal components analysis (PCA) of wing chord, bill height, head length. and tarsus length body measures (using the correlation matrix). I used the first axis of the PC analysis because this axis mainly represents size in comparison to the second axis, which represents shape (Jackson 1993). I examined whether there was any relationship between male or female size and the abundance of any parasites. I also examined whether absolute spleen mass differed between the sexes and whether absolute spleen mass was related to body mass in either sex using ANCOVA, followed by regressions. I then examined whether absolute or relative spleen mass was related to the abundance of each species of helminth, for both males and females.

Finally, I used Spearman Rho tests to determine correlations between parasite species abundances. Statistical analyses were performed using JMP version 4 (SAS Institute Inc. 1989-2000) software. 


\section{Results}

\section{Host sex and parasitism}

I found five species of helminths in cormorants (Table 2.1 ). I found $92 \%$ of males and 94 $\%$ of females were infected by at least one helminth species. Males and females did not differ in prevalence for each species or taxon of helminth (Table 2.1). Contracaecum spp. was the most prevalent helminth $(90 \%)$, followed by Drepanocephalus spathans (Dietz 1909; $39 \%$ ). Paradilepis caballeroi and Andracantha gravida (Alegret 1941) occurred in $<10 \%$ of hosts. Males and females did not differ in species richness $(Z=-0.48, P=$ $0.63)$.

Males carried over twice the median abundance and median intensity of helminths, due essentially to their heavier infections of Contracaecum spp. Males and females did not differ in abundance of the other three species; however, the intensity of D. spathans was greater in males (Table 2.2).

\section{Host size, spleen size and parasite numbers}

Males were significantly heavier than females (males: $2055.1 \pm 16.3 \mathrm{~g}$, females: $1772.4 \pm$ $\left.17.0 \mathrm{~g}, \mathrm{~F}_{1,124}=129.5, \mathrm{P}<0.001\right)$, and structurally larger based on $\mathrm{PCl}$ scores $\left(\mathrm{F}_{1,122}=\right.$ 183.0, $\mathrm{P}<0.001)$. For the PCA analysis, all metrics loaded positively on the first PC axis and accounted for $54 \%$ of the variation in the data. Despite the sexual dimorphism in body mass and structural size based on PCl scores (Fig. 2.1), males and females did not differ in spleen mass (males: $1.4 \pm 0.1 \mathrm{~g}$. females: $1.5 \pm 0.1 \mathrm{~g}, \mathrm{~F}_{1,122}=0.55, \mathrm{P}=0.46$ ). More specifically, sex, body mass and the interaction in an ANCOVA did not influence 
Chapter 2

Table 2.1. Prevalence of helminths in male $(n=163)$ and female $(n=102)$ cormorants (Phalacrocorax auritus). Damage to the anterior digestive tract in 1 male and 1 female bird precluded examination for Contracaecum spp. A single hymenolepidid cestode belonging either to the genus Retinometra or Sobolevicanthus was not included.

Reprinted with the permission of 2008 John Wiley \& Sons, Inc.

\begin{tabular}{lllll}
\hline Helminth & \multicolumn{2}{l}{ Prevalence\% } & $\chi^{2}$ & $\mathrm{P}$ \\
& Male & Female & & \\
& & & & \\
\hline Contracaecum spp. & 90.1 & 89.1 & 0.07 & 0.79 \\
Drepanocephalus spathans & 42.9 & 39.2 & 0.36 & 0.55 \\
Andracantha gravida & 9.2 & 6.9 & 0.46 & 0.50 \\
Paradilepis caballeroi & 6.8 & 8.8 & 0.38 & 0.54 \\
& & & & \\
\hline
\end{tabular}


Table 2.2. Median abundance and median intensity (interquartile ranges also reported) of helminths in cormorants (Phalacrocorax auritus), categorized by host sex. Significant values are in bold. Reprinted with the permission of $\odot 2008$ John Wiley \& Sons, Inc.

\begin{tabular}{lllll}
\hline Helminth/measure & Male (IQR) & Female (IQR) & $Z$ & $P$
\end{tabular}

Contracaecum spp.

$\begin{array}{lllll}\text { Abundance } & 26(5-55) & 13(3-32) & -2.86 & \mathbf{0 . 0 0 4} \\ \text { Intensity } & 30(10-59) & 13(6-36) & -3.21 & \mathbf{0 . 0 0 1}\end{array}$

Drepanocephalus spathans

$\begin{array}{lllll}\text { Abundance } & 0(0-10) & 0(0-5) & -1.14 & 0.25 \\ \text { Intensity } & 15(7-35) & 7(4-24) & -2.23 & \mathbf{0 . 0 3}\end{array}$

Andracantha gravida

$\begin{array}{lllll}\text { Abundance } & 0(0-0) & 0(0-0) & -0.56 & 0.58 \\ \text { Intensity } & 4(2-8) & 1(1-3) & -1.91 & 0.05\end{array}$

Paradilepis caballeroi

$\begin{array}{lllll}\text { Abundance } & 0(0-0) & 0(0-0) & 0.93 & 0.35 \\ \text { Intensity } & 3(1-8) & 2(1-4) & 0.54 & 0.59\end{array}$

All helminths

\begin{tabular}{lllll} 
Abundance & $37(13-75)$ & $15(6-43)$ & -3.43 & $\mathbf{0 . 0 0 1}$ \\
Intensity & $38(19-82)$ & $18(7-44)$ & -4.14 & $<\mathbf{0 . 0 0 1}$ \\
& & & & \\
\hline
\end{tabular}




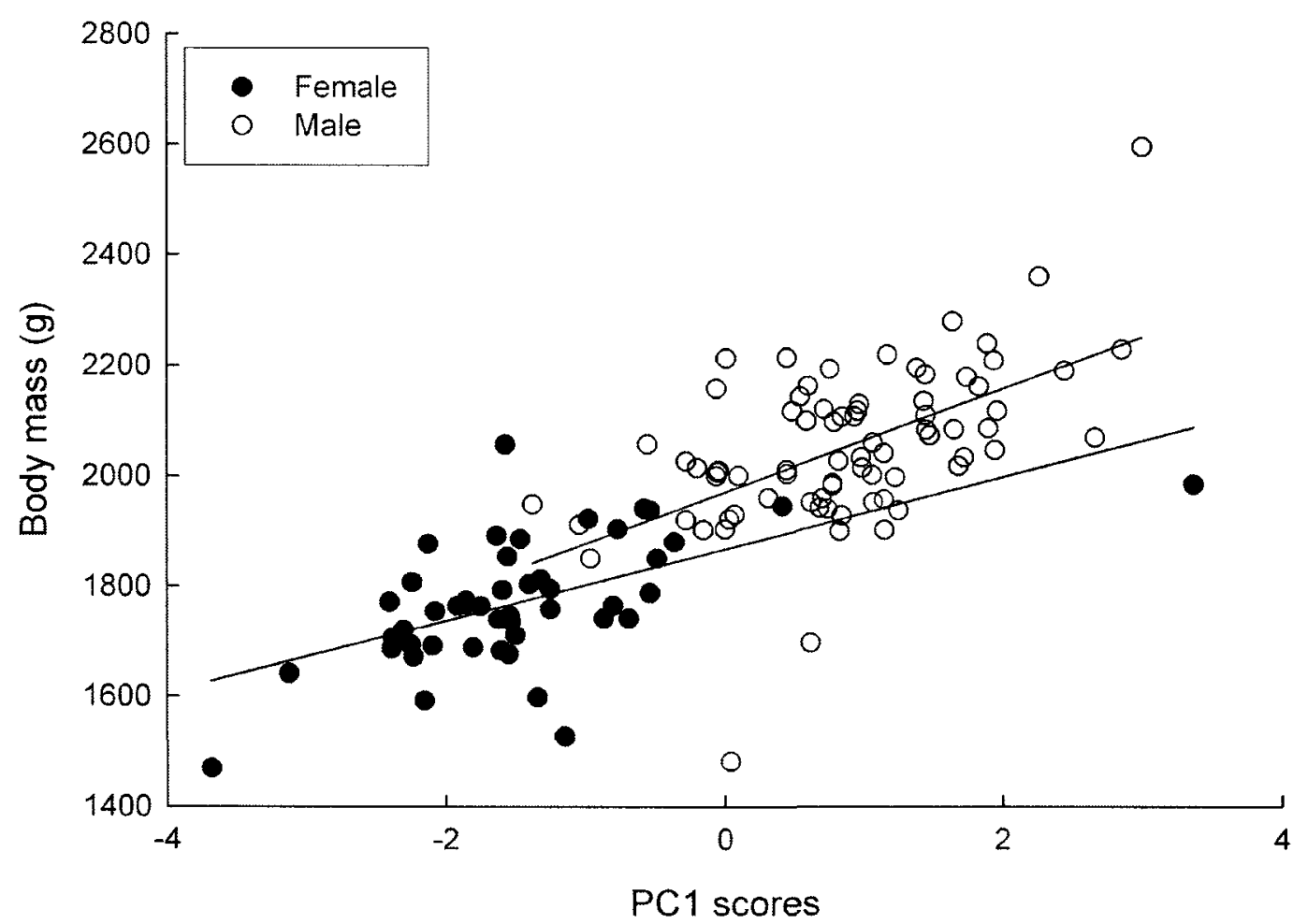

Figure 2.1. Body mass of male and female cormorants (Phalacrocorax anritus) plotted versus an index of structural size (principal component 1 scores from an analysis of morphometric data-see text for details). Reprinted with the permission of $\odot 2008$ John Wiley \& Sons, Inc. 
the spleen mass in cormorants $\left(F_{1.120}\right.$ ranged from 0.56 to 2.11 ; $P$ ranged from 0.15 to 0.45 ). In addition, spleen mass and body mass were unrelated in both sexes tested separately (Fig. 2.2 : males: $R_{\text {Pear on }}=0.06, P=0.60$; females: $R_{\text {Pearson }}=0.15, P=0.31$ ). I tested the sexes separately because they showed minimal overlap in the covariate of body mass, which meant the previous ANCOVA had failed to meet one of its assumptions.

I could not use residual spleen mass as an estimate of relative spleen size, because spleen mass was not related linearly to body mass. Instead, I examined spleen mass as a percentage of body mass, even though any differences between males and females could be due to differences in body mass rather than differences in spleen mass. Notwithstanding. I found no difference between males and females (median for males $0.06 \%$ with an interquartile range from $0.05-0.08 \%$, for females $0.07 \%$ with an interquartile range from $0.05-0.10 \%, Z=1.48, P=0.14$ ).

I next examined body mass and $\mathrm{PCI}$ relative to abundance of the various helminths. I found no relationship for males (Spearman Rho ranged from -0.09 to 0.16: P ranged from 0.16 to 0.40 ). Similarly in females, I found no relationships between estimates of body size and abundance of $P$. caballeroi, A gravida, and Contracaecum spp. (Spearman Rho ranged from -0.22 to 0.03: P ranged from 0.12 to 0.82 ). However, both female body mass and $\mathrm{PCl}$ were related positively to abundance of $D$. spathans (Spearman Rho $=0.34$ and 0.40 , respectively: $\mathrm{P}=0.0 \mathrm{I}$ and 0.005 , respectively).

I next sought to determine whether any of the variation in parasitism was related to spleen mass. Spleen mass was unrelated to abundance of Contracaecum spp. in cormorants (males: Spearman Rho $=-0.09, \mathrm{P}=0.44$, females: Spearman Rho $=-0.28 . \mathrm{P}=$ 


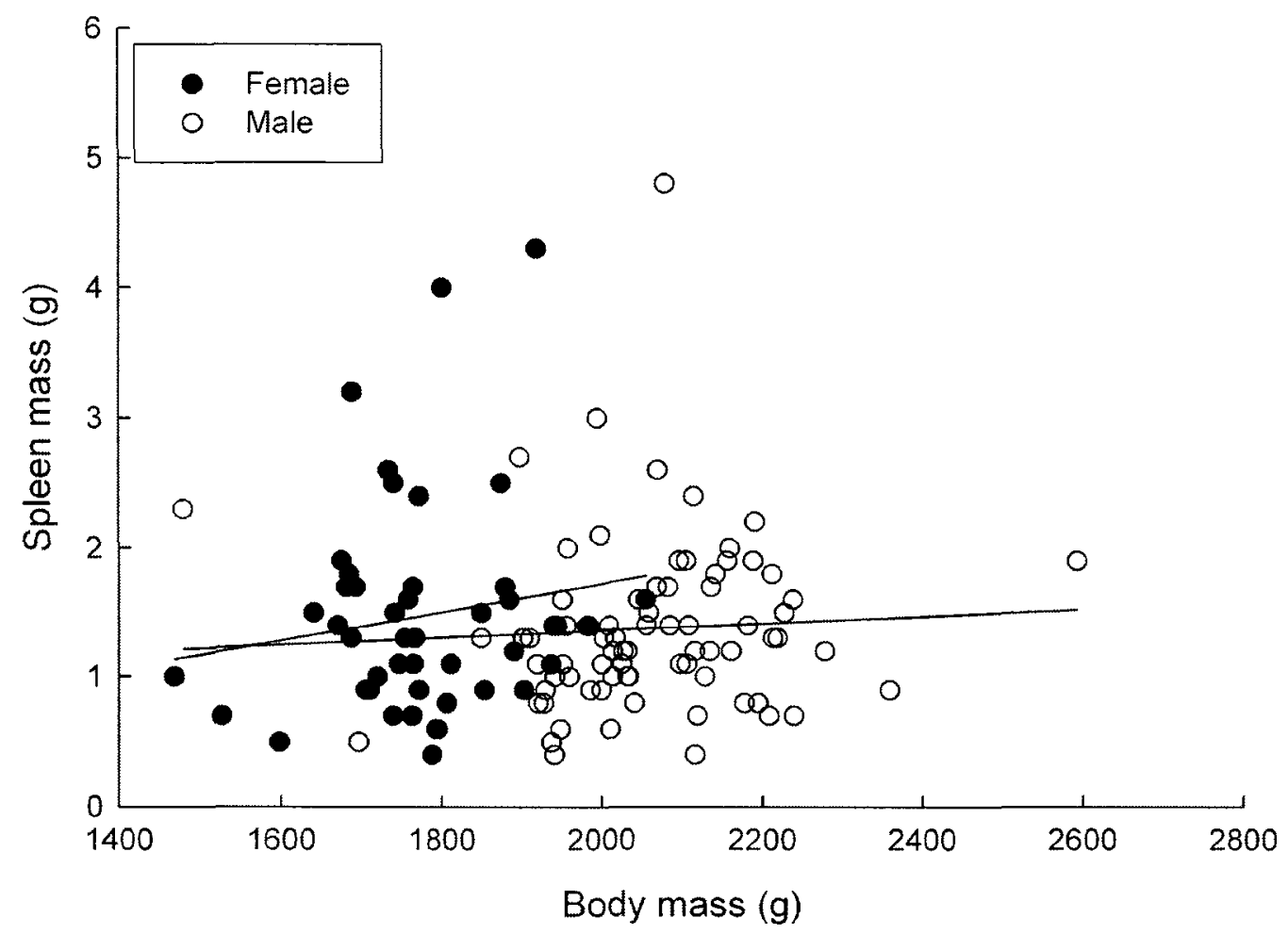

Figure 2.2. Spleen mass plotted in relationship to body mass for male and female cormorants (Phalacrocorax auritus). Reprinted with the permission of $\overparen{\mathrm{C}} 2008 \mathrm{John}$ Wiley \& Sons, Inc. 
0.06). Further, neither males nor females showed relationships between intensity of Contracaecum spp. infections and spleen mass (Spearman Rho ranged from -0.03 to 0.04 , P ranged from 0.76 to 0.84 ). I also considered all other parasite species. For males, spleen mass was unrelated to abundance of D. spathans or A. gravida (Spearman Rho ranged from -0.01 to -0.18 ; P values ranged from 0.10 to 0.87 ). However, there was an inverse relationship between abundance of $P$. caballeroi and spleen mass for males (Spearman Rho $=-0.22 ; \mathrm{P}=0.05$ ). For females, spleen mass was unrelated to abundance of D. spathans, A. gravida, or P. caballeron (Spearman Rho ranged from 0.07 to $0.19 ; \mathrm{P}$ values ranged from 0.19 to 0.66 ). Analyses where relative spleen mass was substituted for absolute spleen mass showed similar results (data not shown).

\section{Parasite-parasite relationships}

For males, abundance of $P$. caballeroi was positively related to abundance of $A$. gravida and D. spathans (Spearman Rho $=0.14$ and 0.22 , respectively, $\mathrm{P}=0.07$ and 0.007 , respectively) and the abundances of $A$. gravida and $D$. spathans were positively related (Spearman $\mathrm{Rho}=0.16, \mathrm{P}=0.04$ ). The three remaining correlations between $D$. spathans and Contracaecum spp., A. gravida and Contracaecum spp., and P. cuballeroi and Contracaecum spp. were not significant (Spearman Rho ranged from -0.05 to $0.08, \mathrm{P}$ ranged from 0.29 to 0.53 ). For females, $P$. caballeroi again related positively to $D$. spathans (Spearman Rho $=0.27, \mathrm{P}=0.006$ ), but no other correlations between species abundance were significant (Spearman Rho ranged from -0.15 to 0.11 . P ranged from 0.12 to 0.73 ). Both (ontracaecum spp. and D. spathans showed greater abundance of 
parasites in males, although abundance of these parasites was not correlated. That different males were responsible for the sex differences in parasitism for Contracaecum spp. and D. spathans' was evident when abundance of Contracaecum spp. were plotted versus abundance of $D$ ). spathans and coded by host sex (Fig. 2.3).

\section{Discussion}

Male cormorants had twice the abundance and intensity of Contracaecum spp. and higher median intensity of $D$. spathans than did females. Cormorants did not show sex differences in parasitism for either P. caballerol or A. gravida; parasites that occurred less commonly. However, $P$. caballeroi and D. spathans were positively related in both sexes, yet only $D$. spathans showed greater intensity of infection in males. Nematodes are most commonly associated with sex differences in parasitism in vertebrates (i.e., greater burdens in males), but the differences are usually of much lower magnitude (Poulin 1996).

For double-crested cormorants, males are structurally larger and heavier than females (see also Glahn \& McCoy 1995). Thus, sexual size dimorphism once again relates to degree of parasitism with the larger sex being more parasitised by some helminths. However, it is important to recognize that males also have greater burdens of parasites in species that are not sexually size dimorphic such as hazel grouse Bonasa bonasta (Linnaeus 1758: Isomursu et al. 2006). For some species, greater burdens of parasites in males do not exist outside of breeding seasons (Dezfuli et al. 2002) and greater burdens of parasites in females have been documented with protozoan infections 


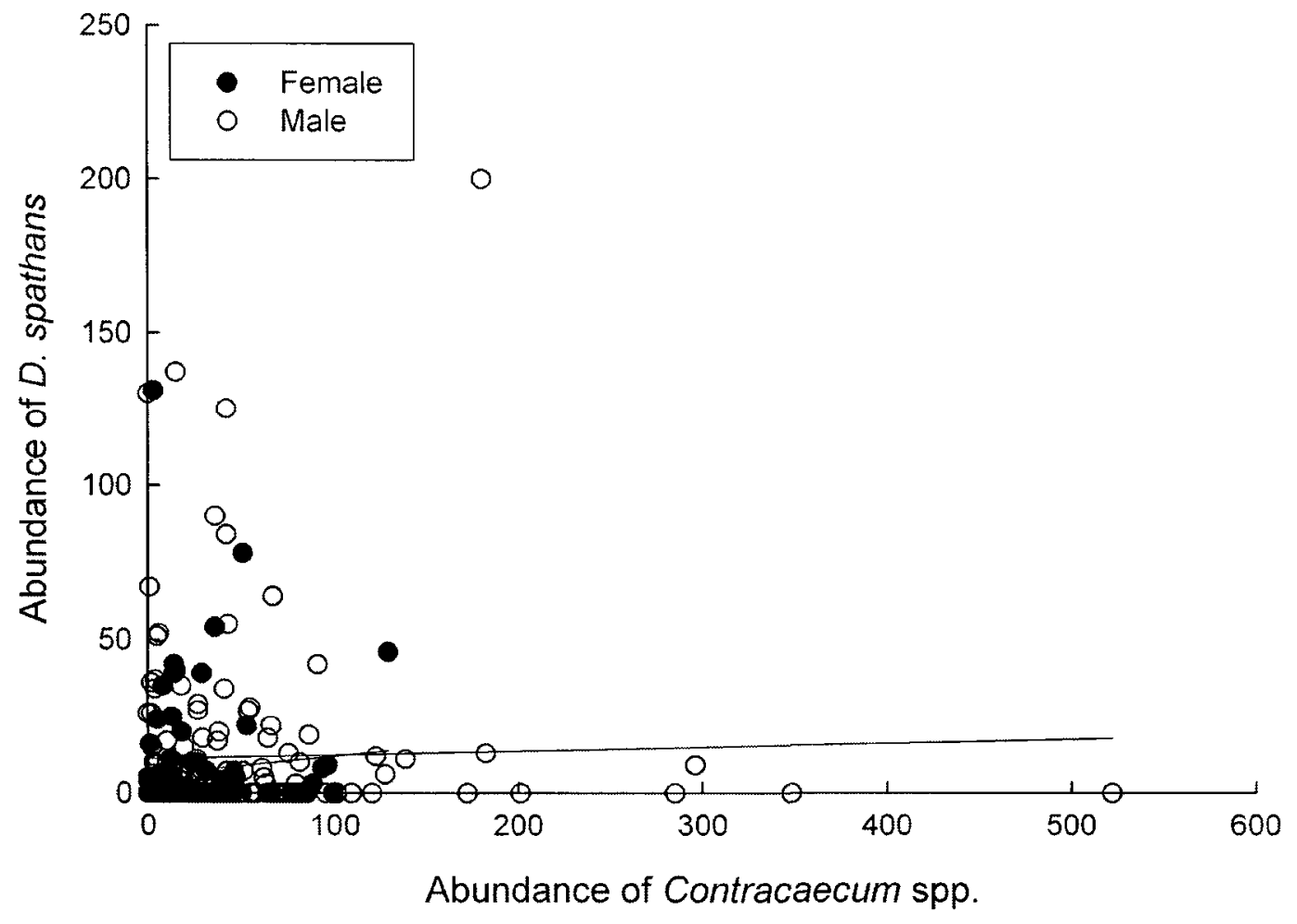

Figure 2.3. Relationships betwreen abundance of Contracaecum spp. and Drepanocephalus spathans in male and female cormorants (Phalacrocorax auritus). The male cormorants responsible for the sex difference in parasitism by Contracaecum spp. are not the same males responsible for the sex difference in parasitism by Drepanocephalus spathans. Reprinted with the permission of (c) 2008 John Wiley \& Sons, Inc. 
(McCurdy et al. 1998; Moore \& Wilson 2002; Morales-Montor et al. 2004). This combined work suggests that sex differences in infection and its relationship to breeding merits further study.

In my study, male and female cormorants averaged similar spleen masses and spleen mass was unrelated to body mass for either sex. However, males were structurally larger and heavier than females, so there is some evidence in support of smaller relative spleens for males. However, the sexes did not show differences in relative spleen size based on another metric. Further, there were no consistent relationships in cormorants between spleen mass and infections (although I did find the predicted relationship for males using abundance of $P$. caballeroi). In comparison, spleen mass has been associated with nematode infections in other bird species (John 1995; Shutler et al. 1999). These associations are thought to exist because nematodes are more pathogenic than other helminths. Nematodes actively feed on host tissues whereas other helminths passively absorb nutrients from the hosts' digested products (Huizinga 1971). Active feeding on host tissues by Contracaecum spp. also occurs and can cause large ulcerations where they attach to the stomach wall: such worms deplete host resources and energy (Huizinga 1971). Therefore the host should attempt to combat nematode infections. Why might a relationship between spleen mass and nematode infection in cormorants be masked? A recent study suggested that a portion of the spleen might be devoted to oxygenated red blood cell supply during deep dives (Nevins 2004). Furthermore, the spleen might only show relationships to parasite burden when exposure is controlled or is relatively invariant across birds being compared. More information is required in diving birds 
regarding the degree to which spleen function is dedicated to immunity versus diving physiology. In cormorants, breeding males might have a reduced immune system, but spleen mass has also evolved to meet the greater requirement for oxygen supply, since males tend to dive deeper and for longer periods of time than do females (Gremillet ef al. 1998: Anderson et al. 2004). This would explain the similar spleen mass for males and females observed in this study. I do not want to make too much of this argument other than to note that more research is needed in diving birds to ascertain the contributions of immunity versus physiology to spleen size.

There are reasons to expect that male and female cormorants would differ in exposure to parasites. Larger individuals might consume larger or more prey, which contain more infective parasitic stages. I suspect that male cormorants also are exposed to infective stages of parasites for slightly longer than females, since males arrive on the breeding grounds before females (Hatch \& Weseloh 1999). Peak exposure to infection occurs early in the breeding season with dissipating exposure as the season progresses (Rausch 1983). Furthermore, there is some suspicion that male and female cormorants use different habitats (Tobin et al. 2002; Hebert et al. 2008): a suspicion that was confirmed for the birds used in this study with stable isotope analysis (see Chapter 3 ). Males might accumulate more nematodes in different over-wintering areas than females, or accumulate nematodes or trematodes from a common breeding ground over a longer period than females. Genetic studies on these parasites helped in determining that males and females were obtaining predominantly genetically similar Contracaecum sp. $(C$. rudolphi, Type 1), most likely from similar source populations (unpublished data). Thus. 
I suspect sex differences in parasitism by Contracaecum spp. and D. spathans in cormorants is a result of differences in foraging behaviour (possibly site segregation). Males and females of several cormorant species show different foraging behaviours (Watanuki et al. 1996; Casaux et al. 2001).

In summary, double-crested cormorants breeding on Lake Ontario show sex differences in parasitism with greater burdens in males of nematodes and trematodes but not cestodes or acanthocephalans. The differences do not relate to differing spleen sizes and relationships between parasitism and host sizes are inconsistent - although larger females have higher abundance of trematodes. Specific parasite relationships with spleen mass are inconsistent and might be spurious. This organ does not prove useful as a proxy for immunity in free-ranging cormorants. I suggest that exposure is more important than physiological differences between the sexes in determining instances and the magnitude of sex differences in parasitism. 
Chapter 3

\section{CHAPTER THREE}

Parasitism, mercury contamination and stable isotopes in fish-eating cormorants: no support for the co-ingestion hypothesis

This chapter formed the basis for the following publication and was reproduced with permission from (C) 2008 NRC Canada:

Robinson, S. A., Forbes, M. R. and Hebert, C. E. 2009. Parasitism. mercury contamination, and stable isotopes in fish-eating double-crested cormorants: no support for the co-ingestion hypothesis. Canadian Journal of Zoology 87: 740-747. 


\begin{abstract}
Mercury and parasitism have been positively correlated in free-ranging birds. One proposed explanation for this correlation is that mercury reduces host immunity resulting in a greater susceptibility to parasitism. However. alternative explanations about relationships between mercury and parasitism have not been examined. I tested whether total mercury and Contracaecum spp. were correlated in double-crested cormorants Phalacrocorax auritus (Lesson 1831) and whether there was support for mercury and infective stages of parasites being co-ingested. For breeding cormorants, males had 1.5 times more total mercury in breast muscle than did females and more than twice the burden of Contracaecum spp. in the proventriculus and stomach region. Males responsible for the sex difference in mercury concentration were not the same males responsible for sex difference in parasitism, hence separate explanations for these patterns were required. Males tended to forage in more pelagic areas and at a slightly lower trophic level than did females, as determined by stable $\mathrm{C}$ and $\mathrm{N}$ isotope signatures, respectively. These sex differences in foraging and expected differential consumption of intermediate fish hosts could explain the sex difference in parasitism but not the sex difference in mercury concentration. I suggest when testing contaminant-parasite linkages that sex differences in exposure be addressed.
\end{abstract}




\section{Introduction}

Exposure to mercury is increasing worldwide because industry and mining are making it more available (Weiner et al. 2003). Mercury is a natural metal in the environment that is non-essential to life; however, when converted in aquatic environments to methylmercury (its organic form) it becomes a contaminant of particular interest as it is toxic to wildlife (Weiner et al. 2003). Methylmercury bioaccumulates with trophic level therefore top consumers are exposed to higher concentrations (Weiner et al. 2003).

Researchers have shown that degree of endoparasitism and methylmercury burden is linked in free-ranging birds (Wayland et al. 2001: Sagerup et al. 2009). A similar positive correlation was also found between endoparasitism and organochlorine levels in a free-ranging population of glaucous gulls Larus hyperboreus (Gunnerus 1767: Sagerup et al. 2000). One hypothesis to explain such relationships is that methylmercury and also organochlorines reduce immunity, thereby resulting in a higher degree of parasitism (e.g.. Luebke et al. 1994: Boroskova et al. 1995). However, when immune status was measured and compared to concentrations of organochlorines and abundance of parasites in northern fulmars Fulmarus glacralis (Linnaeus 1761), there was no relationship with either (Mallory et al. 2007). There are no experimental studies on birds in their native habitat showing that increased methylmercury levels lead to an increased susceptibility to parasitism. Therefore, other issues should be addressed either to test, or help inform, hypotheses about relationships between methylmercury and parasitism.

One such issue is co-ingestion of methylmercury and parasites, where prey with high methylmercury levels, also tend to be those prey species with more infective stages 
of parasites (e.g., Ryman et al. 2008). Co-ingestion of methylmercury and infective stages of parasites is a credible idea insofar as individual differences in prey selection and habitat use can lead to differences in exposure to methylmercury (Weiner et al. 2003) and also to intestinal helminths (Knudsen et al.1996; Marcogliese 2002).

Many male and female birds differ in morphology, physiology or behaviour and as a result show sexual segregation in foraging habitats or sex differences in prey selection (Newton 1998; Cristol et al. 1999; Casaux et al. 2001). For piscivorous birds, larger birds have reduced gape constraints (Forero et al. 2002) and can capture larger fish, which usually occupy higher trophic positions (France et al. 1998). Since methylmercury biomagnifies, feeding on prey from higher trophic levels will increase the potential for methylmercury exposure and accumulation (Cabana \& Rasmussen 1994; Houserova et al. 2007). Furthermore. intestinal helminths often are parasites with indirect life cycles that use prey as intermediate hosts (e.g., Mackiewicz 1988) and larger fish species, or larger fish of a given species. harbor more infective stages of parasites (Thomas 2002). Thus, parasitism. like methylmercury concentration, might simply reflect trophic position or use of habitats for foraging.

To address this co-ingestion hypothesis. it is necessary to explore patterns of foraging. Stable isotopes of carbon and nitrogen often are used to study prey selection based on habitat use and trophic level (often grouped under the term foraging ecology). Carbon isotopes can provide information regarding the origin of prey captured by predators. For example, organisms comprising benthic or littoral food webs are enriched in the heavier ${ }^{13} \mathrm{C}$ isotope resulting in less negative $\delta^{13} \mathrm{C}$ values: whereas, pelagic biota 
have more negative $\delta^{13} \mathrm{C}$ values (Hobson et al.1994; France 1995). The trophic position

of an organism can be determined using nitrogen isotopes $\left({ }^{15} \mathrm{~N}^{14} \mathrm{~N}\right)$. Species occupying higher trophic positions have greater $\delta^{15} \mathrm{~N}$ values (Kelly 1999) and research has shown that biomagnifying contaminants increase with trophic position (Cabana \& Rasmussen 1994).

The objective of this study was to describe patterns of nematode parasitism and mercury concentration in breeding male and female double-crested cormorants Phalacrocorax anrutus (Lesson 1831), a piscivorous waterbird. I previously reported a strong sex difference where greater burdens of nematodes (Contracaecum spp.) were found in male cormorants from Lake Ontario (Chapter 2). Using a sub-sample from Chapter 2 I investigated whether sex differences in mercury concentrations also existed. I compared sexes for differences in their foraging ecology using stable isotopes $\left(\delta^{13} \mathrm{C}\right.$, $\delta^{15} \mathrm{~N}$ ), and with respect to relationships between body size and either parasitism or mercury concentration. Such information might help to explain sex differences in both factors and address the plausibility of mercury-parasite relationships occurring due to coingestion. Of course, sexes could similarly be exposed to both mercury and infective stages of parasites but differ physiologically in their ability to eliminate or reduce mercury burdens or parasite levels (a problem I return to).

\section{Methods}

I collected 126 breeding cormorants from Presqu'ile Provincial Park $\left(43^{\circ} 59^{\prime} \mathrm{N}, 77^{\circ}\right.$ $42^{\prime} \mathrm{W}$ ) on Lake Ontario during May 2006. These birds were collected as part of a larger 
study where details of collection. sample preparation, enumeration and expert identification of nematodes are described (see Chapter 2). Sex of cormorants was determined by gonadal inspection.

I collected a $10 \mathrm{~g}$ sample of breast muscle from each bird and froze each sample in a chemically-clean glass jar at $-40^{\circ} \mathrm{C}$ until processed for total mercury analysis. Muscle was chosen for analysis because in seabirds most of the mercury in muscle tissue is methylmercury (Houserova et al. 2007). It is methylmercury that is the predominant mercury species transmitted trophically and is the most toxic to wildlife (Weiner et al. 2003). Breast muscle samples from all 126 birds were thawed, homogenized and weighed out into acid-washed polypropylene vials, which were then freeze-dried and dry mass recorded. I crushed the freeze-dried breast muscle into a powder and measured total mercury using a Milestone DMA-80 direct mercury analyzer (Shelton. CT, USA). Quality control was maintained by using certified reference material (Dogfish Liver certified reference material for trace metals [DOLT-2]. Metals Toxicology Laboratory, National Wildlife Research Centre. Ottawa, ON, Canada) and sample replicates. All values were expressed as a dry mass concentration and mean values were reported for sample replicates.

I used $\delta^{13} \mathrm{C}$ and $\delta^{15} \mathrm{~N}$ values to investigate foraging ecology of males and females. I used a sub-sample of 60 cormorants ( 30 males and 30 females) with the highest and lowest abundance of (ontracaecum spp. (within each sex) for stable carbon and nitrogen isotope analysis. This sub-sample also had the full range of mercury levels that were observed in the larger sample (data not shown). One milligram $( \pm 0.2 \mathrm{mg}$ ) of breast 
muscle powder was encapsulated in tin. Isotope analysis was accomplished using a CE 1110 Elemental Analyser (CE Instruments) followed by gas chromatograph separation and on-line analysis by continuous-flow with a DeltaPlus Advantage isotope ratio mass spectrometer (Thermo Scientific) coupled with a ConFlo III (G.G. Hatch Isotope Laboratories, University of Ottawa, Ottawa, ON, Canada). The data were normalized using international standards for calibration (IAE-CH-6, IAEA-NBS22, IAEA-N1, IAEA-N2. USGS-40, USGS-4I) and further quality control was maintained through sample duplicates. Values are reported in delta notation in parts per thousand (\%o, per mil) relative to the above standards and mean values are reported for samples taken in duplicate. Analytical precision, based on repeat measures of a standard (C-55), was \pm 0.2 $\%$. I corrected the $\delta^{13} \mathrm{C}$ values for lipid content using Kojadinovic et al. (2008) seabirdadapted version of McConnaughey \& McRoy (1979) lipid normalization equation.

(1) $\quad \delta^{13} C_{\text {predicted }}=\delta^{13} C_{\text {hulk }}+6((-0.18+3.9) /(1+287 / L))$

(2) where $L=93^{\prime}\left(0.246^{*}(\mathrm{C}: \mathrm{N})-0.775\right)^{-1}$

I first used a non-parametric Wilcoxon test (Zar 1999) to compare levels of mercury and Contracaecum spp. between 79 males and 47 females because the mercury and parasite data did not meet the assumption of normality even after log-transformation (according to Shapıro-Wilk test). I then used a non-parametric Spearman Rho correlation to determine relationships between levels of mercury and abundance of Contracaecum spp. I further compared $\delta^{13} \mathrm{C}$ and $\delta^{15} \mathrm{~N}$ values between 30 males and 30 females, using analysis of variance tests (ANOVA). I then used Spearman Rho correlations to determine relationships among $\delta^{13} \mathrm{C}, \delta^{15} \mathrm{~N}$, mercury concentration, body mass, and parasite levels. 
Previous reports showed that body mass and abundance of Contracaecum spp. were not correlated. for either the males or females (Chapter 2). I reported median and associated $25 \%$ and $75 \%$ interquartile ranges for male and female mercury concentrations and means ( \pm SE) for isotope analyses. I used JMP version 4 statistical software (SAS Institute Inc. 1989-2000) for analyses. Bonferroni corrections were applied when multiple analyses of the same hypothesis were performed.

\section{Results}

\section{Host sex, parasitism and mercury concentration}

Males had 2.8 times the abundance of Contracaecum spp. compared to females. The median number of Contracaecum spp. for males was 36 with an interquartile range from 10 to 69 , versus 13 Contracaecum spp. for females, with an interquartile range from 2 to $36(Z=-3.27, P<0.001)$

Mercury was detected in all breast muscle samples in 79 male and 47 female cormorants. There was also a significant sex difference in mercury concentrations, where males had mercury concentrations 1.5 times greater than females. The median for males was $1.74 \mu \mathrm{g} / \mathrm{g}$ (dry mass) with an interquartile range from 1.34 to $2.80 \mu \mathrm{g} / \mathrm{g}$ (dry mass), whereas for females, the value was $1.14 \mu \mathrm{g} / \mathrm{g}$ (dry mass) with an interquartile range from 0.97 to $1.45 \mu \mathrm{g} / \mathrm{g}$ (dry mass; $\mathrm{Z}=-6.06, \mathrm{P}<0.0001$ ).

Analyses including both males and females indicated that the correlation between total mercury and abundance of Contracaecum spp. was statistically significant (Table 3.1; Fig. 3.1). However, I note that only 2 of the 79 males had both high abundance of 
Table 3.1. Correlations between parasitism and mercury concentration with associating relationships with body mass, and foraging ecology with the sexes of cormorants (Phalacrocorax auritus) analysed together and separately. For any $P$ observed $<0.05$ Bonferroni correction was used based on the number of multiple tests of the same hypothesis, which was usually 3 (i.e., significance at $P<0.02$ ). Significant relationships are in bold. Reprinted with permission from 2008 NRC Canada.

Correlations

Contracaecum spp. vs. [Hg]

Males and females together

Males only

Females only
Spearman Rho

0.22

0.07

0.14

0.49

0.25

$-0.12$

$-0.23$

0.08

$-0.01$

0.94

Males only

Females only

$[\mathrm{Hg}]$ vs. $\delta^{15} \mathrm{~N}$ values

Males and females together

Males only

Females only

$-0.29$

0.12

$-0.41$

0.001

$-0.06$

0.75

$-0.11$

0.56 
Chapter 3

Table 3.1. Continued

Correlations

Spearman Rho

$P$

Contracaecum spp. vs. $\delta^{13} \mathrm{C}$ values

Males and females together

$-0.38$

$\mathbf{0 . 0 0 3}$

Males only

$-0.37$

0.04

Females only

$-0.41$

0.03

Contracaecum spp. vs. $\delta^{15} \mathrm{~N}$ values

Males and females together

$-0.14$

0.27

Males only

$-0.003$

0.99

Females only

0.10

0.60 


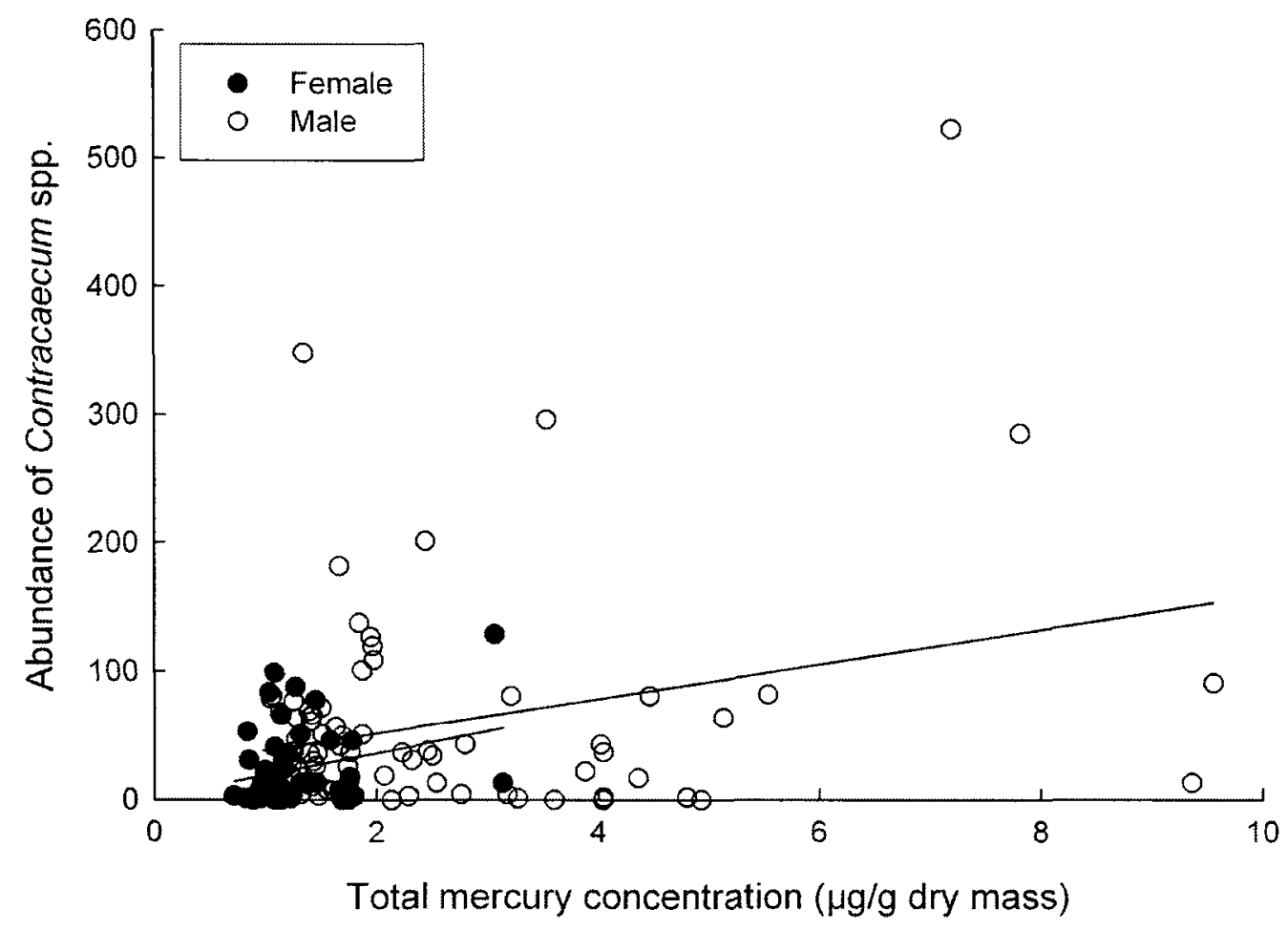

Figure 3.1. Relationships between abundance of Contracaecum spp. and mercury concentration for 79 male and 47 female cormorants (Phalacrocorax auritus). There appears to be two groups of males where males with greater than 100 nematodes follow the predicted pattern of a positive relationship between abundance of Contracaecum spp. and total mercury concentration and a second group of males that have less than 100 nematodes that do not follow the positive relationship with total mercury concentration. A shift in food web dynamics is occurring in the Laurentian Great Lakes where there is an increasing reliance on benthic food webs (Rennie et al. 2009). Perhaps the males with less than 100 worms are reducing their exposure to infective stages by foraging in benthic habitats. Reprinted with permission from 2008 NRC Canada. 
Contracaecum spp. and high mercury concentrations. When these two males were removed, the parasitism-mercury correlation, seen when the sexes were analysed together initially, was not maintained (after Bonferroni correction; $P=0.04$ ). Furthermore, within each sex, the correlation between abundance of Contracaecum spp. and mercury concentration was not statistically significant (Table 3.1: Fig. 3.1). Comparisons between cormorants driving the two sex differences suggested the males responsible for the sex difference in parasitism were different from the males responsible for the sex difference in mercury concentration (Fig. 3.1). I removed the males driving the sex difference in parasitism (males removed $n=15, \mathrm{Z}=-1.87, \mathrm{P}=0.06$ ) and found the sex difference in mercury concentration persisted $(Z=-5.52, P<0.001)$ indicating that the sex difference in parasitism and sex difference in mercury concentration were independent patterns.

When males and females were analysed together there was a positive correlation between abundance of Contracaecum spp. and body mass (Spearman Rho $=0.22, \mathrm{P}=$ $0.01)$. However, there was no relationship between body mass and abundance of Contracaecum spp. in either males or females analysed separately (Chapter 2). Additionally, there was a positive correlation between mercury concentration and body mass when males and females were analysed together, but not when analysed separately (Table 3.1).

\section{Foraging ecology, mercury concentration and parasitism}

Mercury concentration and $\delta^{13} \mathrm{C}$ values were not correlated when males and females were analysed together or separately (Table 3.1). In comparison, a significant 
correlation between mercury concentration and $\delta^{15} \mathrm{~N}$ values was found when males and females were analysed together, but not when analysed separately (Table 3.1). Similarly, abundance of Contracaecum spp. was negatively correlated with $\delta^{13} \mathrm{C}$ values when males and females were analysed together, but again not when analysed separately (Table 3.1: Fig. 3.2). Importantly, abundance of Contracaecum spp. was not significantly correlated with $\delta^{15} \mathrm{~N}$ values for males and females analysed together or separately (Table 3.1), suggesting that Contracaecum spp. are not aggregated in higher trophic level prey but may be aggregated in pelagic areas. Males and females had significantly different $\delta^{15} \mathrm{~N}$ values and tended towards different $\delta^{13} \mathrm{C}$ values (Fig. 3.3). Males tended to lower $\delta^{13} \mathrm{C}$ values $\left(-21.18 \pm 0.20 \%\right.$ for males and $-20.65 \pm 0.21 \%$ for females; $F_{1.58}=3.46, P=$ 0.07 ) and lower $\delta^{15} \mathrm{~N}$ values (mean for males $14.52 \pm 0.08 \%$, for females $15.08 \pm 0.11$ $\% 0, F_{1,58}=15.98, P<0.0002$ ), suggesting pelagic, and slightly lower trophic foraging for males. When males and females were analysed together there was no significant correlation between body mass and $\delta^{13} \mathrm{C}$. but there was a significant correlation between body mass and $\delta^{15} \mathrm{~N}$ values $\left(\delta^{13} \mathrm{C}: R_{\text {Pearson }}=-0.26, P=0.05, \delta^{15} \mathrm{~N}: R_{\text {Pearson }}=-0.34, P=\right.$ $0.001)$. However, when males and females were analysed separately body mass did not significantly correlate with $\delta^{13} \mathrm{C}$ nor with $\delta^{15} \mathrm{~N}$ values for males $\left(\delta^{13} \mathrm{C}: R_{\text {Pearson }}=-0.30, P\right.$ $\left.=0.10, \delta^{15} \mathrm{~N}: R_{\text {Pearron }}=-0.06, P=0.76\right)$ or for females $\left(\delta^{13} \mathrm{C}: R_{\text {Pearson }}=0.11, P=0.57\right.$, $\left.\delta^{15} \mathrm{~N}: R_{\text {Pear on }}=-0.06, P=0.77\right)$. 


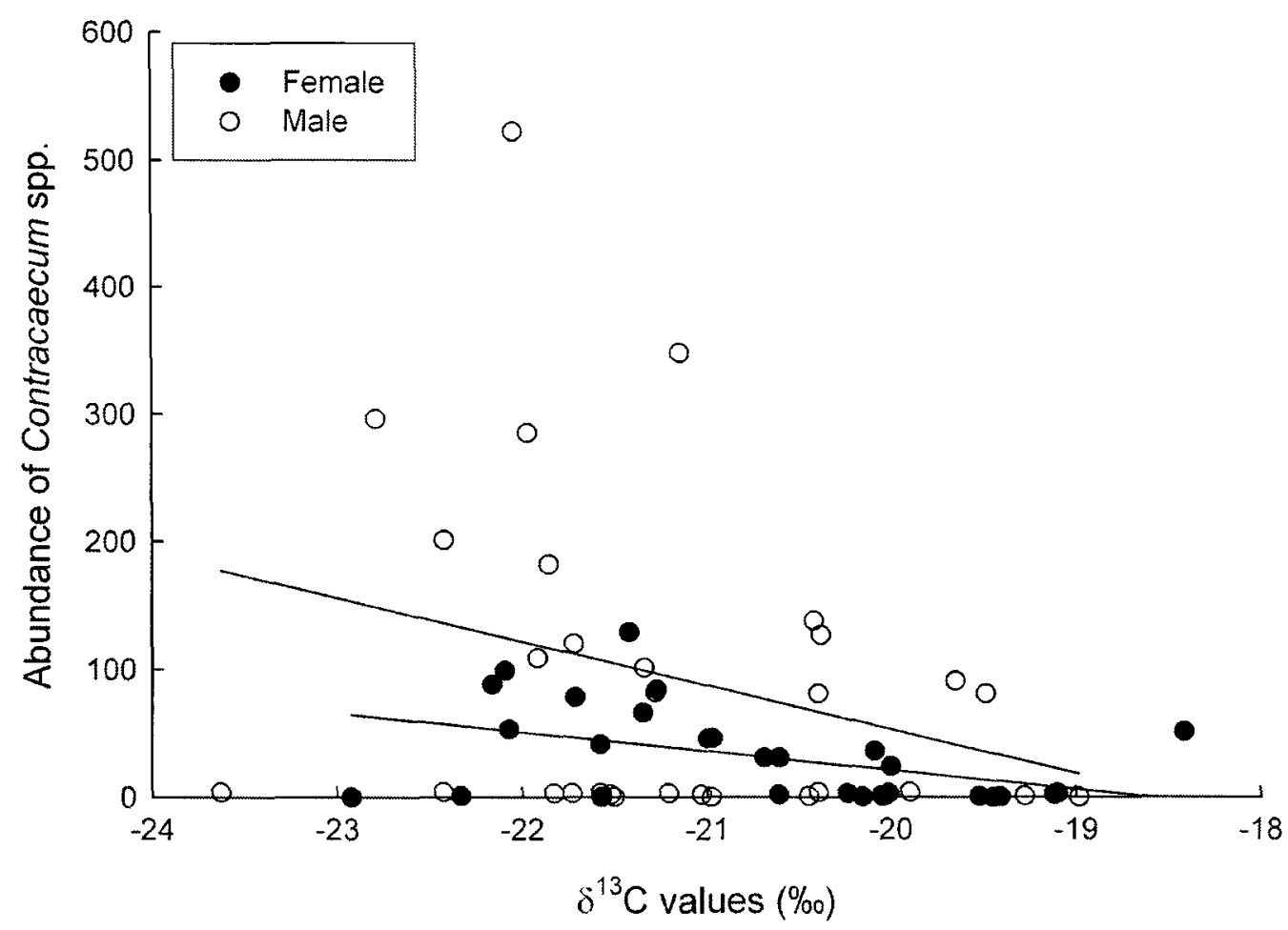

Figure 3.2. Relationships between abundance of Contracuecum spp. and $\delta^{13} \mathrm{C}$ values in 30 male (open circle) and 30 female (closed circle) double-crested cormorants (Phalacrocorax auritus). A negative non-linear relationship between abundance of Contracuecum spp. and $\delta^{13} \mathrm{C}$ values appears for males that have greater than 100 nematodes, whereas males with less than 100 nematodes do not show a relationship with $\delta^{13} \mathrm{C}$ values. Perhaps the two groups of males (i.e., those with high parasitism and those with low parasitism) have different prey selection and hence exposure to parasites because the males with the highest levels of parasitism have intermediate $\delta^{13} \mathrm{C}$ values. Reprinted with permission from (c) 2008 NRC Canada. 


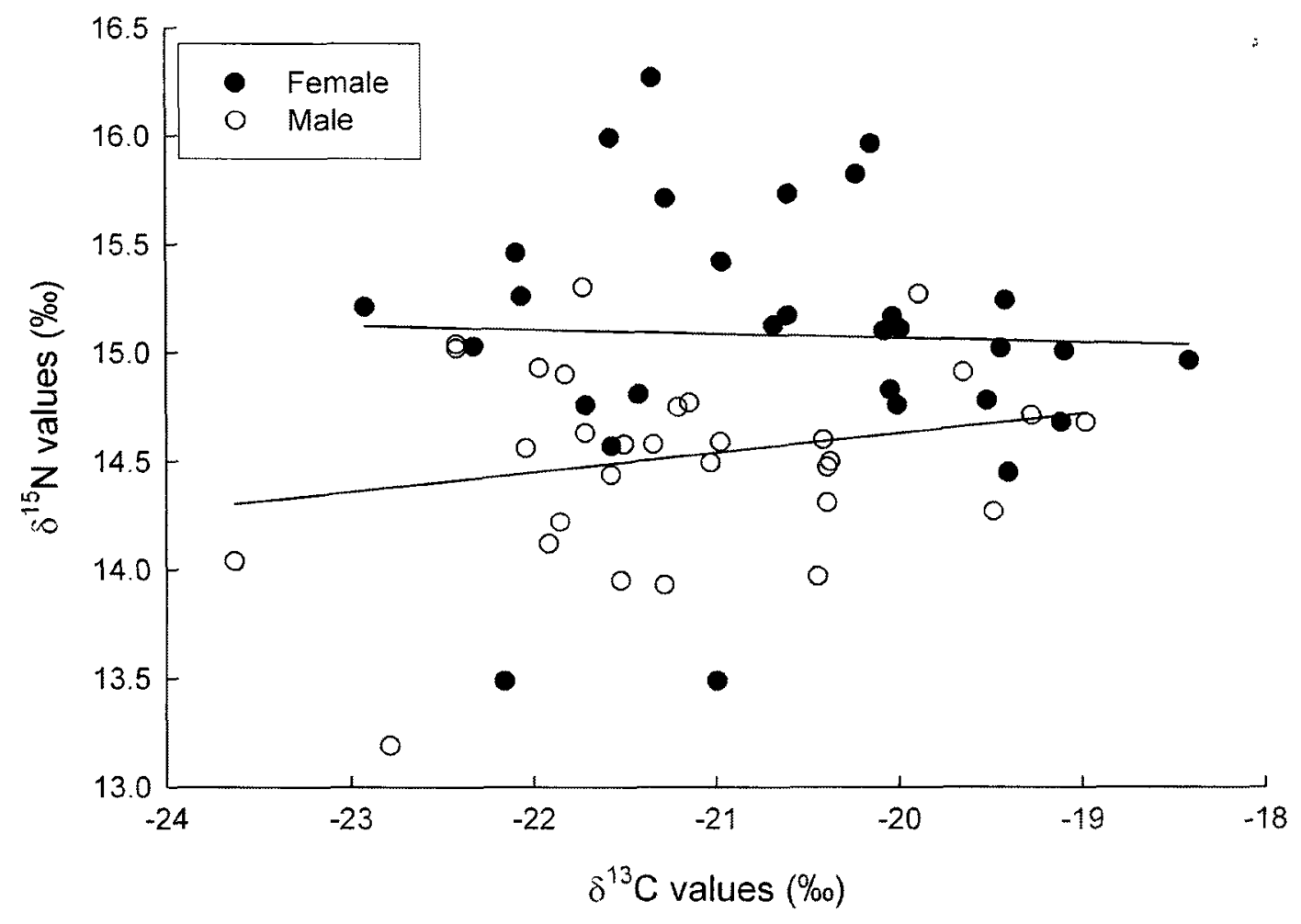

Figure 3.3. Relationships between $\delta^{15} \mathrm{~N}$ and $\delta^{13} \mathrm{C}$ values for 30 male (open circles) and 30 female (closed circles) double-crested cormorants (Phalacrocorax anritts). Reprinted with permission from 2008 NRC Canada. 


\section{Discussion}

I found that although males were both more parasitised and carried higher mercury burdens than did females, total mercury and abundance of ('ontracaecum spp. were unrelated in either sex. Furthermore, the males responsible for the sex difference in parasitism were not the same males that appeared responsible for the sex difference in total mercury. Males and females had different stable isotope signatures. suggesting sex differences in foraging ecology. I found that abundance of Contracaecum spp. was related to $\delta^{13} \mathrm{C}$ values (but not $\delta^{15} \mathrm{~N}$ values), suggesting that male and female cormorantsthat feed on prey from less benthic or littoral areas are exposed to, and accumulate, more Contracaecum spp. In Lake Ontario, fish show patterns in $\delta^{13} \mathrm{C}$ signatures that are consistent with less negative $\delta^{13} \mathrm{C}$ values in benthic fish (e.g., round goby Apollonia melanostoma (Pallas 1814); mean $( \pm \mathrm{SD}) \delta^{13} \mathrm{C}:-19.91 \pm 1.41 \%$ ) compared to pelagic fish (e.g., alewife Alosa psendoharengus (Wilson 1811 ); $\delta^{13} \mathrm{C}$ : $22.05 \pm 0.69 \%$ : significant difference (Student's $t$ test); C. Hebert. unpublished data). However, foraging ecology $\left(\delta^{13} \mathrm{C}\right.$ or $\left.\delta^{15} \mathrm{~N}\right)$ could not explain the sex difference in mercury concentration. Thus, there appears to be little or no support for the co-ingestion hypothesis. However, there might be a cost where high levels of both parasites and mercury are fatal and therefore these cormorants were not typically part of my sample (making the co-ingestion hypothesis difficult to test). I further cannot dismiss the possibility that parasites and mercury are co-ingested, but some birds are better able to clear infections or mercury. thereby reducing or eliminating the expected relationship. My study nonetheless suggests the independent sex differences in mercury and parasitism 
might be related to behaviour rather than immunology and co-ingestion need not be invoked in such studies, i.e. mercury and parasites are not obviously being frequently coingested by male cormorants.

In this study, males had 1.5 times more mercury in breast muscle than did females. Females cluster at low mercury concentrations compared to the wide variability seen in males (Fig. 3.1). Similar sex differences in mercury burden have been observed in other studies (Burgess et al. 2005; Ackerman et al. 2007). Lower mercury levels in females often are attributed to the deposition of mercury in eggs (Fimreite 1974; Fimreite et al. 1982). Males lack this excretion mechanism which leads to higher and more variable concentrations of mercury based more on differences among males in exposure. Cormorants were sampled approximately two weeks after a full clutch was laid, therefore. lower mercury levels in females might have reflected mercury depuration to their eggs. However, there has been some doubt regarding the extent to which depuration of mercury into eggs drives sex-related differences (Burgess et al. 2005; Ackerman et al. 2007). An experimental study showed that when Cory's shearwaters Calonectris diomedea (Hazevoet 1995) were dosed with mercury prior to egg laying, excretion of mercury in eggs ( $14 \%$ of experimental dose) could not explain the $28 \%$ lower levels of mercury in blood of females compared to males (Monteiro \& Furness 2001). Female cormorants would have to excrete $>50 \%$ of their mercury body burden into eggs to explain the difference found here between males and females, which is unlikely because female cormorants only invest approximately $3 \%$ of body mass into their clutch, compared to the $11 \%$ that is invested for other seabirds (Hatch \& Weseloh 1999). 
Sex differences in mercury concentrations in piscivorous birds might relate to exposure differences. Male cormorants are heavier and structurally larger than females (Glahn \& McCoy 1995; Chapter 2) and had larger fish in their stomach than did females (Glahn et al. 1995; Withers \& Brooks 2004). Larger fish often have higher concentrations of mercury than smaller fish (Weiner et al. 2003). Therefore, the larger male cormorants could accumulate more mercury on average than females. However, male cormorants also could be consuming a greater quantity of fish, which also could lead to greater mercury concentrations in males (Weiner et al. 2003).

Independent of the sex difference in mercury concentration, there was a sex difference in parasitism. Often, androgen mediated immunosuppression is used to partly explain sex differences in parasitism where males have greater burdens (e.g., Klein 2000). I used breeding birds. where androgen levels in males should be at peak levels: however, one coarse measure of immune function (spleen mass) indicated that males did not have a significantly reduced immune potential compared to females (Chapter 2 ). Furthermore, the degree of sex difference ( $>2$ times more Contracaecum spp. compared to females) also suggested sex differences in exposure to parasitism.

Males and females tended to have different stable isotope signatures. Breast muscle tissue has an isotopic turnover in Japanese quail Coturnix japonıca (Temminck \& Schlegel 1849) of 12.4 days (Hobson \& Clark 1992). This turnover rate suggests isotope values I reported reflect the diets on the breeding grounds because cormorants arrive a month before breeding (Hatch \& Weseloh 1999) and I collected birds during midincubation. Based on their less negative $\delta^{13} \mathrm{C}$ values in muscle, female cormorants might 
have foraged to a greater extent on benthic or littoral prey compared to males. In contrast, Ishikawa \& Watanuki (2002) found that male Japanese comorants Phalacrocorax capillatus (Temminck \& Schlegel 1850) fed more on benthic prey whereas females fed on pelagic and coastal prey. Unfortunately, stable $\mathrm{C}$ isotopes cannot distinguish between particular benthic or littoral prey species.

Notwithstanding, these findings are important because I found that abundance of Contracaecum spp. increased as male and female cormorants foraged further away from benthic or littoral areas (i.e., more negative $\delta^{13} \mathrm{C}$ values). Both larval stages and adult nematodes were collected from the cormorants and therefore were most likely accumulated on the breeding grounds since infective parasitic stages of Contracaecum spp. had enough time to develop into $4^{\text {th }}$ stage larvae and adults at the time of sampling (Anderson 2000). However, I can not rule out the possibility that a proportion of Contracaecum spp. were from over-wintering habitats and therefore do not necessarily relate to the isotopic signatures measured in the breast muscle.

Contracaecum spp. uses general predator-prey interactions where various intermediate fish host species transmit infective stages trophically to cormorants, a definitive host (Anderson 2000). Many of the species of fishes that cormorants feed on, are intermediate hosts for Contracaecum spp. (Hoffman 1999), but could differ in how important they are as intermediate hosts and how important they are in diets of male and female cormorants. In fact, fishes acquire infective parasitic stages of Contraceacum spp. by ingesting infected copepods, a first intermediate host (Anderson 2000). Copepods are food for many pelagic planktivorous fishes, but are less available for littoral fishes 
(Williamson 1991). Perhaps slight diet specializations linked to benthic or littoral versus pelagic fish species are causing females to be less exposed to Contracaecum spp. than are males.

Diet studies on cormorants from Lake Ontario found that the round goby and the alewife contribute approximately $70 \%$ of the adult pre-chick diet (Johnson et al. 2006). These two prey fish have distinct habitats where the round goby $\left(\delta^{13} \mathrm{C}\right.$ signature $\geq-22 \%$ ; see Figure 6 in Barton et al. 2005) is in nearshore benthic areas, while the alewife (mean $\delta^{13} \mathrm{C}$ signature of $-24.02 \pm 3.90 \%$; Thompson et al. 2005) is in pelagic waters (Scott \& Crossman 1998). The round goby was first reported in cormorant diets recently (Somers et al. 2003) and is fairly depauperate in parasites in the Great Lakes, in fact, Contracaecum spp. has not been reported in round gobies from this locality (e.g., Camp et al. 1999: Kvach \& Stepien 2008). Alternatively, alewives are well-known intermediate hosts for Contracaecum spp. (Hoffman 1999). Other major prey fish for cormorants, such as yellow perch Perca flavescens (Mitchill 1814), rock bass Ambloplites rupestris (Rafinesque 1817) and pumpkinseed Lepomis gibbosis (Linnaeus 1758) have less distinct benthic or littoral and pelagic habitats (Scott \& Crossman 1998), but are intermediate hosts for Contracaecum spp. (Hoffman 1999; Johnson et al. 2006). The wide variability in male isotope signatures compared to females suggests males have a more varied diet, that is, they are likely feeding on the yellow perch, rock bass and pumpkinseed that are available more so than females, which increases the chance of exposure to parasitic infective stages (Hoffman 1999). Furthermore, piscivorous birds exhibiting sexual size dimorphism. like cormorants, often demonstrate sex differences in 
diet composition and foraging habitat (Bearhop et al. 2006). These differences could account for sex differences in abundance of Contracaecum spp. in my sample of cormorants especially if round gobies are the more accessible prey for females that forage in benthic or littoral areas and alewife are more accessible prey for males foraging in pelagic waters. Similar situations of dietary preferences between individuals have been linked to levels of parasitism in Arctic charr Salvelinus alpimis (Linnaeus 1758) and Brook charr Salvelmus fontmalis (Mitchill 1814) (Knudsen et al. 1996; Bertrand et al. 2008).

There was no relationship with foraging location $\left({ }^{13} \mathrm{C}\right)$ on the breeding grounds and mercury concentration, again indicating alternative factors responsible for the separate pattern of sex differences in mercury concentration. A few studies have found contradictory relationships between $\delta^{13} \mathrm{C}$ and mercury concentration, where mercury concentrations increased with more benthic or littoral foraging (e.g., Nisbet et al. 2002) and, alternatively, with more pelagic foraging (e.g., Ricca et al. 2008).

Males and females differed in $\delta^{15} \mathrm{~N}$ values. However, the negative correlation between $\delta^{15} \mathrm{~N}$ and mercury concentration when males and females were analysed together was not expected. Positive relationships between $\delta^{15} \mathrm{~N}$ and mercury concentration were found in other studies such that increased mercury concentrations occurred with increases in $\delta^{15} \mathrm{~N}$ values of approximately $1 \%$ (Cabana \& Rasmussen 1994). Furthermore, when the sexes were analysed separately, there was no relationship between $\delta^{15} \mathrm{~N}$ and mercury concentration even though there was sufficient range in $\delta^{15} \mathrm{~N}$ values $(>1 \%)$ to detect a relationship. However, round gobies could influence the $\delta^{15} \mathrm{~N}$ values I observed. This 
species might occupy higher trophic positions (mean $\delta^{15} \mathrm{~N}$ signature of $13.95 \pm 0.50 \%( \pm$ SD) in eastern Lake Ontario; C. Hebert, unpublished data) because they feed on invertebrates and small fishes, whereas alewife, because of their planktivorous diet (Hubbs \& Lager 2007), might occupy lower trophic positions (mean $\delta^{15} \mathrm{~N}$ signature of $13.29 \pm 0.82 \%( \pm \mathrm{SD})$ in eastern Lake Ontario; significant difference from round gobies (t-test); C. Hebert, unpublished data). Therefore. one explanation for the patterns I found with mercury concentration and $\delta^{15} \mathrm{~N}$ values is males might be accumulating more mercury by consuming a greater quantity of lower trophic level prey than females which might be accumulating less mercury by consuming smaller quantities of higher trophic level prey.

I also did not find any relationship between body mass and abundance of Contracaecum spp. (Chapter 2). I might expect that the larger males might consume a greater quantity of prey, which could increase the chances of exposure to infective parasitic stages (Bush et al. 2001). However, body mass does not always have a straightforward or predictable relationship with parasitism (Hudson \& Dobson 1991).

In summary, I had set out to determine the relationship between mercury and parasitism and found sex differences in both concentrations of mercury and abundance of Contracaecum spp. (greater burdens of both in males). However, upon closer inspection. I found that the sex differences were most likely a consequence of different processes since different males were responsible for the sex difference in mercury concentration and parasitism. I found that males tended to forage in more pelagic habitats (i.e., more negative $\delta^{13} \mathrm{C}$ values) than did females and that pelagic $\delta^{13} \mathrm{C}$ values related to higher 
abundance of Contracaecum spp. Therefore, differences between male and female conmorants can cause sex differences in parasitism and mercury concentration, whilst also failing to produce mercury-parasitism relationships within a sex.

I suggest that future studies on contaminant-parasite relationships consider examining the intricacies that are involved in exposure and susceptibility to contaminants and parasitism, especially the influence of host sex. I hypothesize that behavioural and physiological differences between sexes might affect both total mercury and Contracaecum spp. exposure, but independently. Addressing alternative hypotheses for potential relationships will help tease apart intricate patterns and aid the understanding of ecological relationships between contaminants and parasites. 
Chapter 4

\section{CHAPTER FOUR}

Sex differences in parasitism in cormorants and relationships with foraging ecology on Lake Erie, Canada

This chapter formed the basis for the following publication and was reproduced with permission from $(2010$ Waterbirds Society:

Robinson, S. A., Forbes, M. R., Hebert, C. E. and McLaughlin, J. D. 2010. Male biased parasitism in cormorants and relationships with foraging ecology on Lake Erie, Canada. Waterbirds 33: 307-313. 


\begin{abstract}
Existing hypotheses only partially explain sex differences in parasitism in mammals and birds. The present study examined whether sex differences in parasitism by a common trematode and nematode exists in breeding double-crested cormorants (Phalacrocorax auritus; Lesson 1831) from Lake Erie and if any sex difference in parasitism could be explained by sex differences in body size or foraging ecology, evaluated using stable isotope profiles (based on $\delta^{13} \mathrm{C}, \delta^{15} \mathrm{~N}$ ). Male cormorants had three times the abundance of Drepanocephalus spathans (Dietz 1909; a trematode) compared to females; however, there were no significant sex differences in abundance or intensity of Contracaecum spp. Relationships between body size and parasitism were inconsistent and weak. Stable carbon isotope profiles indicated that male and female cormorants that foraged in more pelagic habitats had more Contracaecum spp. In summary, male cormorants had greater burdens of parasites in a sample from Lake Erie and differences in foraging ecology might affect the levels of parasitism in cormorants.
\end{abstract}




\section{Introduction}

Sex differences in parasitism occur in mammals and birds, where males are more heavily parasitised than females; these patterns of sex differences in parasitism were uncovered using meta-analyses (Poulin 1996; Schalk \& Forbes 1997). There are several hypotheses to explain the occurrence of greater parasite burdens in males (see McCurdy et al. 1998). These include life history explanations related to differences in growth trajectories between males and females and explanations based on sex differences in homones resulting in heterogeneities in susceptibility to parasites (see Zuk \& McKean 1996; McCurdy et al. 1998). Sex differences in exposure to infective stages of parasites are also deemed important, although less often studied explicitly. Sex differences in exposure might mirror sex differences in susceptibility to parasites or the two factors might be totally unrelated or even cancel one another out.

In Chapter 3, I used stable isotope results $\left(\delta^{13} \mathrm{C}\right.$ and $\left.\delta^{15} \mathrm{~N}\right)$ to infer possible sex differences in foraging ecology that might lead to differences in exposure to infective stages of parasites and thereby explain the greater burden of parasites in males. I found that inferred feeding location (i.e. nearshore versus offshore) in Lake Ontario was associated with the occurrence and intensity of infection by Contracaecum spp. (Chapter 3). Specifically, double-crested cormorants Phalacrocorax aurtus (Lesson 1831) foraging on more pelagic prey (i.e. more negative $\delta^{13} \mathrm{C}$ values) had more Contracaectm spp. Further, males had $\delta^{13} \mathrm{C}$ values that showed a tendency to feed on more pelagic prey whereas females tended to have more benthic prey signatures (Chapter 3 ). 
Double-crested cormorants are colonial breeding aquatic birds which primarily consume fishes (Hatch \& Weseloh 1999). They are top level consumers and definitive hosts for many indirect life cycle helminths (Hatch \& Weseloh 1999). Drepanocephalus spathans (Dietz 1909) and Contracaecum spp. are two common parasites of cormorants in the Great Lakes (Chapter 2). Both have indirect life cycles that require two intermediate hosts and are transmitted by infected fish (Salgado-Maldonado \& Kennedy 1997; Anderson 2000, respectively) to piscivorous birds where they reach sexual maturity. Trematodes use molluscs as their first intermediate hosts and nematodes commonly use crustaceans as first intermediate hosts (Bush et al. 2001; Anderson 2000, respectively). Spatial differences in the distribution of the first intermediate hosts, coupled with similar differences in foraging by fishes or cormorants could lead to different exposure to infective parasitic stages of trematodes and nematodes.

I might expect differences in parasitism and foraging ecology between cormorants from Lake Ontario and a second lake ecosystem. such as Lake Erie, because of the differences in the fish fauna between the two lakes (Coon 1999). Although both Lake Ontario and Lake Erie are of similar size, the latter is shallower, therefore water temperatures are warmer and there are more diverse habitats for fishes (Coon 1999). Diet studies confirm that cormorants feed on different fish in the different lakes (Bur et al. 1999: Johnson ef al. 2002) but it is not known whether this affects parasitism in cormorants or if there are any sex differences in foraging ecology.

Few ecological studies determine the consistency and reliability of their results through repeatability (Kelly 2006). Repeatability is needed to understand the generality 
of patterns and ultimately to rule out chance explanations for phenomena being investigated. Here, I determined whether sex differences in parasitism by $D$. spathans and by Contracaecum spp. occurred in double-crested cormorants, collected from Lake Erie. I examined if foraging ecology measured using stable isotope signatures could explain any variation between males and females with respect to parasitism and whether relationships between foraging ecology and parasitism were consistent between Chapter 3 and this study.

\section{Methods}

I collected 193 breeding double-crested cormorants from Lake Erie at Point Pelee National Park of Canada-Middle Island $\left(41^{\circ} 41^{\prime} \mathrm{N}, 82^{\circ} 41^{\prime} \mathrm{W}\right)$ during May 2008. These birds were culled as part of a Parks Canada management program and were collected in a similar manner as my previous work on Lake Ontario where details of collection, sample preparation, enumeration and identification of trematodes and nematodes are described (see Chapter 2). The site on Lake Erie is $475 \mathrm{~km}$ from my previous sampling site on Lake Ontario. Sex of cormorants was determined by gonadal inspection. I assessed structural size of cormorants as described in Chapter 2: however, I only used body measures of wing chord, bill height and tarsus length (using the correlation matrix) in the principal component analysis (PCA) as head lengths were not available.

I collected a $10 \mathrm{~g}$ sample of breast muscle from each bird and froze each sample in a chemically-clean glass jar at $-40^{\circ} \mathrm{C}$ until processed for analyses of carbon and nitrogen stable isotopes. I used $\delta^{13} \mathrm{C}$ and $\delta^{15} \mathrm{~N}$ values to investigate foraging ecology of 
males and females, where decreasing $\delta^{13} \mathrm{C}$ values signify benthic to pelagic foraging locations (Hobson et al.1994; France 1995) and increasing $\delta^{15} \mathrm{~N}$ values show higher trophic level feeding (Kelly 1999). I do not have food web data for first level consumer baseline values in Lake Erie and therefore I'm using $\delta^{15} \mathrm{~N}$ values as an assumed surrogate for trophic level. I used a sub-sample of 100 cormorants (50 males and 50 females) for stable carbon and nitrogen isotope analysis. Three sampling categories were delineated to obtain a complete representation of the abundance of Contracaecum spp. in cormorants. The categories were as follows: uninfected (16 males and 16 females), highest and lowest abundance of Contracaecum spp. within each sex (17 individuals for each of four sex-byparasitism categories). Also, the sub-sampling method fully represented the abundance of D. spathans. More specifically, the range in abundance for $D$. spathans in my sub-sample was 0 to 45 trematodes (median of three trematodes), which was very similar to the range of abundance ( 0 to 71 trematodes, median of three trematodes), in the larger sample of cormorants. Sample preparation, stable isotope analysis and the lipid correction equation applied to $\delta^{13} \mathrm{C}$ values are described in Chapter 3. Data quality was assured using international standards (IAE-CH-6, IAEA-NBS22, IAEA-N1, IAEA-N2, USGS-40, USGS-41) and further quality control was maintained through sample duplicates. Values are reported in delta notation in parts per thousand (\%, per mil) relative to PeeDee belemnite (for C) and atmospheric air (for $\mathrm{N}$ ) standards and mean values are reported for samples analyzed in duplicate. Analytical precision, based on repeat measures of a standard (C-55), was $\pm 0.09 \%$. 
I first tested for sex differences in prevalence (number of infected individuals), abundance (number of parasites in an individual), and intensity (number of parasites in an infected individual) of D. spathans and Contracaecum spp. For prevalence analyses, I used $\chi^{2}$ tests. I used Wilcoxon tests for abundance and intensity analyses because the data were not normally distributed even after transformation (according to Shapiro-Wilk test; Zar 1999). Also, I determined correlations between the abundance of $D$. spathans and Contracaecum spp. for each sex using Spearman Rho correlation tests.

I assessed the level of sexual size dimorphism for my sample of cormorants (described in Chapter 2) and examined whether there was any relationship between male or female size and the abundance of either D. spathans or Contracaecum spp.

I further compared $\delta^{13} \mathrm{C}$ and $\delta^{15} \mathrm{~N}$ values between the sub-sample of 50 males and 50 females, using analysis of variance tests (ANOVA). I then used Spearman Rho correlations to determine relationships among $\delta^{13} \mathrm{C}, \delta^{15} \mathrm{~N}$, body mass, and abundance of D. spathans and Contracaecum spp. I reported median and associated $25 \%$ and $75 \%$ interquartile ranges for male and female parasite data and means ( $\pm S E$ ) for isotope data. I used JMP version 4 (SAS Institute Inc. 1989-2000) software for analyses. Bonferroni corrections were applied when multiple analyses of the same hypothesis were performed.

\section{Results}

\section{Host sex and parasitism}

The most prevalent helminths were D. spathans, Paradilepis caballeroi (Rysavy \& Macko 1973) and Contracaecum spp. which were found in $~ 50 \%$ or more of hosts. 
However, I limited further analyses to D. spathans and Contracaecum spp. as these two helminths were the most prevalent in Chapter 3, my comparison study. I found $88.3 \%$ of male cormorants $(\mathrm{N}=120)$ and $76.7 \%$ of female cormorants $(\mathrm{N}=73)$ were infected with at least one of either D. spathans or Contracaecum spp. Males had a greater prevalence of $D$. spathans than did females (males infected: $74.2 \%$, females infected: $50.7 \% ; \chi^{2}=$ $11.04, \mathrm{P}<0.001)$. However, the $-10 \%$ higher prevalence of Contracaecum spp. in males compared to females was not significant (males infected: $57.5 \%$. females infected: 46.6 $\left.\% ; \chi^{2}=2.18 . P=0.14\right)$.

Males had three times the median abundance of $D$. spathans than females; however, males and females that were infected with $D$. spathans had similar intensities of infection (Table 4.1). There was no significant difference between the sexes in abundance or intensity of Contracaecum spp. (Table 4.1). Furthermore, the two helminths were not significantly correlated, particularly for males but also not for females (Spearman Rho ranged from -0.10 to 0.03 , all $\mathrm{P}>0.41$; Fig. 4.1 ).

\section{Parasitism and host size}

Males weighed approximately $200 \mathrm{~g}$ more than females (mean $(95 \%$ confidence interval); males: $2013.7 \mathrm{~g}$ (1990.7 to $2037.0 \mathrm{~g}$ ), females: $1803.0 \mathrm{~g}(1778.3$ to $1828.1 \mathrm{~g})$, $\left.F_{1.190}=144.59, P<0.001\right)$ and were larger in structural size according to $\mathrm{PCI}$ scores $\left(F_{1.171}=261.41, P<0.001\right)$. The first PC axis of the PCA had all metrics loaded positively and explained $59 \%$ of the variation in the data. 
Table 4.1. Median abundance (median number of parasites from all birds) and median intensity (median number of parasites from infected birds) with $25 \%$ and $75 \%$ interquartile ranges (IQR) of trematodes (Drepanocephalus spathans) and nematodes (Contracaecum spp.) in male and female double-crested cormorants (Phalacrocorax auritus $)$. Wilcoxon test was used and significant results $(\mathrm{P}<0.05)$ are in bold. Reprinted with permission from 2010 Waterbird Society.

\begin{tabular}{cllll}
\hline Helminth measure & Male (IQR) & Female (IQR) & Z & $\mathrm{P}$ \\
\hline $\begin{array}{c}\text { Drepanocephalus spathans } \\
\text { Abundance }\end{array}$ & $3(0-15)$ & $1(0-5)$ & -3.60 & $<\mathbf{0 . 0 0 1}$ \\
$\quad$ Intensity & $7(3-18)$ & $5(3-9)$ & -1.59 & 0.11 \\
Contracaecum spp. & & & & \\
Abundance & $1(0-8)$ & $0(0-5)$ & -1.78 & 0.08 \\
Intensity & $6(2-17)$ & $5(2-11)$ & -1.10 & 0.27 \\
\end{tabular}




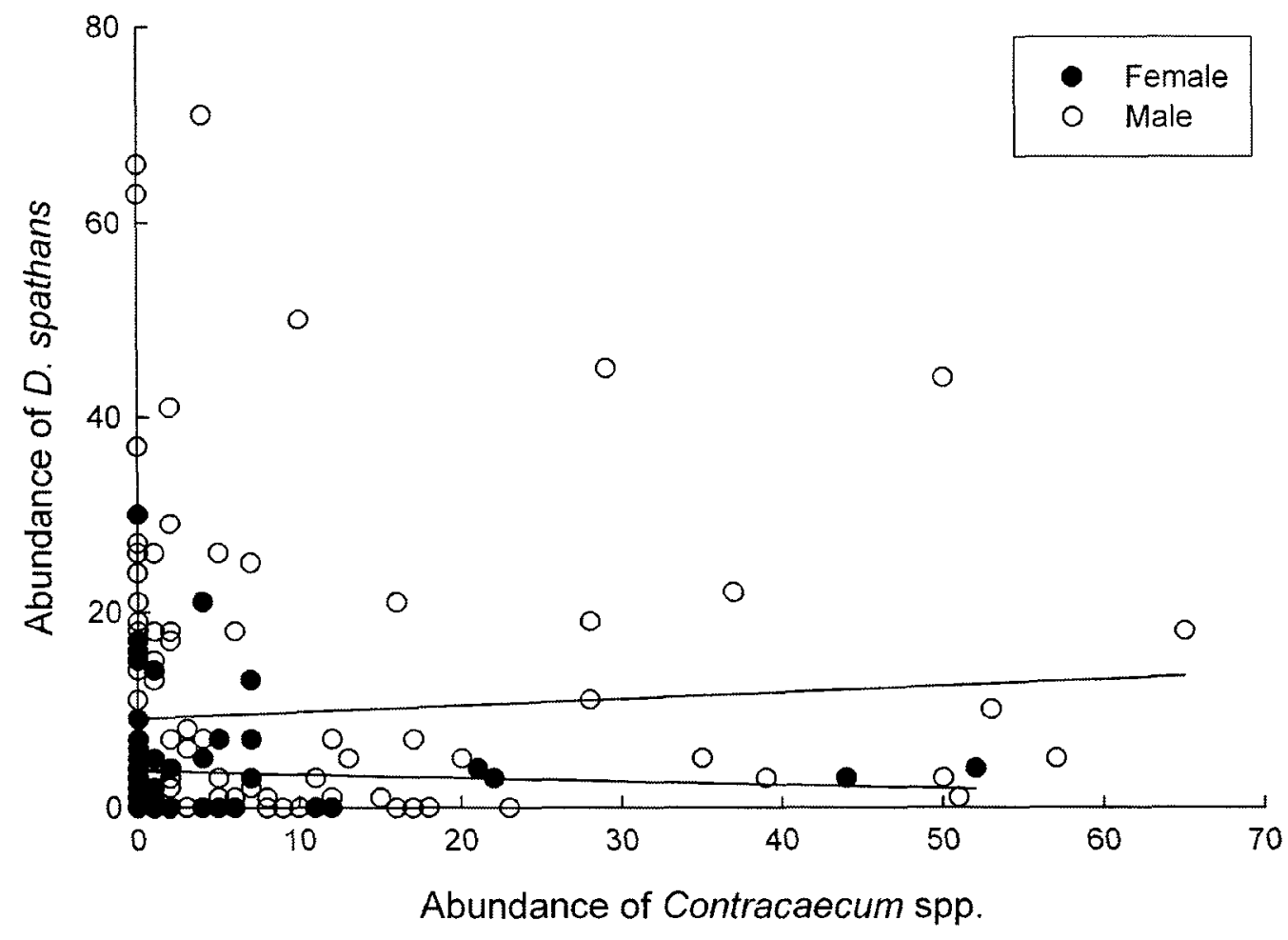

Figure 4.1. No correlation between the abundance of Drepanocephalus spathans and Contracaecum spp. in male and female double-crested cormorants (Phalacrocorax auritus). Reprinted with permission from $(0) 2010$ Waterbird Society. 
I examined the relationship between body mass and size $(\mathrm{PC} 1)$ and abundance of parasites. There was no significant correlation between body mass or size and abundance of $D$. spathans for male and female cormorants (Spearman Rho ranged from -0.18 to 0.13: all $P>0.14)$. Further, there was no significant correlation between the abundance of Contracaecum spp. and body size for males or females (Spearman Rho ranged from 0.08 to 0.12 ; all $\mathrm{P}>0.33$ ). However, I found a significant negative correlation between abundance of Contracaecum spp. and body mass in females (Spearman Rho $=-0.38 . \mathrm{P}<$ 0.001 ), but not for males (Spearman Rho $=-0.14, \mathrm{P}=0.13$ ).

\section{Parasitism and foraging ecology}

Males and females overlapped in their $\delta^{13} \mathrm{C}$ and $\delta^{15} \mathrm{~N}$ values (Fig. 4.2) and had similar mean $\delta^{13} \mathrm{C}$ and $\delta^{15} \mathrm{~N}$ values $\left(\delta^{13} \mathrm{C}:-20.21 \% \pm 0.19 \%\right.$ for males, $-19.73 \% \pm 0.20 \%$ for females, $F_{1.98}=2.94, P=0.09 ; \delta^{15} \mathrm{~N}: 15.39 \% 0 \pm 1.01 \% 0$ for males, $15.69 \% \pm 0.81 \%$ for females, $F_{1.98}=2.62, P=0.11$ ). There were no relationships between $\delta^{13} \mathrm{C}$ values and body mass for males or females when they were analysed together or when analysed separately (Spearman Rho ranged from -0.14 to 0.03 , all $\mathrm{P}>0.17$ ). Also, there was no significant correlation between $\delta^{15} \mathrm{~N}$ values and body mass when males and females were analysed together or separately (Spearman Rho ranged from -0.27 to 0.002 , all $P>0.03$ ).

There was no relationship between $\delta^{13} \mathrm{C}$ values and abundance of $D$. spathans (Table 4.2). However, I found a significant negative correlation between $\delta^{13} \mathrm{C}$ values and abundance of Contracaecum spp. (Fig. 4.3) when males and females were analysed together, but not when analysed separately (Table 4.2 ). There was a significant negative 


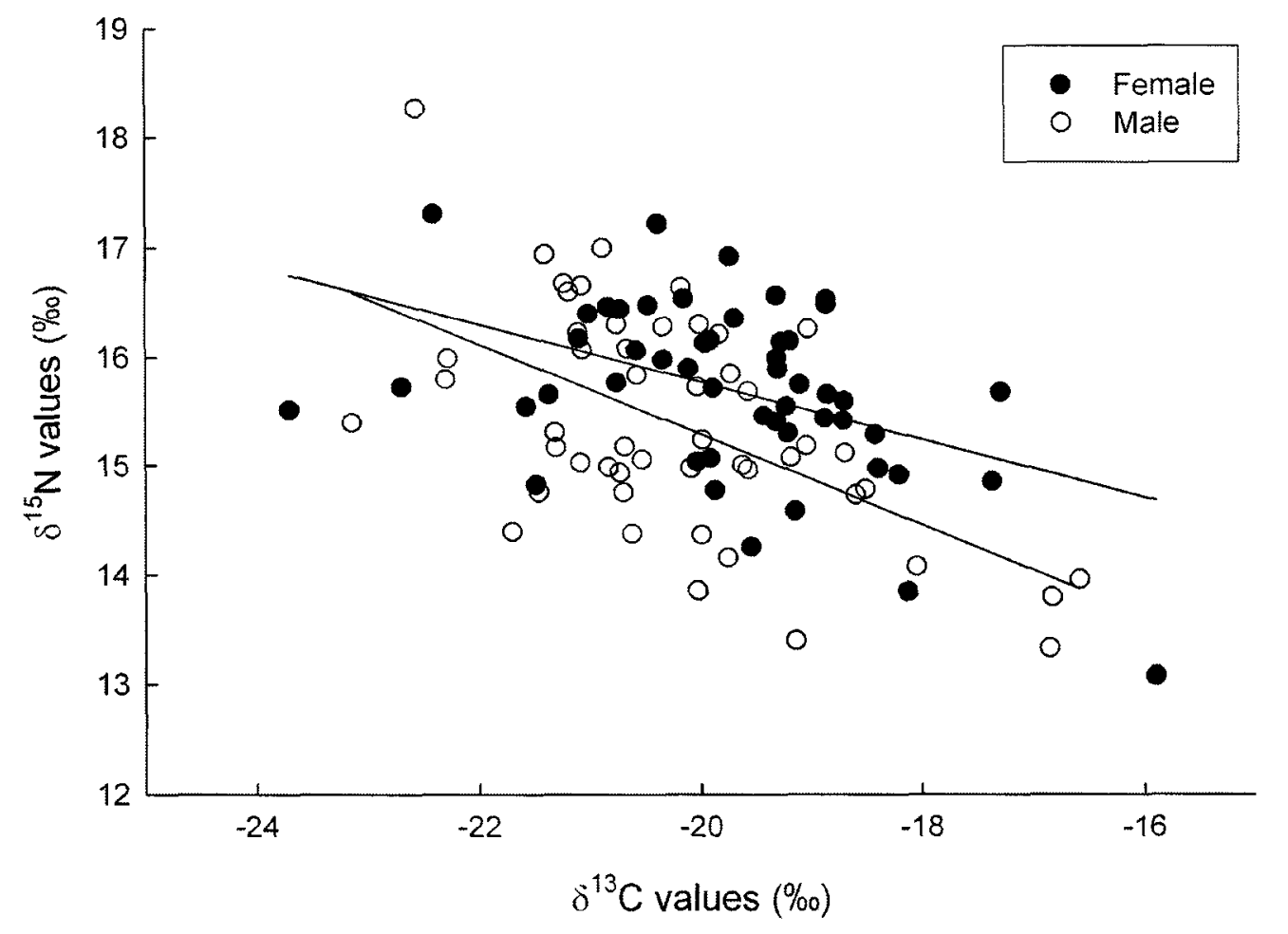

Figure 4.2. Relationships between $\delta^{13} \mathrm{C}$ and $\delta^{15} \mathrm{~N}$ values in breast muscle of male and female double-crested cormorant (Phalacrocorax curitus). Reprinted with permission from $\stackrel{(C)}{\mathrm{C}} 2010$ Waterbird Society. 
Table 4.2. Correlations between parasitism and foraging ecology $\left(\delta^{1.3} \mathrm{C}\right.$ and $\delta^{15} \mathrm{~N}$ values $)$ with the sexes of double-crested cormorants (Phalacrocorax auritus) analysed together and separately. For any P observed $<0.05$ Bonferroni correction was used based on the number of multiple tests of the same hypothesis, which was usually 3 (i.e., significance at $P<0.02$ ). Significant relationships are in bold. Reprinted with permission from 02010 Waterbird Society.

Correlations

D. spathans vs. $\delta^{13} \mathrm{C}$ values

Males and females together

Males only

Females only

D. spathans vs. $\delta^{15} \mathrm{~N}$ values

Males and females together

Males only

Females only

Contracuecum spp. vs. $\delta^{13} \mathrm{C}$ values

Males and females together

Males only

Females only

Contracaecum spp. vs. $\delta^{15} \mathrm{~N}$ values

Males and females together

Males only

Females only
Spearman Rho

0.04

0.73

0.06

0.69

0.17

0.26

$-0.25$

0.01

$-0.04$

0.78

$-0.38$

0.007

$-0.24$

$-0.19$

0.19

$-0.31$

0.03

0.07

0.50

0.12

0.38

0.03

0.81 


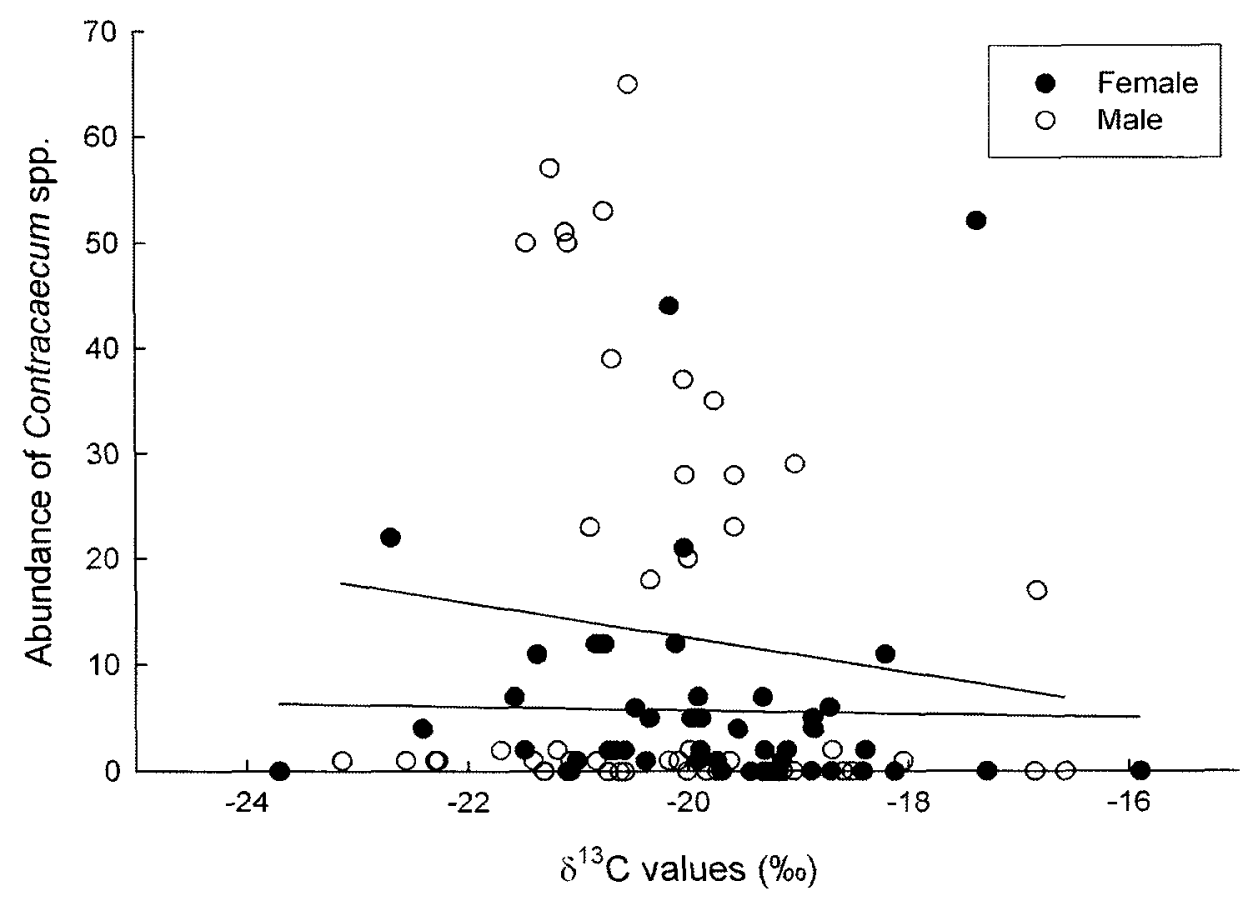

Figure 4.3. Negative correlation between $\delta^{13} \mathrm{C}$ values and abundance of Contracaecum spp. in male and female double-crested cormorants (Phalacrocorax auritus). There appears to be two groups of males, one group that has greater than 10 nematodes and show a negative non-linear relationship between abundance of Contracaecum spp. and $\delta^{13} \mathrm{C}$ values. High abundance of Contracaecum spp. is particularly evident at intermediate $\delta^{13} \mathrm{C}$ values. suggesting suitable intermediate hosts might not be available to birds that have more negative or less negative $\delta^{13} \mathrm{C}$ values. The second group of males has less than 10 nematodes that show no relationship between abundance of Contracaecum spp. and $\delta^{13} \mathrm{C}$ values. Perhaps the two groups of males are specializing on different prey or habitats thus providing an opportunity for different exposure to infective stages. Reprinted with permission from 2010 Waterbird Society. 
correlation between $\delta^{15} \mathrm{~N}$ values and abundance of $D$. spathans when the sexes were analysed together and for female cormorants analysed separately (Table 4.2); however, there was no significant correlation between $\delta^{15} \mathrm{~N}$ values and abundance of Contracaecum spp. either when the sexes were analysed together or separately.

\section{Discussion}

Male cormorants were more often infected by D. spathans than females. Furthermore, males had three times the abundance of $D$. spathans. There was no significant sex difference in the abundance or intensity of Contracaecum spp. I note that the nonsignificant difference in abundance of ('ontracaecum spp. was maintained by only two female cormorants $(<3 \%$ of the female sample) that had approximately twice as many Contracaecum spp. as the next nearest female, signifying extreme values relative to the other females (albeit females from Lake Ontario had higher levels of parasitism; Chapter 2). When these two females were removed a significant sex difference was found ( $P=$ 0.03 ). The greater abundance of Contracaecum spp. in males compared to females was significant in the Lake Ontario sample of cormorants (Chapter 2) where abundances of parasites were much higher than in the Lake Erie cormorants. The highest abundance for Lake Erie cormorants was 71 D. spathans and 65 Contracaecum spp. whereas in Lake Ontario cormorants it was 200 D. spathans and 522 Contracaecum spp. (Chapter 2). By sampling this second population of cormorants from Lake Erie with its broader prey fish community, I provide evidence that greater burdens of parasites in breeding male cormorants is not completely contingent on the particular lake ecosystem being studied. 
Male cormorants are heavier and structurally larger than females (see also Glahn \& McCoy 1995; Chapter 2). Therefore, I further established that the larger sex in this sexually size dimorphic species is more parasitised by some parasites. However, I found that lighter females had a higher abundance of Contracaecum spp. than heavier females. Therefore, although double-crested cormorants are sexually size dimorphic with males being larger than females, the inverse relationship found between body mass and abundance of Contracaecum spp. in females suggests that size may not explain fully the greater burden of parasites in males. Further support is provided by studies that found greater burdens of parasites in males of non-sexually size dimorphic species (Isomursu et al. 2006) or greater parasite burdens in females (albeit protozoans not helminths: McCurdy et al. 1998: Moore \& Wilson 2002: Morales-Mentor et al. 2004). However, it is possible that the females with higher abundances of Contracaecum spp. are lighter because they are losing resources and energy to the nematodes (Huizinga 1971). Also possible is that these lighter females were originally more susceptible to infection because of their smaller size (Wilson et al. 2002). If Contracaecum spp. were adversely affecting cormorant condition I would expect the relationship with body mass to be even more pronounced in male and female cormorants from Lake Ontario where they had higher levels of Contracaecum spp.: however, no significant relationship between body mass and abundance of Contracaecum spp. was detected in the Lake Ontario cormorants (Chapter 2).

Finally, I found evidence to suggest that parasitism in cormorants might be a result of differences in exposure to infective stages (Chapter 3). Double-crested 
cormorants are opportunistic foragers: they will prey upon the most readily available prey (Hatch \& Weseloh 1999). The variety of fish cormorants consume obscures their isotopic signature because cormorants forage across isotopically distinct habitats as may some of the fish species they are consuming. A difference in $\delta^{13} \mathrm{C}$ values of 3 to $12 \%$ is often reported between littoral and pelagic consumers (France 1995) and successive trophic levels often have a difference in $\delta^{15} \mathrm{~N}$ values of $3.4 \%$ (Kelly 1999) I found males and females had similar foraging strategies as reflected in their $\delta^{13} \mathrm{C}$ and $\delta^{15} \mathrm{~N}$ values. Although the mean difference in $\delta^{13} \mathrm{C}$ values between males and females cannot be used to categorize distinct littoral or pelagic foraging, the range of $\delta^{13} \mathrm{C}$ values from -15.9 to $23.7 \%$ is sufficient to suggest foraging is likely occurring in both littoral and pelagic habitats (France 1995). Therefore, the significant negative correlation between abundance of Contracaecum spp. and $\delta^{13} \mathrm{C}$ values strongly suggests that male and female cormorants feeding on prey with more pelagic signatures were more exposed to Contracaecum spp. than were cormorants that foraged in more littoral habitats. The range of $\delta^{15} \mathrm{~N}$ values from 13.1 to $18.3 \%$ is also sufficient to suggest prey fish from varying trophic levels were being consumed (Kelly 1999). The significant negative correlation between abundance of $D$. spathans and $\delta^{15} \mathrm{~N}$ values further indicates that foraging differences can affect a host's exposure to infective stages of D. spathans. The different relationships between $\delta^{13} \mathrm{C}$ and $\delta^{15} \mathrm{~N}$ values and Contracaecum spp. and D. spathans, respectively, also suggests that cormorants can be exposed to different species of parasites depending on their foraging strategies. 
In Lake Ontario, I previously postulated that males and females were consuming different species of fish, specifically alewife Alosa pseudoharengus (Wilson 1811) and round goby Apollonia melanostoma (Pallas 1814) respectively, which occupy distinct habitats and exhibit different levels of parasitism (see Chapter 3). Also, they could be feeding selectively on these fish in Lake Erie as both species are present: however, the fish community in the western basin of that lake is much more diverse than in Lake Ontario (Coon 1999). In the western basin of Lake Erie, mean $( \pm \mathrm{SD}) \delta^{13} \mathrm{C}$ values in pelagic prey fish (e.g., alewife, emerald shiner Notropis atherinoides (Rafinesque 1818)) and benthic prey fish (e.g., round goby, freshwater drum Aplodinotus grunniens (Rafinesque 1819), logperch Percina caprodes (Rafinesque 1818)) were not statistically different (pelagic fish: $-21.13 \% \pm 0.91 \%$; benthic fish: $-20.65 \% \pm 0.91 \%$ (Student's $t$ test); C. Hebert, unpublished data). For lake ecosystems with diverse fish communities like Lake Erie, a more sensitive diet tracer than carbon and nitrogen stable isotopes is needed to detect sex differences of opportunistic foragers like cormorants.

Lake Ontario adult cormorants had a much greater intensity of infection by Contracaecum spp. than Lake Erie adult cormorants. This is most likely an effect of the different basin characteristics of each lake, where Lake Ontario is a deeper lake with a more distinct littoral and pelagic habitat compared to the western basin of Lake Erie (Great Lakes Bathymetry 2011). The western basin of Lake Erie is relatively shallow compared to the eastern basin and Lake Ontario and therefore it does not support the pelagic fauna that is found in the eastern basin or in Lake Ontario (Coon 1999). Contracaecum spp. predominantly use a pelagic copepod as an intermediate host 
(Anderson 2000) and therefore, the shallower nature of the western basin of Lake Erie likely does not support a large population of copepods and thus limits the propagation of the Contracaecum spp. life cycle. However, the presence of Contracaecum spp. in cormorants does suggest that the life cycle can be supported and the similar negative relationship betwreen abundance of Contracaecum spp. and $\delta^{13} \mathrm{C}$ values suggests further that pelagic copepods conducive to the life cycle of Contracaecum spp. do exist in the western basin of Lake Erie. Furthermore, in Lake Erie, the greater diversity of prey may have reduced exposure of cormorants to infective stages (see Keesing et al. 2006). Nevertheless, the higher abundance of parasites in males does suggest they are consuming fishes that are either more frequently infected or have heavier infections than those consumed by females.

In summary, I found male cormorants had more $D$. spathans than female cormorants. Therefore, I confirmed a pattern of greater burdens of parasites in male freeranging birds involving the same host species but using a sample population from a different lake ecosystem and prey fish community. Also, I found supporting evidence that differences in foraging ecology might affect the levels of parasitism by Contracaecum spp. and D. spathans in cormorants. 
Chapter 5

\section{CHAPTER FIVE}

Sex differences in nematode parasitism and stable isotope signatures, but not total mercury concentration, occur at the chick stage in double-crested cormorants

\section{Phalacrocorax auritus}

This chapter formed the basis for the following publication:

Robinson, S. A., Forbes, M. R.. Hebert, C. E. and McLaughlin, J. D. Submitted. Sex differences in nematode parasitism and stable isotope signatures, but not total mercury concentration, occur at the chick stage in double-crested cormorants Phalacrocorax auritus. Journal of Avian Biology. 


\begin{abstract}
Strong sex differences in parasitism, and also in methylmercury contamination, occur for adult double-crested cormorants Phalacrocorax anritus (Lesson 1831). In that species. males have greater burdens than do females which appears common in free-ranging birds. I collected cormorant nestlings to further test my previously proposed explanation of sex differences in exposure accounting for greater burdens of Contracaecum spp. (Nematoda) in adult males. Male nestlings had a greater prevalence of Contracaecum spp. than did females; however, males and females had similar concentrations of total mercury. Male and female nestlings also differed in their $\delta^{13} \mathrm{C}$ values, suggesting that sex differences in exposure to parasites could result from differences in provisioning by parents. Differences in feeding (or provisioning) did not translate into sex differences in total mercury exposure in nestlings. Observed patterns in nestlings suggest that sex differences in dietary exposure to parasites remains a strong explanation for sex differences in parasitism in cormorants whereas exposure differences need not be invoked for sex differences in mercury concentrations in adults.
\end{abstract}




\section{Introduction}

Often, male birds and mammals have greater parasite burdens than females (Poulin 1996; Schalk \& Forbes 1997). Furthermore, when examined, male birds show higher mercury concentrations compared to females (Burger 2007). Proposed mechanisms for these sex differences in parasitism and contaminant concentrations include sex differences in physiology, immunology, morphology, and exposure (see Zuk \& McKean 1996; McCurdy et al. 1998; Klein 2000; Burger 2007: Fimreite 1974; Fimreite et al. 1982). Previously, adult double-crested cormorants Phalacrocorax aurltus (Lesson 1831) from Lake Ontario had sex differences in parasitism by Contracaecum spp. and total mercury concentration (males had greater burdens; Chapter $2 \& 3$ ). In Chapter 3 , I reported that the two sex differences were independent, where male birds responsible for the sex differences either had high abundance of Contracaecum spp. or high concentrations of total mercury, but not both. Therefore, explanations for the sex differences in parasitism and mercury concentration were investigated separately (Chapter 3).

The greater burden of parasites in adult male cormorants could not be explained by sex differences in body mass, structural size, or spleen mass (proxy for immune function; John 1994a, b, 1995) (Chapter 2). I then used carbon isotopes to determine if feeding location (benthic/littoral vs. pelagic following from Hobson et al. 1994; France 1995) and trophic level (based on $\delta^{15} \mathrm{~N}$ values: Minagawa \& Wada 1984; Kelly 1999) related to levels of parasitism (Chapter 3). I found males tended to forage in more pelagic habitats (i.e.. more negative $\delta^{13} \mathrm{C}$ values) and that abundance of Contracaectim spp. increased with increasing pelagic foraging signatures (Chapter 3). Therefore, I suggested 
that differences in exposure were likely the predominant explanation for sex differences in parasitism in adult cormorants (Chapter 3).

Conversely, total mercury concentration was not well explained by foraging ecology (Chapter 3) and required a separate explanation. Sex differences in total mercury concentration in adult cormorants are likely related to adult associated physiological differences in the dynamics of ingested methylmercury, such as egg depuration (Braune \& Gaskin 1987; Lewis et al. 1993) and/or liver demethylation excretion capability (see Chapter 7).

When sex differences in parasitism and mercury concentration are studied in freeranging birds, the age, foraging specializations or behaviour of the birds are not well known, but could be very different between males and females and affect lifetime exposure (see Newton 1998; Cristol et al. 1999; Casaux et al. 2001). Nestlings offer a unique opportunity for study, where influences of age, lifetime exposure and prey item consumption are known or are fairly homogenous between sexes. For example, nestling double-crested cormorants are fed by both parents for approximately six weeks after hatching (Hatch \& Weseloh 1999). Therefore, nestling age can be approximated based on the breeding phenology for a given area. Furthermore, nestlings are exposed only to parasites and contaminants through locally consumed prey. Also, both cormorant parents feed the nestlings (Hatch \& Weseloh 1999), therefore male and female nestlings should consume similar prey. Another advantage to studying parasites and mercury in nestlings is that their gonadal system is only starting to develop (Apanius 1998) and therefore sex 
differences in testosterone related effects on the immune system are likely negligible (Fargallo et al. 2007).

Different growth trajectories between males and females have been hypothesized to relate to levels of parasitism or mercury accumulation (see Moore \& Wilson 2002: Burger 2007). Male and female nestlings are expected to exhibit these size differences. If the hypothesis that the larger sex (e.g., males) is more susceptible to parasite establishment is true, I would still expect the relationships to be pronounced in actively growing nestlings. Therefore, by studying nestlings I can control for some of the factors that are thought to influence levels of parasites and mercury concentration in adults and thus I can determine the reliability of the explanations I suggested for sex differences in parasitism and total mercury concentration in adult cormorants (Chapter 3). Specifically, if exposure is a primary explanation for sex differences in parasitism in cormorants, I would predict that male and female nestlings do not differ in levels of parasitism or in exposure, unless they differ in provisioning by parents. Additionally, I do not expect any sex differences in mercury concentration between male and female nestlings because I only expect sex differences to be manifested in adults because of adult associated physiological differences in methylmercury dynamics (see Chapter 7).

The objectives of my study were to first determine if there were any sex differences in parasitism by Contracuecum spp., provisioning by parents (i.e., provisioning ecology using $\delta^{13} \mathrm{C}$ and $\delta^{15} \mathrm{~N}$ values) or total mercury concentration and then to determine their relationships. I also documented sex differences in body mass or 
structural size and determined if these had any relationship with the levels of Contracaecum spp. or total mercury concentration in nestlings.

\section{Methods}

I collected 60 double-crested cormorant nestlings on June 22, 2009 from Pigeon Island, Lake Ontario ( $\left.44^{\circ} 04^{\prime} \mathrm{N}, 76^{\circ} 33^{\prime} \mathrm{W}\right)$. Double-crested cormorants breeding on Lake Ontario lay their eggs from the end of April to early May with eggs hatching from the end of May to early June (Weseloh \& Ewins 1994). I selected the largest nestlings in the colony at the time; which were approximately 3 to 4 weeks old. Cormorant nestlings fledge at six weeks and then are no longer fed by parents (Hatch \& Weseloh 1999). Nestlings were collected under Ontario Ministry of Natural Resources wildlife scientific collector's permit no. 1051693 and were humanely euthanized onsite as per the approved animal care protocol from Carleton University (B09-13). Carcasses were brought to the National Wildlife Research Centre at Carleton University, where they were frozen at $-40^{\circ} \mathrm{C}$ until processing.

I made morphological measurements, and collected $10 \mathrm{~g}$ samples of breast muscle and the gastro-intestinal helminths, as described elsewhere (Chapter $2 \& 3$ ). I used the morphological measurements to assess structural size using Principal Component Analysis (PCA) (see Chapter 2). I estimated the age (in days) of the nestlings by using a logistic growth equation from Dunn's (1975) morphological measurements and age data for cormorant chicks. Dunn (1975) reported ulna length as the best criterion to age 
nestlings; therefore I used Dunn's (1975) ulna measurements and age data to develop a logistic growth curve to estimate the age of my samples (see Ricklefs 1967):

$$
\text { Age }=-\left\{\log _{e}[(\mathrm{~A} / \mathrm{uln} \mathrm{a})-1]-\mathrm{K}^{*} \mathrm{t}_{1}\right\} / \mathrm{K}
$$

The asymptote ulna value $(180 \mathrm{~mm})$ is $\mathrm{A}, \mathrm{K}$ is the growth coefficient $(=0.16$, calculated following Ricklefs 1967) and $t_{1}$ is the age at the point of inflection (=14.1, see Ricklefs 1967). A multivariate measure of body size, such as PC I scores, has been suggested to be a better criterion than a univariate measurement to age young birds (Gilliland \& Ankney 1992); however, when I developed PCl scores for Dunn's (1975) data and then estimated nestling age using a logistic growth equation the difference between observed and estimated age was approximately 6 times less precise than when using the univariate ulna measurements (mean difference (observed-estimated) using ulna measurements was 0.3 days, and using $\mathrm{PCl}$ scores was 1.9 days).

Details of breast muscle sample preparation, total mercury analysis and stable isotope analysis are described in Chapter 3 . I corrected the $\delta^{13} \mathrm{C}$ values for lipid content using the lipid correction equation described in Chapter 3. Data quality for total mercury analysis was assured using standard reference material (Dogfish liver [DOLT-3] and muscle [DORM-2] certified reference material for trace metals, Metals Toxicology Laboratory, National Wildlife Research Centre, Ottawa, ON, Canada) and for stable isotope analysis international standards were used (IAE-CH-6, IAEA-NBS22, IAEA-NI, IAEA-N2, USGS-40, and USGS-41). Further quality control for both total mercury and stable isotope analysis was maintained through sample duplicates and mean values from these duplicates were used in the final reports for statistical analysis. Relative percent 
standard deviation $(\% \mathrm{RSD})$ for sample replicates averaged $<10 \%$ for all analyses. Total mercury values are reported in $\mu \mathrm{g} / \mathrm{g}$ dry mass; however, to enable comparison with other studies reporting wet mass concentrations, the mean percent moisture of the breast muscle was $81.7 \pm 0.2 \%$. The stable isotope values are reported in delta notation in parts per thousand (\%, per mil) relative to PeeDee belemnite (for C) and atmospheric air (for N) standards. Analytical precision for total mercury analysis was $\pm 0.1 \mu \mathrm{g} / \mathrm{g}$ (dry mass) and was based on repeat measures of DOLT-3 standard; for stable isotope analysis it was $\pm 0.13 \%$ and was based on repeat measures of standard (C-55).

I determined if males and females differed in prevalence (proportion of infected individuals), median abundance (median number of parasites for all individuals) and median intensity (median number of parasites for infected individuals) of Contracaecum spp. I used $\chi^{2}$ tests for prevalence analyses and Wilcoxon tests for abundance and intensity analyses because the data did not meet the assumption of normality for equivalent parametric tests (according to Shapiro-Wilk test; Zar 1999). I determined if male and female nestlings were being fed different prey items based on stable isotope analysis; that is, whether they differed in $\delta^{13} \mathrm{C}$ and $\delta^{15} \mathrm{~N}$ values. using Wilcoxon tests. I determined if males and females differed in total mercury concentration using Wilcoxon tests. I also assessed the level of sexual size dimorphism in males and females (described in Chapter 2).

I then examined if $\delta^{13} \mathrm{C}$ and $\delta^{15} \mathrm{~N}$ values correlated with the abundance of Contracaecum spp. or total mercury concentration in males and females using Spearman Rho correlation tests. Furthermore, I determined whether there were any correlations 
between abundance of Contracaecum spp. or total mercury concentration and body mass/size using Spearman Rho correlation tests.

All statistical analyses were done using JMP statistical software version 4 (SAS Institute Inc., 1989-2000). I report median values with associated $25 \%$ and $75 \%$ interquartile range for data that were not normally distributed and mean $( \pm \mathrm{SE})$ for data that were normally distributed.

\section{Results}

\section{Host sex and parasitism, mercury, stable isotopes and body mass/size}

Contracaecum spp. was the most prevalent helminth, infected $68.3 \%$ of the cormorant nestlings. I limited further analyses to Contracaecum spp. as this was also the most prevalent species in Chapter 3, my comparison study. I found that male cormorant nestlings had a higher prevalence of Contracaecum spp. than females $\left(\chi^{2}=5.02, \mathrm{P}=\right.$ 0.03, Table 5.1). However, there was no significant difference between males and females in median abundance or median intensity of Contracaecum spp. (median abundance: $Z=-1.74, P=0.08$; median intensity: $Z=0.41, P=0.68$, Table 5.1).

Total mercury was assessed in all 43 male and 17 female cormorant breast muscle samples. There was no difference in median total mercury concentration between males and females (males: $0.43 \mu \mathrm{g} g$ dry mass, interquartile range from 0.39 to $0.51 \mu \mathrm{g} / \mathrm{g}$ dry mass: females: $0.45 \mu \mathrm{g} / \mathrm{g}$ dry mass. interquartile range from 0.39 to $0.49 \mu \mathrm{g} / \mathrm{g}$ dry mass; $Z$ $=-0.05, P=0.96)$. Furthermore, there was no significant difference between males and 
Table 5.1. Prevalence, median abundance and median intensity of Contracuecum spp. in male $(n=43)$ and female $(n=17)$ nestling double-crested cormorants (Phalacrocorax antritus). Prevalence is reported as the percentage of infected hosts and median values with associating $25 \%$ and $75 \%$ interquartile range (IQR) are indicated for abundance and intensity.

Helminth

Contracaecum spp.

Prevalence $(\%)$

Abundance (IQR)

Intensity (IQR)
Male nestling

72.1

$2(0-3)$

$2(2-5)$
Female nestling

41.2

$0(0-4)$

$4(1-5)$ 
females in mercury body burden (calculated using mercury concentration (wet mass) * (body mass) (mean $\pm \mathrm{SE}$, males: $123.1 \pm 5.1 \mu \mathrm{g}$. females: $117.5 \pm 8.7 \mu \mathrm{g}, \mathrm{F}_{1.58}=0.3, \mathrm{P}=$ 0.56 ).

I found a significant difference in what male and female nestlings were fed based on $\delta^{13} \mathrm{C}$ and $\delta^{15} \mathrm{~N}$ values. Males had a more pelagic feeding signature (i.e.. a more negative median $\delta^{13} \mathrm{C}$ value) than females (males: $-20.98 \%$, interquartile range from 21.29 to $-20.51 \%$; females: $-20.50 \%$, interquartile range from -21.06 to $-19.84 \% ; Z=$ $2.43, \mathrm{P}=0.02$ ) and a slightly greater trophic signature (i.e., more positive median $\delta^{15} \mathrm{~N}$ value; males: $15.23 \%$, interquartile range from 14.99 to $15.36 \%$; females: $15.00 \%$, interquartile range from 14.56 to $15.17 \%: Z=-3.06 . P=0.002)$.

Sexual size dimorphism was expected in cormorant nestlings; male cormorant nestlings were approximately $120 \mathrm{~g}$ heavier than females (males: $1515.7 \pm 25.4 \mathrm{~g}$; females: $1393.1 \pm 34.9 \mathrm{~g} ; \mathrm{F}_{1.58}=7.08, \mathrm{P}=0.01$ ). Males were not detected to be structurally larger according to $\mathrm{PCl}$ scores $\left(\mathrm{F}_{157}=3.05, \mathrm{P}=0.09\right)$; however, one male was particularly smaller than all other males and females and when this small male was removed from the analysis there was a statistically significant sex difference in size $\left(F_{1,56}\right.$ $=6.09, \mathrm{P}=0.02$ ). The first $\mathrm{PC}$ axis of the PCA had all metrics loaded positively and explained $56 \%$ of the variation in the data. Although males were heavier and structurally larger than females, I found no significant difference in the mean $( \pm S E)$ age of male and female nestlings (males: $25.8 \pm 0.5$ days, females: $25.1 \pm 0.8$ days, $F_{1,58}=0.5, P=0.49$ ). 
Parasitism, mercury concentration, stable isotopes and body mass/size relationships

There were no significant correlations for males between abundance of Contracaecum spp. and $\delta^{13} \mathrm{C}$ values or $\delta^{15} \mathrm{~N}$ values (Spearman Rho was -0.05 and 0.22 . both $\mathrm{P}>0.15$ : Fig. 5.1) and between total mercury concentration and $\delta^{13} \mathrm{C}$ values (Spearman Rho $=0.21, \mathrm{P}=0.17$ ) or $\delta^{15} \mathrm{~N}$ values (Spearman $\mathrm{Rho}=-0.02, \mathrm{P}=0.90$ ). However, for females, there were significant negative correlations between abundance of Contracaecum spp. and $\delta^{13} \mathrm{C}$ values (Spearman $\mathrm{Rho}=-0.53, \mathrm{P}=0.03 ;$ Fig. 5.1 ) and between total mercury concentration and $\delta^{17} \mathrm{C}$ values (Spearman $\mathrm{Rho}=-0.65, \mathrm{P}=0.005$ ) Furthermore, for females, there was a significant positive correlation between abundance of Contracaectm spp. and $\delta^{15} \mathrm{~N}$ values (Spearman $\mathrm{Rho}=0.54, \mathrm{P}=0.02$ ) and between total mercury concentration and $\delta^{15} \mathrm{~N}$ values (Spearman $\mathrm{Rho}=0.62 . \mathrm{P}=0.01$ ). Thus, at least for female nestlings, both abundance of Contracaecum spp. and total mercury concentration increased with more pelagic foraging and greater trophic signatures.

There was no significant correlation between the abundance of Contracaecum spp. and body mass or PCI scores for male or female cormorants (males: Spearman Rho was 0.09 and 0.16 , respectively, $P>0.57$; females: Spearman Rho was 0.38 and 0.43 , respectively, $\mathrm{P}>0.09$ ). However, there was a significant positive correlation for females but not for males between total mercury concentration and body mass (males: Spearman Rho $=-0.06, P=0.69 ;$ females: Spearman $R h o=0.73, P<0.001)$. Similar correlations were found when comparing total mercury concentration and body size (using PCI scores), where females had a significant positive correlation, whereas there was no significant correlation for males (males: Spearman $R$ ho $=0.05, P=0.78$; females: 


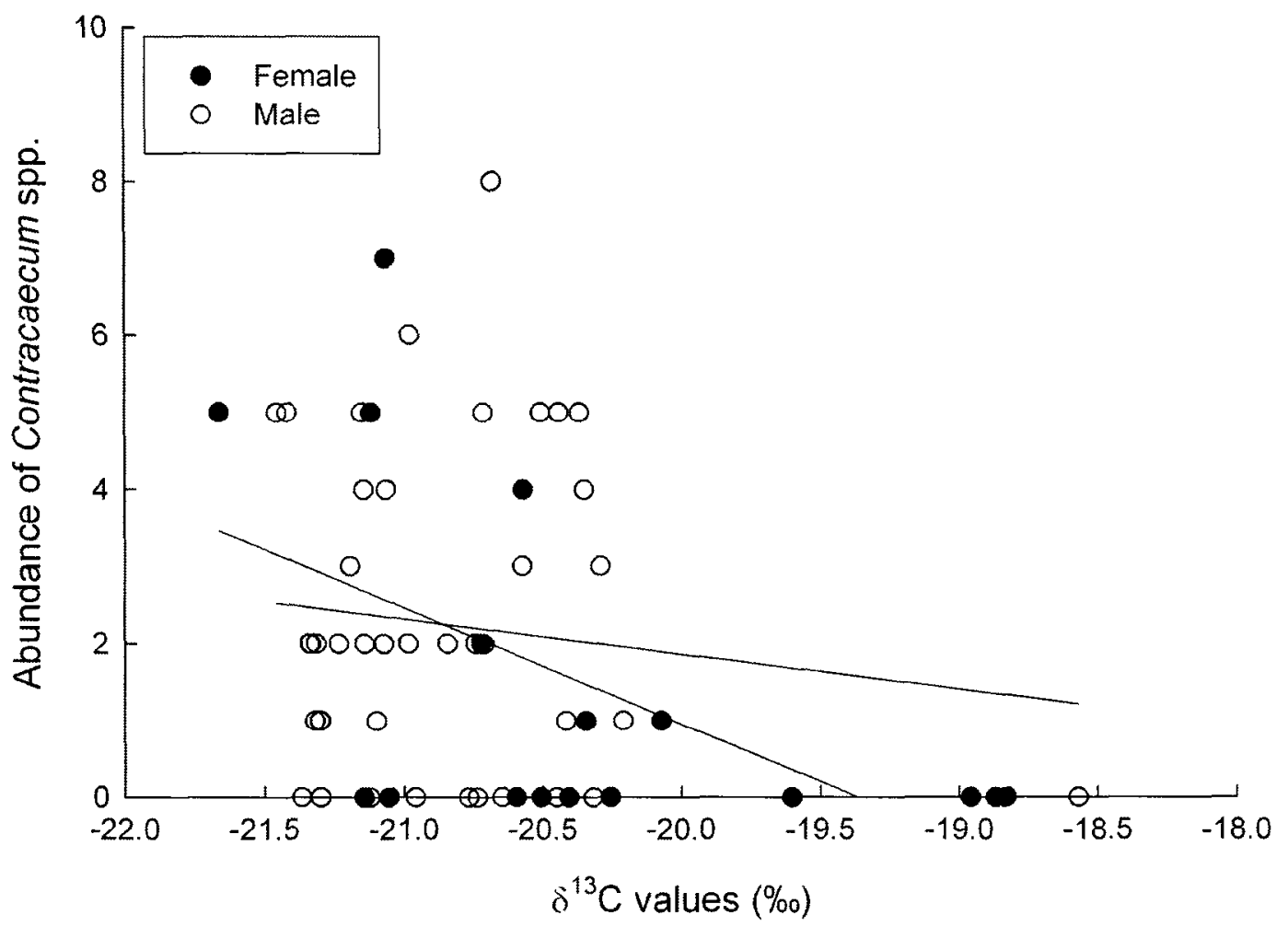

Figure 5.1. Correlations between abundance of Contracaecum spp. and $\delta^{13} \mathrm{C}$ values in breast muscle of male and female cormorant nestlings. 
Spearman Rho $=0.76, \mathrm{P}<0.001)$.

Interestingly, $\delta^{13} \mathrm{C}$ values negatively correlated with body mass in males but not females (males: Spearman Rho $=-0.35, \mathrm{P}=0.02$; females: Spearman $\mathrm{Rho}=-0.41, \mathrm{P}=$ $0.10)$, and $\delta^{13} \mathrm{C}$ values negatively correlated with $\mathrm{PCl}$ scores in females but not males (males: Spearman Rho $=-0.24, \mathrm{P}=0.13$ : females: Spearman $\mathrm{Rho}=-0.58, \mathrm{P}=0.0 \mathrm{I}$ ) Furthermore, $\delta^{15} \mathrm{~N}$ values positively correlated with body mass in males and females (males: Spearman $\mathrm{Rho}=0.34, \mathrm{P}=0.03$; females: Spearman $\mathrm{Rho}=0.60, \mathrm{P}=0.01$ ) and PCl scores (males: Spearman Rho $=0.33, P=0.03$; females: Spearman Rho $=0.61, P=$ 0.009).

\section{Discussion}

I found sex differences in parasitism, but not total mercury concentration in three to four week old nestling cormorants where male nestlings had a greater occurrence of infection by Contracaecum spp. than did females. Males also had higher median abundance of Contracaecum spp. than did females, although this difference did not reach statistical significance. Both adults and nestlings are exposed to infective stages of Contracaecum spp. and mercury through the prey fish they consume (Anderson 2000; Weiner et al. 2003). However, nestlings are also exposed to adult Contracaecum spp. from their parents because Contracaecum spp. can detach from their host's stomach wall to migrate through the fish tissue in the cormorant's stomach, and can be transferred when the fish is regurgitated for the nestlings (Huizinga 1971; Torres et al. 2005). As noted elsewhere, a greater abundance of Contracaecum spp. was found in adult male compared to adult 
female cormorants (Chapter 2). In Chapter 3, I suggested that males were more exposed to infective stages based on the prey fish they consumed compared to females. The greater prevalence of infection in male nestlings compared to female nestlings suggests that male nestlings theoretically might be more susceptible to infection, either due to immune or exposure differences or both factors.

I found significant differences in $\delta^{13} \mathrm{C}$ and $\delta^{15} \mathrm{~N}$ values in males and females. These stable isotope signatures reflect the signatures of prey fish consumed by nestlings via diet-tissue isotopic fractionation during diet assimilation (DeNiro \& Epstein 1978: Kelly 1999 and references therein). Growth rate can affect the interpretation of some stable isotopes (Trueman et al. 2005). Nitrogen stable isotopes are most affected by growth rate because during growth phases there is high protein turnover and nitrogen stable isotopes are primary components of proteins (Hobson et al. 1993; Kempster et al. 2007). Carbon stable isotopes are less affected by growth rate (Trueman et al. 2005; Sears et al. 2009).

In sexually size dimorphic species, such as the cormorant, differences in $\delta^{15} \mathrm{~N}$ values might be a result of different growth trajectories between male and female nestlings, given that nestlings and sub-adults/adults that have different growth rates also had different $\delta^{15} \mathrm{~N}$ values (Sears et al. 2009). When an organism is growing it is efficiently using consumed nitrogen to build protein related structures (Martinez del Rio et al. 2005; Koch 2007). During this period, nitrogen use efficiency increases, reflected by a decrease in the ratio of nitrogen loss to nitrogen intake. Reduced nitrogen isotope diet-tissue fractionation during growth leads to a reduction in $\delta^{15} \mathrm{~N}$ values in faster 
growing individuals compared to slower or non-growing individuals (Gaye-Siessegger $e t$ al. 2004; Trueman et al. 2005; Sears et al. 2009). Therefore, I would expect the faster growing males to have lower $\delta^{15} \mathrm{~N}$ values than females; however, I found that males had greater $\delta^{15} \mathrm{~N}$ values than females and therefore the difference in $\delta^{15} \mathrm{~N}$ values between male and female nestlings is likely a real diet difference. I note that moderate nutritional stress could reduce the $\delta^{15} \mathrm{~N}$ values in the food-deprived individual (Sears et al. 2009; Williams et al. 2007); therefore, it is possible that the larger male siblings are outcompeting their smaller female siblings for food and causing a slight food restriction and reduced $\delta^{15} \mathrm{~N}$ values in the female siblings.

Only one other study has used stable isotopes to examine if male and female seabird nestlings are fed different prey items by their parents. The authors did not find a significant sex difference in either $\delta^{13} \mathrm{C}$ or $\delta^{15} \mathrm{~N}$ values between male and female southern giant petrel Macronectes giganteus (Gmelin 1789) nestlings (Forero et al. 2005).

However, Forero et al. (2005) did find that nestlings had a higher trophic signature than adults, which has also been found for other seabird nestling and adult isotope studies (Hobson 1993: Hodum \& Hobson 2000; Forero et al. 2002). These studies suggest that the differences in isotopic values can be attributed to different diet composition between nestlings and adults (Hodum \& Hobson 2000; Forero et al. 2002, 2005). The actual mean isotopic differences found between nestlings and adult female southern giant petrels $(\sim 0.5$ $\%$ and $0.8 \%$ for $\delta^{13} \mathrm{C}$ and $\delta^{15} \mathrm{~N}$. respectively; see Forero et al. 2005) are similar (at least in respect to $\delta^{13} \mathrm{C}$ values) to what I found between male and female nestlings $(0.5 \%$ and 
$0.2 \%$ for $\delta^{13} \mathrm{C}$ and $\delta^{15} \mathrm{~N}$, respectively), again suggesting real, and biologically relevant sex differences in diet composition in cormorant nestlings.

Interestingly, the $\delta^{13} \mathrm{C}$ distributions in male and female nestlings are similar to the respective distributions in male and female adults (i.e., slightly more negative for adult males (median $\delta^{13} \mathrm{C}:-20.3 \%$ ) compared to adult females (median $\delta^{13} \mathrm{C}:-19.5 \%$ ); see Chapter 3); however, $\delta^{15} \mathrm{~N}$ values in nestlings do not reflect adult patterns (median adult $\delta^{15} \mathrm{~N}$, males: $15.2 \%$, females: $15.7 \%$ ) (likely a result of ${ }^{15} \mathrm{~N}$ use efficiency differences between nestlings and adults as described above). The similarity in $\delta^{13} \mathrm{C}$ patterns in male and female nestlings and adults suggest that adult female cormorants might be predominantly feeding female nestlings. There is some evidence in seabirds that male and female parents will differentially provision male and female chicks (Weimerskirch \& Lys 2000; Weimerskirch et al. 2000; Cameron-MacMillan et al. 2007; Beaulieu et al. 2009). For example, male common murre Iria aalge (Pontoppidan 1763) parents were found to increase their feeding rate to sons but not daughters as the nestlings increased in size, whereas female parents increased their feeding rate for both sexes (Cameron-MacMillan et al. 2007). Hence, the sex specific feeding strategy could explain why the isotopic signatures in male nestlings are more reflective of the male parent than the female parent. Sex specific nestling provisioning by parents has also been suggested in European shags Phalacrocorax aristotelis (Linnaeus 1761) and was related to levels of parasitism in the adults (Reed et al. 2008). The greater occurrence of infection in male cormorant nestlings studied here might also be related to this sex specific nestling feeding strategy since I found adult males had a greater abundance of Contracaecum spp. in two different 
colonies (see Chapters $3 \& 4$ ) and I suspect adults on this colony where the nestlings were sampled might also follow this pattern of sex differences in parasitism.

Consequently, male adult cormorants with their greater abundance of nematodes might even be transferring some nematodes to the male nestlings more often than the adult female cormorants.

Sexual size dimorphism has been invoked to explain both sex differences in parasitism and total mercury concentration (e.g., Moore \& Wilson 2002; Burger 2007). Male cormorant nestlings were significantly heavier and larger than females at three to four weeks of age (males and females similar age, see results). Adult male cormorants are also larger than females (Glahn \& McCoy 1995; Chapters 2 \& 4). Larger nestlings are fed more (Weimerskirch et al. 2000; Daunt et al. 2001) which could increase their exposure to parasites and mercury. However, body mass or structural size of nestlings did not relate to abundance of Contracaecum spp. and even though male nestlings were larger than females there was no difference in total mercury concentration (or body burden) between the sexes. Therefore, even at the nestling stage, body mass or structural size differences between males and females does not explain sex differences in parasitism by Contracaecum spp. or total mercury concentration in cormorants.

The significantly larger male nestlings also might be fed, by both parents, slightly different prey items than the smaller females (Weimerskirch \& Lys 2000; Weimerskirch et al. 2000; Cameron-MacMillan et al. 2007; Beaulieu et al. 2009). In fact, in ring-billed gulls Lanis delawarensis (Ord 1915), grey herons Ardea cinerea (Linnaeus 1758) and common terns Sterna hirundo (Linnaeus 1758) there are gape-size contraints on the size 
of prey that can be swallowed by nestlings of different ages (Kirkhain \& Morris 1979; Courtney \& Blokpoel 1980: Moser 1986). In common terns, the rotundness and relative body depth, in addition to the length of the fish, are important criterion affecting the smaller nestlings' ability to swallow the fish offered (Courtney and Blokpoel 1980). Specifically, alewives were found to be difficult to swallow by smaller nestlings because of their deep body shape (Courtney and Blokpoel 1980). Interestingly, Slagsvold \& Wiebe (2007) and Wiebe \& Slagsvold (2009) suggested a gape-size constraint hypothesis for sex differences in provisioning in the pied flycatcher Ficedula hypoleuca (Pallas 1764). The authors found that larger food items delivered to smaller nestlings were redirected to larger nestlings after the smaller nestling was unable to swallow it (Slagsvold \& Wiebe 2007; Wiebe \& Slagsvold 2009). Therefore, if adult male cormorants are provisioning their nestlings with larger prey items (such as alewife - see Chapter 3) compared to adult female cormorants, a greater proportion of adult male deliveries would be swallowed by the larger male nestlings. Furthermore, the smaller female nestlings might only be able to swallow the smaller prey delivered by females and thus consume a greater fraction of the fish delivered by adult females than adult males. The negative correlation between body mass'size and $\delta^{13} \mathrm{C}$ values for male and female nestlings (respectively) suggests nestling size influences the type of prey consumed. Therefore male and female nestlings could be differentially exposed to Contracaecum spp. which might relate to the similarities between adult sex and offspring sex in stable carbon isotope signatures. In fact, abundance of Contracaecum spp. increased with greater pelagic foraging signatures (i.e., more negative $\delta^{13} \mathrm{C}$ values) and increased with 
increasing trophic signature in female nestlings but not in male nestlings. Conversely, male and female nestlings did not differ in total mercury concentration despite the significant sex difference in stable nitrogen signatures. Therefore, sex differences in exposure through differential provisioning/feeding ecology once again relates to sex differences in parasitism in cormorants but does not need to be invoked to explain total mercury concentration.

In conclusion, I predicted that there would be no sex difference in parasitism because I did not expect sex differences in exposure in nestlings; however, I found a sex difference in provisioning ecology and a sex difference in parasitism (males were more often infected by Contracaecum spp.). The sex difference in parasitism was related to $\delta^{13} \mathrm{C}$ and $\delta^{15} \mathrm{~N}$ values: hence, I found confirmatory evidence that feeding (or provisioning) ecology is a likely explanation for sex differences in parasitism in cormorants. As I predicted, I did not find a sex difference in total mercury concentration even though male nestlings were significantly larger than female nestlings. Also there were no informative relationships between provisioning ecology or morphology and total mercury concentration, which suggests detoxification or depuration differences might be more important in creating differences in mercury concentration in adult males and females. 


\section{CHAPTER SIX}

Mercury in parasitic nematodes and trematodes and their double-crested cormorant hosts: bioaccumulation in the face of sequestration by nematodes

This chapter formed the basis for the following publication and was reproduced with permission from (c) 2010 Elsevier:

Robinson, S. A.. Forbes, M. R. and Hebert, C. E. 2010. Mercury in parasitic nematodes and trematodes in double-crested cormorant hosts: Bioaccumulation in the face of sequestration by nematodes. Science of the Total Environment 408: 5439-5444. 


\section{Abstract}

Endoparasites can alter their host's heavy metal concentrations by sequestering metals in their own tissues. Contracaecum spp. (a nematode), but not Drepanocephalus spathans (Dietz 1909; a trematode), were bioaccumulating mercury to concentrations 1.5 times above cormorant hosts. Nematodes did not have significantly greater stable nitrogen isotope values $\left(\delta^{15} \mathrm{~N}\right)$ than their hosts, which is contradictory to prey-predator trophic enrichment studies, but is in agreement with other endoparasite-host relationships. However, Contracaecum spp. $\delta^{13} \mathrm{C}$ values were significantly greater than their hosts', suggesting that nematodes were consuming host tissues. Nematodes were accumulating and thus sequestering some of their cormorant hosts' body burden of methylmercury: however. they were not significantly reducing their hosts' accumulation of methylmercury. 


\section{Introduction}

It is now evident that there can be relationships between pollution and parasitism.

Originally, investigations looked at the effects of pollution on the distribution and abundance of parasites in a particular host or ecosystem (Lafferty 1997: Vidal-Martinez

et al. 2010). However, this avenue of research resulted in very few generalizable patterns between parasites and pollution; in fact, many studies demonstrate positive associations between pollution and parasitism, whereas others show no relationship or inverse relationships (Lafferty 1997; Vidal-Martinez et al. 2010). Notwithstanding, researchers continue to try and understand interactions between pollution and parasites as such relationships might be important for understanding constraints on biodiversity or wildlife health for particular hosts. One area of evolving research is directed at determining the ability of parasites to alter heavy metal levels in their hosts, either by changing the hosts' physiology and its ability to accumulate heavy metals (e.g. Evans et al. 2001; Bergey et al. 2002) or by accumulating and therefore sequestering heavy metals in their own tissues (Sures et al. 1999; Sures 2001, 2003).

Several examples warrant mention. Molluscs Littorina liftorea (Linnaeus 1758) parasitised by trematodes (Evans et al. 2001), grass shrimp Palaemonetes pugio (Holthuis 1949) parasitised by isopods Probopyrus pandalucola (Packard 1879) and killifish Fundulus heteroclitus (Linnaeus 1766) parasitised by nematodes (Eustrongylides sp.; Bergey et al. 2002) all accumulated lower concentrations of heary metals than their unparasitised counterparts. It has been suggested that behavioural and physiological changes. resulting from parasitism, could alter a host's feeding and metabolism which 
would affect the accumulation of heary metals (Bergey et al. 2002). However, it has also been recognized that the parasites causing these changes in their host are themselves potentially accumulating the heavy metals and therefore reducing the hosts' exposure. Adult intestinal helminths, particularly acanthocephalans and cestodes, accumulate heavy metals to orders of magnitude above their fish hosts (Sures \& Siddall 1999), mammalian hosts (Sures et al. 1998; Sures et al. 2003) and avian hosts (Barus et al. 2000a, b; Barus et al. 2001). This ability of parasites to accumulate heavy metals thereby reduces the accumulation in fish host tissues (Sures \& Siddall 1999; Sures et al. 2003).

Whether or not nematodes biomagnify heavy metals, such as methylmercury, is not well studied (Bergey et al. 2002). Mercury is a natural metal in the environment that has no known biological function, but is highly toxic to wildlife, especially in its methylated form (Weiner et al. 2003). Methylmercury biomagnifies with trophic level; therefore. higher concentrations are found in top consumers (Weiner et al. 2003). As consumers, nematodes possess a complete digestive system and can actively feed on host tissues whereas trematodes, acanthocephalans and cestodes absorb host digested nutrients across their tegument (Roberts \& Janovy 2005). Therefore, nematodes should occupy higher trophic positions than their hosts and accumulate greater concentrations of biomagnifying heavy metals.

Such trophic relationships and their importance to heavy metal dynamics can be studied by various means, including the use of stable carbon and nitrogen isotopes. Trophic relationships using stable carbon and nitrogen isotopes are measured using the ratio of heavy to light isotopes $\left({ }^{13} \mathrm{C} /{ }^{12} \mathrm{C}\right.$ and ${ }^{15} \mathrm{~N}^{14} \mathrm{~N}$, respectively) because with each 
interaction between consumer and its diet there is an increase in the ratio (Kelly 1999). Typically, $\delta^{13} \mathrm{C}$ values increase between 0 and $1 \%$ with each trophic transfer and $\delta^{15} \mathrm{~N}$ values increase by $-3.4 \%$ (Kelly 1999 and references therein). Furthermore, a positive relationship occurs between methylmercury concentrations and $\delta^{15} \mathrm{~N}$ values; therefore, top consumers have greater $\delta^{15} \mathrm{~N}$ values and greater mercury concentrations (Cabana $\&$ Rasmussen 1994).

In a previous study, I found that male cormorants with high nematode abundance had lower concentrations of mercury than male cormorants with low nematode abundance (Chapter 3). Therefore, I was interested in determining if mercury concentration in cormorants is reduced by the accumulation of mercury in nematodes. To this end, here I investigate the bioaccumulation of mercury in a bird host, the doublecrested cormorant Phalacrocorax auritus (Lesson 1831) and its nematode parasite, Contracuecum spp. By calculating the percentage of the host body burden of mercury sequestered by nematodes I determine whether nematodes could explain the difference in magnitude of mercury between males showing low versus high mercury concentrations. I also determine Contracaecum spp. feeding ecology and compare that to the feeding ecology of the cormorant host, using stable carbon and nitrogen isotopes $\left(\delta^{13} \mathrm{C}\right.$ and $\left.\delta^{15} \mathrm{~N}\right)$. Finally, I compare mercury accumulation and feeding ecology between Contracaecum spp. and Drepanocephalus spathans (Dietz 1909; a trematode) which represent two different parasite feeding strategies (i.e.. ingestion vs. absorption). I compare stable carbon and nitrogen isotope values and mercury concentrations between host and parasites to address if nematodes are more likely to be accumulating mercury from the 
host (greater $\delta^{13} \mathrm{C}$ and $\delta^{15} \mathrm{~N}$ values in nematode than host) or from the prey fish the cormorant consumed (similar $\delta^{13} \mathrm{C}$ and $\delta^{15} \mathrm{~N}$ values between nematode and host).

\section{Methods}

\section{Sample collection and preparation}

I collected 30 double-crested cormorants (15 males and 15 females) from Presqu'ile Provincial Park $\left(43^{\circ} 59^{\prime} \mathrm{N}, 77^{\circ} 42^{\prime} \mathrm{W}\right.$ ) on Lake Ontario during May 2006. These birds were from a larger study, where details regarding sample collection, preparation, parasite enumeration and identification are described (Chapter 2). The birds were selected from the larger study based on their high abundance of Contracaecum spp. Parasites were stored in chemically-clean glass jars at $-40^{\circ} \mathrm{C}$ until processed for total mercury and carbon and nitrogen $\left(\delta^{13} \mathrm{C}\right.$ and $\left.\delta^{15} \mathrm{~N}\right)$ isotope analysis. Samples were thawed, and from each of the 30 cormorants, 5 to 25 adult male Contracaecum spp. (body length $>13 \mathrm{~mm}$ and presence of spicules) and adult female Contracaecum spp. (body length $>25 \mathrm{~mm}$, spicules absent and eggs in uterus) were selected (number of Contracaecum spp. from each bird depended on the number of nematodes available per sample).

Ten cormorants ( 7 of which were represented in the samples described above used to obtain nematodes) were selected for additional study. These birds were selected for their high abundance of $D$. spathans (range from 10 to 131 D. spathans). This 'select sample' enabled comparisons between host and parasite species for mercury and carbon and nitrogen isotopes. Each sample of parasite tissue was stored in an acid-washed polypropylene vial, homogenized and wet mass recorded. Parasite tissue samples were 
freeze-dried for a minimum of $48 \mathrm{~h}$, dry mass was recorded and $\%$ moisture content was calculated (88.7\% moisture for nematodes and $78.3 \%$ for trematodes).

In a previous study, samples of breast muscle from cormorants were analysed for

total mercury concentration and $\delta^{13} \mathrm{C}$ and $\delta^{15} \mathrm{~N}$ values, details of sample preparation, lipid normalization of $\delta^{13} \mathrm{C}$ values and analysis are described elsewhere (Chapter 3). Mercury in avian breast muscle tissue is predominantly methylmercury; therefore measuring total mercury well represents the biomagnification of the toxic form of mercury (e.g., Houserova et al. 2007).

\section{Mercury analyses}

Freeze-dried parasite tissue was crushed into a powder and total mercury was measured using a Milestone DMA-80 direct mercury analyzer (Shelton, Connecticut, USA). I also measured methylmercury in 10 samples of nematode tissue ( 6 female nematode samples and 4 male nematode samples) which were selected based on the amount of tissue in the sample. I measured methylmercury in nematodes to determine the percentage of total mercury that was bioaccumulating and was the toxic form: this information is not available in the literature. I extracted methylmercury from nematode tissue using a modification of the method of Callum et al. (1981) as described in Scheuhammer et al. (1998a) and measured the concentration of methylmercury using the Milestone DMA- 80 .

Quality control was assured by processing and analysing procedural blanks. certified reference material (dogfish liver certified reference material for trace metals [DOLT-3]. Metals Toxicology Laboratory, National Wildlife Research Centre, Ottawa. 
ON. Canada) and sample replicates. The average accuracy was within $10 \%$ of certified values for all analyses and analytical precision (percent relative standard deviation (\% RSD) of replicate samples) averaged $<10 \%$ for all analyses. All values were expressed as a dry mass concentration in $\mu \mathrm{g} / \mathrm{g}$ (unless stated otherwise as wet mass) and mean values were used for sample replicates. I calculated wet mass total mercury concentration by multiplying ( $1-\%$ moisture of tissue/100) by the dry mass total mercury concentration of the tissue.

\section{Stable isotope analyses}

I calculated $\delta^{13} \mathrm{C}$ and $\delta^{15} \mathrm{~N}$ values to investigate the trophic position of Contracaecum spp. and D. spathans compared to their cormorant host and relationships between carbon and nitrogen signatures and total mercury concentration. Half a milligram $( \pm 0.2 \mathrm{mg}$ ) of parasite tissue powder was encapsulated in tin. Isotope analysis was accomplished using a Vario EL III (Elementar, Hanau, Germany) followed by gas chromatograph separation and on-line analysis using a DeltaPlus Advantage isotope ratio mass spectrometer (Thermo Scientific) coupled with a ConFlo III (G.G. Hatch Isotope Laboratories, University of Ottawa, Ottawa, ON, Canada). Data quality was assured using international standards for calibration (IAE-CH-6, IAEA-NBS22, IAEA-N1, IAEA-N2, USGS-40, and USGS-41) and further quality control was maintained through sample duplicates. Values are reported in delta notation in parts per thousand (\%, per mil) relative to an atmospheric air standard. Mean values are reported for samples analysed in duplicate. Analytical precision, based on repeat measures of a standard (C-55), was $\pm 0.06 \%$. 


\section{Data analyses}

I used non-parametric tests for all analyses to ensure all comparisons between sexes and host and parasite were consistent in testing the same null hypothesis; thereby allowing the results to be easily compared. I used Wilcoxon tests to determine differences in median values (i.e., abundance of Contracaecum spp., total mercury concentration, $\delta^{13} \mathrm{C}$ and $\delta^{15} \mathrm{~N}$ values) between sexes and between host and parasite. I used Spearman Rho correlations to determine relationships between parasite and host mercury concentrations and $\delta^{13} \mathrm{C}$ and $\delta^{15} \mathrm{~N}$ values. For the non-parametric analyses I reported median values with $25 \%$ and $75 \%$ interquartile ranges. All analyses were done using JMP version 4 (SAS Institute Inc., 1989-2000) software.

I performed a series of calculations to determine whether the nematode burden in heavily parasitised male cormorants could account for their lower methylmercury burden compared to lightly parasitised male cormorants. I used equations adapted from Lewis et al. (1993) to calculate the percentage of host body burden of mercury sequestered by nematodes in cormorants. First, I calculated male comorant mercury body burden using Braune \& Gaskin's (1987) estimate that approximately $36 \%$ of the mercury body burden in birds was contained in the liver. I relied on liver mass and total mercury concentrations from a Lake Erie cormorant sample to calculate cormorant mercury body burden because I did not have this information for the Lake Ontario cormorants: however, all other values used in the subsequent calculations are from the Lake Ontario cormorant sample. I expect that liver mercury concentrations are similar between the two sampling locations because 
I found a strong positive correlation between breast muscle and liver total mercury concentrations for male cormorants from the Lake Erie sample $\left(\mathrm{R}_{\mathrm{Pearson}}=0.93, \mathrm{P}<0.001\right.$, S.A. Robinson, unpublished data) and the median mercury concentration in breast muscle was similar between Lake Ontario and Lake Erie male cormorants (Lake Ontario: median of $1.74 \mu \mathrm{g} / \mathrm{g}$ (dry mass; interquartile range from 1.34 to $2.80 \mu \mathrm{g} / \mathrm{g}$ ); Lake Erie: median of $1.80 \mu \mathrm{g} / \mathrm{g}$ with interquartile range from 1.45 to $2.51 \mu \mathrm{g} / \mathrm{g}(\mathrm{Z}=-0.55, \mathrm{P}=0.58:$ S.A. Robinson, unpublished data)). Therefore, the liver mercury concentrations are reflective of the breast muscle concentrations and since the breast muscle values are similar between Lake Erie and Lake Ontario I expect that the liver values are also similar.

\section{Results}

\section{Host sex, parasitism and mercury concentration}

The 15 male cormorants had 2.5 times more Contracaecum spp. compared to the 15 female cormorants $(Z=3.90, P<0.001)$. Median number of worms per infected male and female host (or median intensity of Contracaecum spp.) was 127 (interquartile range of 91 to 285) and 51 (interquartile range of 36 to 84), respectively. Male cormorants had 1.7 times more mercury than female cormorants $(Z=3.65, P<0.001$, Table 6.1). Subsequent analyses pertaining to mercury concentration were done separately by sex because of the significant difference in these values between male and female cormorants. 
Table 6.1. Total mercury (TotHg) concentrations for male and female cormorant (Phalacrocorax auritus) breast muscle, male and female nematode (Contracaecum spp.) tissue and trematode (Drepanocephalus spathans) tissue are reported as median values in $\mu \mathrm{g} / \mathrm{g}$ (dry mass) with their $25 \%$ and $75 \%$ interquartile range (IQR). The ratio of methylmercury (MeHg) to total mercury concentrations are reported as median values in $\mu \mathrm{g} / \mathrm{g}$ (dry mass) with their $25 \%$ and $75 \%$ IQR. The percentage of total mercury concentration that is methylmercury is reported as median values with their $25 \%$ and $75 \%$ IQR. Percentages over $100 \%$ are a result of analytical uncertainties. Sample size $(n)$ is indicated for each analysis. Reprinted with permission from (c) 2010 Elsevier.

\begin{tabular}{|c|c|c|c|c|c|c|}
\hline \multirow{2}{*}{$\begin{array}{l}\text { Ilost Sex } \\
\text { Male Cormorant }\end{array}$} & \multicolumn{2}{|c|}{ Totl Ig (median $(\mathrm{IQR})) n$} & \multirow[t]{2}{*}{ Mellg/Totllg (mean $\pm \mathrm{SE})$} & \multirow[t]{2}{*}{$n$} & \multicolumn{2}{|c|}{$\% \mathrm{Mel} \lg (\operatorname{mcan} \pm \mathrm{SE}) n$} \\
\hline & & & & & & \\
\hline Host breast muscle & $1.98(1.84-5.53)$ & 15 & - & & - & \\
\hline Female nematode & $2.77(2.12-6.04)$ & 14 & $(4.98 \pm 1.22) /(5.65 \pm 1.20)$ & 3 & $87.1 \pm 3.6$ & 3 \\
\hline Male nematode & $2.69(2.36-6.71)$ & 15 & $(5.86 \pm 1.36) /(6.44 \pm 1.73)$ & 3 & $94.0 \pm 5.7$ & 3 \\
\hline \multicolumn{7}{|l|}{ Female Cormorant } \\
\hline Host breast muscle & $1.17(1.08-1.45)$ & 15 & - & & - & \\
\hline Female nematode & $1.65(1.32-2.27)$ & 15 & $(2.12 \pm 0.43) /(2.08 \pm 0.33)$ & 3 & $100.2 \pm 5.8$ & 3 \\
\hline Male nematode & $1.71(1.42-2.29)$ & 15 & $(3.27) /(3.07)$ & 1 & 107.2 & 1 \\
\hline Trematode & $1.49(1.32-1.69)$ & 4 & - & & - & \\
\hline
\end{tabular}




\section{Host and parasite mercury concentrations}

Enough tissue $(>5 \mu \mathrm{g})$ was available to determine total mercury concentrations in 59 of 60 Contracaecum spp. samples. There were significant positive correlations between total mercury concentration in Contracaecum spp. (males and females analysed separately) and their male and female cormorant hosts (Spearman Rho ranged from 0.80 to 0.95 , all $\mathrm{P}<0.001$, Fig. 6.1 ). Furthermore, the median total mercury concentrations for both male and female Contracaecum spp., were significantly different between male and female cormorants (greater if found in male cormorants: $Z$ was 3.44 and 3.38 . respectively, all $\mathrm{P}<0.001$, Table 6.1 ). The difference in total mercury concentration in both male and female Contracaecum spp. sampled from male and female cormorants resembled the difference in total mercury concentration in the breast muscle of male and female cormorants (i.e., same ratio). Male and female Contracaecum spp. had up to 1.5 times greater median total mercury concentrations than their male and female cormorant hosts (Table 6.1). However, the difference in median total mercury concentration between Contracaecum spp. and cormorant hosts was significant only for female cormorants ( $\mathrm{Z}$ ranged from 2.24 to 2.49 , all $\mathrm{P}<0.03$, whereas for male cormorants $Z$ ranged from 1.16 to 1.31 , all $\mathrm{P}>0.19$ ). Importantly, the median percentage of total mercury that was methylmercury in female nematodes was $91.2 \%$ (interquartile range of 84.8 to $105.8 \%$ ) and for male nematodes it was $96.9 \%$ (interquartile range of 88.2 to $106.7 \%$ ) (Table 6.1 ). Therefore, most of the mercury in nematode tissue is the toxic methylated form. 


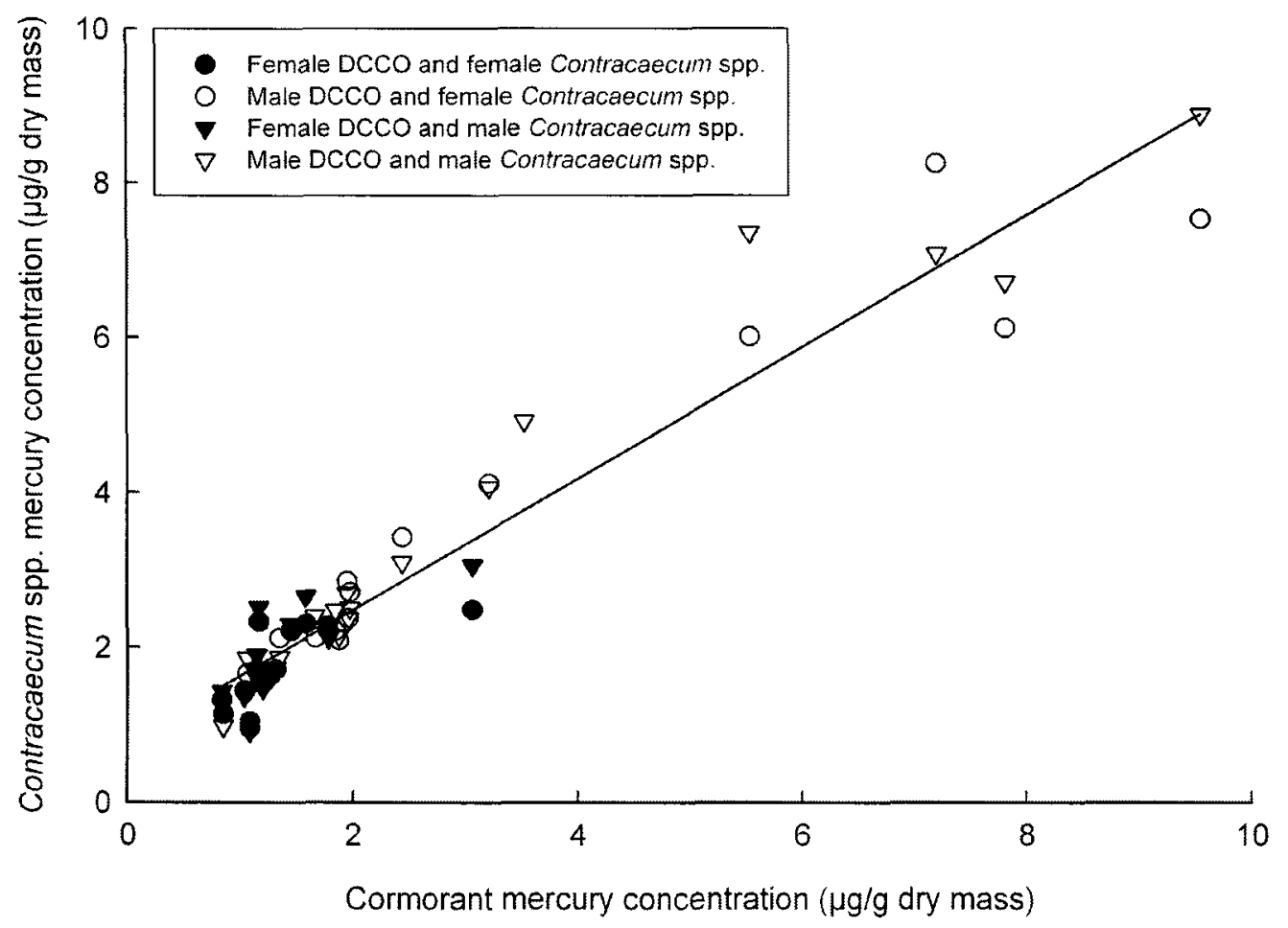

Figure 6.1. Positive correlation between male (open symbol) and female (closed symbol) double-crested cormorant (Phalacrocorax auritus) total mercury concentration in breast muscle and the total mercury concentration in their male (inverted triangle) and female (circle) Contracaecum spp. ( $\mu \mathrm{g} / \mathrm{g}$ dry mass). Reprinted with permission from 02010 Elsevier. 
Only 4 of $10 \mathrm{D}$. spathans samples had enough tissue $(>5 \mu \mathrm{g})$ available to determine total mercury concentrations. The median total mercury concentration for $D$. spathans was not significantly different from the median total mercury concentration of their four female cormorant hosts (median for the four female cormorants was $1.27 \mu \mathrm{g} / \mathrm{g}$ (dry mass) with an interquartile range of 0.93 to $1.66 \mu \mathrm{g} / \mathrm{g}$ (dry mass); $\mathrm{Z}=1.01, \mathrm{P}=0.31$, Table 6.1). Furthermore, two female cormorants had co-infections of $D$. spathans and Contracaecum spp. where total mercury concentrations were measured and found to be within a similar range for both parasite species (mean $( \pm S E)$ total mercury concentration for D. spathans was $1.49 \pm 0.16 \mu \mathrm{g} / \mathrm{g}$ (dry mass), for male Contracaecum spp. was $1.58 \pm$ $0.15 \mu \mathrm{g} / \mathrm{g}$ (dry mass), and for female Contracaecum spp. was $1.51 \pm 0.19 \mu \mathrm{g} / \mathrm{g}$ (dry mass)).

I next determined if nematodes could be responsible for the $\sim 20 \%$ difference in breast muscle total mercury concentration between male cormorants responsible for the sex difference in parasitism and the male cormorants driving the sex difference in mercury concentration (median mercury concentration was $1.94 \mu \mathrm{g} / \mathrm{g}$ (dry mass) with an interquartile range of 1.39 to $3.53 \mu \mathrm{g} / \mathrm{g}$ versus $2.44 \mu \mathrm{g} / \mathrm{g}$ (interquartile range from 1.74 to $3.88 \mu \mathrm{g} / \mathrm{g}$ )). I multiplied liver mass (wet mass) by liver total mercury concentration (wet mass: mean liver moisture content was $68.5 \%$ ) for 10 male cormorants from Lake Erie and divided each value by $36 \%$, which resulted in a mean mercury body burden of $672.18 \mu \mathrm{g}$ (wet mass; range from 144.15 to $2863.17 \mu \mathrm{g}$ ). Second. I determined the mercury sequestered in nematode tissue by multiplying the concentration of total mercury in nematodes (wet mass) by the total mass of the nematodes (wet mass) found in the male 
cormorants responsible for the sex difference in parasitism, which resulted in mean mercury content in nematode tissue of $0.59 \mu \mathrm{g}$ (wet mass; range from 0.08 to $3.20 \mu \mathrm{g}$ ). Therefore, using my calculated total amount of mercury in nematode tissue and cormorant tissue I determined that the percentage of cormorant mercury body burden sequestered by nematodes in the male cormorants responsible for the sex difference in parasitism was $0.59 /(672.18+0.59)=0.1 \%$ (range from $0.003 \%$ to $2.2 \%$ ).

\section{Host and parasite stable isotope signatures}

Male and female cormorants had similar median $\delta^{13} \mathrm{C}$ values $(Z=-0.85, P=$ 0.40 ); however, female cormorants had greater median $\delta^{15} \mathrm{~N}$ values than male cormorants $(Z=-3.40, P<0.001$, Table 6.2), similar to my previous findings (Chapter 3 ).

Subsequent analyses pertaining to $\delta^{15} \mathrm{~N}$ values were done separately by sex because of the significant difference in these values between male and female cormorants. I measured $\delta^{13} \mathrm{C}$ and $\delta^{15} \mathrm{~N}$ values of female Contracaecum spp. because there was enough tissue available for isotope analysis for 29 of 30 female Contracaecum spp. samples but not for most male Contracaecum spp. samples. Furthermore, I expected that male and female Contracaecum spp. from the same host would have similar isotopic values because their mercury concentrations were also similar. To confirm this, I measured the $\delta^{13} \mathrm{C}$ and $\delta^{15} \mathrm{~N}$ values of 5 samples of male Contracaecum spp. and found significant positive correlations between male and female Contracaecum spp. $\delta^{13} \mathrm{C}$ and $\delta^{15} \mathrm{~N}$ values from the same five hosts (Spearman Rho was 0.90 and 1.00 , both $\mathrm{P}<0.04$, respectively). Furthermore, there was no difference between the median $\delta^{13} \mathrm{C}$ and $\delta^{15} \mathrm{~N}$ values of male 
Table 6.2. Stable carbon $\left(\delta^{13} \mathrm{C}\right)$ and nitrogen isotope $\left(\delta^{15} \mathrm{~N}\right)$ values for male and female cormorants and their female nematodes and trematodes. Median values with their $25 \%$ and $75 \%$ interquartile range (IQR) are reported as per mil (\%o, dry mass). Sample size $(n)$ is provided for each tissue analysed. Reprinted with permission from (C) 2010 Elsevier.

\begin{tabular}{llll}
\hline$\delta^{17} \mathrm{C}$ values (\%o) & $\delta^{15} \mathrm{~N}$ values (\%o) & $\mathrm{n}$ \\
$($ median (IQR)) & $($ median (IQR)) & \\
\end{tabular}

Male Cormorant

Host breast muscle $\quad-21.31(-21.96-(-20.40)) \quad 14.53(14.23-14.74) \quad 16$

Female nematode $\quad-20.12(-21.78-(-19.79)) \quad 13.85(13.63-14.14) \quad 15$

Trematode $\quad-21.59(-22.10-(-21.22)) \quad 15.48(14.88-15.87) \quad 5$

Female Cormorant

Host breast muscle $\quad-21.00(-21.65-(-20.16)) \quad 15.13(14.80-15.72) \quad 17$

$\begin{array}{llll}\text { Female nematode } & -20.39(-21.26-(-19.56)) & 14.09(13.77-14.25) & 14\end{array}$

Trematode $\quad-21.23(-21.32-(-20.66)) \quad 16.26(15.10-16.59) \quad 3$ 
and female Contracaecum spp. $\left(\delta^{13} \mathrm{C}\right.$ : male: $-20.54 \%$ (interquartile range from -21.60 to $-19.00 \%$ ), female: $-21.30 \%$ (interquartile range from -22.05 to $-20.06 \%$ ). $Z=0.84, P=$ $0.40 ; \delta^{15} \mathrm{~N}$ : male: $13.87 \%$ (interquartile range from 13.11 to $14.51 \%$ ), female: $13.81 \%$ (interquartile range from 13.24 to $14.54 \%$ ), $Z=0.00, P=1.0$, Table 6.2 ).

There was a significant positive correlation between female Contracaecum spp. $\delta^{13} \mathrm{C}$ values and cormorant $\delta^{13} \mathrm{C}$ values (Spearman Rho $=0.59, \mathrm{P}<0.001$ ). The female Contracaecum spp. had more positive median $\delta^{13} \mathrm{C}$ values than their cormorant hosts $(\mathrm{Z}=$ $2.52, \mathrm{P}=0.01$, Table 6.2). There was no significant correlation between $\delta^{15} \mathrm{~N}$ values of female Contracaecum spp. and the $\delta^{15} \mathrm{~N}$ values of their male or female hosts (Spearman Rho was 0.08 and 0.31 , all $\mathrm{P}>0.29$ ). However, median $\delta^{15} \mathrm{~N}$ values of female Contracaecum spp. were significantly lower than those in their male and female hosts (male cormorants: $Z=-3.55, P<0.001$, female cormorants: $Z=-2.92, P=0.004$, Table 6.2).

I measured the $\delta^{13} \mathrm{C}$ and $\delta^{15} \mathrm{~N}$ values of $D$. spathans in 8 cormorants and found no correlation between $\delta^{13} \mathrm{C}$ or $\delta^{15} \mathrm{~N}$ values in $D$. spathans and their cormorant hosts (Spearman Rho ranged from 0.57 to 0.69 , all $\mathrm{P}>0.06$ ). Drepanocephalus spathans appear to have slightly greater $\delta^{15} \mathrm{~N}$ values than their male hosts and female hosts and similar $\delta^{13} \mathrm{C}$ values as their male and female hosts (Table 6.2). I also report $\delta^{13} \mathrm{C}$ and $\delta^{15} \mathrm{~N}$ values in D. spathans and Contracaecum spp. that were co-occurring in 4 male and 2 female cormorants. I found that male cormorants had D. spathans with a median $\delta^{13} \mathrm{C}$ value of $-21.56 \%$ (interquartile range from -21.85 to $-21.07 \% 0$ ) and median $\delta^{15} \mathrm{~N}$ value of $15.60 \%$ (interquartile range from 15.13 to $15.95 \%$ ) and Contracaecum spp. with a 
median $\delta^{13} \mathrm{C}$ value of $-19.81 \%$ (interquartile range from -20.85 to $-19.60 \%$ ) and median $\delta^{15} \mathrm{~N}$ value of $14.15 \%$ (interquartile range from 13.83 to 14.20 ). In female cormorants, D. spathans had a median $\delta^{13} \mathrm{C}$ value of $-20.99 \%$ (interquartile range from -21.32 to $20.66 \%$ ) and median $\delta^{15} \mathrm{~N}$ value of $15.85 \%$ (interquartile range from 15.10 to $16.59 \% 0$ ) and Contracaecum spp. had a median $\delta^{13} \mathrm{C}$ value of $-20.68 \%$ (interquartile range from 22.03 to $-19.33 \%$ ) and $\delta^{15} \mathrm{~N}$ value of $13.65 \%$ (interquartile range from 13.08 to $14.2 \mathrm{I}$ $\%$ ).

Finally, there was no significant correlation between mercury concentration and $\delta^{13} \mathrm{C}$ values for male or female cormorants (Spearman Rho was -0.24 and 0.15 , respectively, both $\mathrm{P}>0.39$ ). Also. there was no significant correlation between mercury concentration and $\delta^{15} \mathrm{~N}$ values in male cormorants (Spearman Rho $=0.09, \mathrm{P}=0.75$ ); however in female cormorants there was a significant negative correlation (Spearman Rho $=-0.69, \mathrm{P}=0.004)$. Furthermore, there were no significant correlations between female Contracaecum spp. mercury concentrations and their $\delta^{13} \mathrm{C}$ or $\delta^{15} \mathrm{~N}$ values in either male or female hosts (Spearman Rho ranged from -0.42 to 0.25 , all $\mathrm{P}>0.14$ ).

\section{Discussion}

I found that Contracaecum spp. bioaccumulate mercury to concentrations above their cormorant hosts. Both male and female Contracaecum spp. exceeded the mercury concentration in the muscle of their hosts; however, the difference was not statistically significant in male hosts. No other studies have looked at mercury accumulation in nematodes of birds, and there have only been three other studies that have analysed 
mercury concentration in nematodes, where the host was the European eel Anguilla anguilla ((Linnaeus 1758); Palikova \& Barus 2003; Eira et al. 2009) and the killifish (Bergey et al. 2002). The eel nematode Anguillicola crassus (Kuwahara, Niimi \& Itagaki 1974 ) is found in the swimbladder and had a lower concentration of mercury than the hosts muscle, liver and kidney (Palikova \& Barus 2003; Eira et al. 2009). The killifish nematode is found encysted in the abdominal cavity of its fish host and was also found to have lower mercury concentrations than its host muscle tissue (Bergey et al. 2002). Other studies on nematode bioaccumulation have looked at non-biomagnifying heavy metals. such as lead and cadmium in fishes, birds, and mammals (Sures 2004; Barus et al. 2007 and references therein). In these studies, nematodes can exceed their host tissue concentrations (Barus et al. 2007), but not as often or to the magnitude of cestodes and acanthocephalans (Sures 2003, 2004).

Adult trematodes have rarely been studied for their bioaccumulation potential (Sures 2003); however, they are similar to cestodes and acanthocephalans in that they absorb nutrients across their tegument from the hosts' intestinal lumen because they lack a complete intestinal system (Roberts $\&$ Janovy 2005). One of the few studies that have analysed trematode bioaccumulation found that adult Fasctola hepatica (Linnaeus 1758) had greater lead concentrations than bovine host muscle, kidney and liver (Sures et al. 1998). In comparison, yellow perch Perca flavescens (Mitchill 1814) muscle tissue and Apophallus brevis (Ransom 1920) metacercariae had similar concentrations of methylmercury (Ryman et al. 2008). In my study, D. spathans can bioaccumulate 
mercury but not to concentrations that are detectably different than host tissues or coinfecting male and female Contracaecum spp.

Methylmercury biomagnifies with trophic level (Weiner ef al. 2003) and I predicted that Contracuecum spp. would have higher mercury concentrations than their host because they could be feeding on host tissues. Methylmercury is lipophilic and therefore can accumulate in lipid rich tissues; however, it will preferentially bind to sulfhydryl groups in proteins (Weiner et al. 2003). Parasites are generally depleted in lipids compared to their hosts (Barrett 1981; Sures 2004 (and references therein)); therefore I did not expect lipid content to influence the accumulation of methylmercury in Contracaecum spp. I found that Contracaecum spp. total mercury concentration was predominantly methylmercury, which means that they were accumulating the most readily available and toxic form of mercury and had the potential to reduce mercury exposure to the cormorant host. However, based on my calculations the percentage of methylmercury sequestered in nematode tissue $(\sim 0.1 \%)$ cannot explain the $20 \%$ difference in mercury concentration between the male cormorants responsible for the sex difference in parasitism and the male cormorants responsible for the sex difference in mercury concentration.

In using $\mathrm{N}$ isotopes to infer trophic position, I found that Contraccecum spp. had significantly lower $\delta^{15} \mathrm{~N}$ values than their male or female host. There are only a few studies on host-parasite trophic relationships; however, it appears that the general pattern is that endoparasites are depleted in ${ }^{15} \mathrm{~N}$ compared to their host (e.g., Pinnegar et al. 2001; Dubois et al. 2009). This inconsistency with conventional expectations of trophic 
enrichment from prey to predator might be due to parasite-specific physiology and biochemistry involving selective feeding and excretion of nitrogenous compounds (Barrett 1981). Although the dynamics of nitrogen utilisation and excretion have not been determined fully for parasites there are some biochemical explanations for ${ }^{15} \mathrm{~N}$ depletion in some endoparasites (see Power \& Klein 2004). In particular, excretion of nitrogen (i.e.. ammonia vs. urea) was found as a significant source of variation in $\delta^{15} \mathrm{~N}$ values, where ammonotelic organisms had lower $\delta^{15} \mathrm{~N}$ values than ureotelic uricotelic organisms (Vanderklift \& Ponsard 2003). Parasitic helminths excrete $80 \%$ of their nitrogenous waste as ammonia (Barrett 1981); furthermore, selective feeding of ${ }^{15} \mathrm{~N}$ depleted amino acids by parasites could reduce $\delta^{15} \mathrm{~N}$ values (Hare et al. 1991). In addition to the physiological and biochemical explanations for ${ }^{15} \mathrm{~N}$ depletion in parasites, Contracaecum spp. could also be feeding on fish tissue consumed by the cormorants (Anderson 2000) and not relying on host tissues for nutrients thus further reducing the potential ${ }^{15} \mathrm{~N}$ enrichment between host and parasite. However, I would expect $\delta^{13} \mathrm{C}$ values to be similar between host and parasite if they were both assimilating the same nutrient source (i.e., fish; Power \& Klein 2004). The more positive $\delta^{13} \mathrm{C}$ values in Contracaecum spp. suggest that they are consuming some host tissues. The fishes that cormorants tend to consume during the pre-chick period when I sampled have $\delta^{13} \mathrm{C}$ values that range from 24 to $-22 \%$ (C.E. Hebert, unpublished data). Therefore. I would expect cormorant $\delta^{13} \mathrm{C}$ values to be at the values I found $(-1 \%$ above fishes) and Contracaecum spp. are $\sim 1 \%$ above the cormorant's $\delta^{13} \mathrm{C}$ values which suggest that Contracaecum spp. were feeding on host tissues. I do not expect lipid content in cormorant breast muscle to be 
significantly influencing the difference between host and parasite $\delta^{13} \mathrm{C}$ values because I have lipid normalized the $\delta^{13} \mathrm{C}$ values (see methods and Chapter 3 ). Similar ${ }^{13} \mathrm{C}$ enrichment was found in nematodes known to feed on their host rabbit tissues where they had more positive $\delta^{13} \mathrm{C}$ values than their host's diet and host tissues (Boag et al. 1998). Furthermore, cestodes known to rely on host digested nutrients had $\operatorname{similar} \delta^{13} \mathrm{C}$ values as their host because both were relying on the same food source (Boag et al. 1998; Persson et al. 2007). Therefore, stable carbon isotopes in Contracaecum spp. more consistently follow the conventional enrichment pattern found between prey and predator (DeNiro \& Epstein 1978) than stable nitrogen isotopes.

I cannot explain the slightly greater $\delta^{15} \mathrm{~N}$ values found in $D$. spathans compared to their hosts or co-occurring Contracaecum spp. I would expect trematodes like $D$. spathans to have $\delta^{15} \mathrm{~N}$ values similar to their host because both host and trematode are exposed to similar digested food contents or trematodes may be depleted compared to the host for the biochemical reasons mentioned above. However, $\delta^{13} \mathrm{C}$ values were slightly lower in $D$. spathans compared to Contracaecum spp. (Table 6.2) which suggest that $D$. spathans were relying on host digested nutrients more so than Contracaecum spp. My ability to interpret these results is limited because of small samples sizes for D. spathans. Finally, in cormorants, I did not find the predicted positive relationship between mercury concentration and trophic level as inferred from $\delta^{15} \mathrm{~N}$ values (Cabana \& Rasmussen 1994). The only significant relationship was negative, where greater mercury concentration related to lower $\delta^{15} \mathrm{~N}$ values in female cormorants. In my previous study using the larger sample I found a similar negative relationship but only when the data 
were analysed with the male and female cormorant data sets combined (Chapter 3). A negative correlation between $\delta^{15} \mathrm{~N}$ values and mercury concentration was found for several species of toothed whales from Japan (Endo et al. 2010). They indicated that the negative correlation was likely a result of the geographical variation in mercury and $\delta^{15} \mathrm{~N}$ values in the foraging areas of the toothed whales (Endo et al. 2010). I do not have an explanation for the negative correlation in female cormorants, but have previously suggested that it might be a result of sex differences in consumption of round gobies Apollona melanostoma (Pallas 1814) and alewife Alosa pseudoharengus (Wilson 1811 ; see Chapter 3).

In summary, Contracaecum spp. bioaccumulate mercury and therefore could be reducing the hosts' exposure to some dietary methylmercury. However, the magnitude of mercury bioaccumulation by Contracaecum spp. is much less than what acanthocephalans were found to bioaccumulate when they reduced lead concentrations in their fish host (Sures \& Siddall 1999). Furthermore, I found that Contracaecum spp. likely occupy a higher trophic position than their hosts based on $\delta^{13} \mathrm{C}$ values but not $\delta^{15} \mathrm{~N}$ values, which is in agreement with other host-parasite studies where nematodes are not enriched in ${ }^{15} \mathrm{~N}$ compared to their host (e.g., Pinnegar et al. 2001). Of course, the possibility remains that male and female parasites, and indeed different parasite species, assimilate and excrete nitrogenous compounds at different rates and this accounts for some of the differences in isotopic signatures. 
Chapter 7

\section{CHAPTER SEVEN}

Evidence for sex differences in mercury dynamics in double-crested cormorants

This chapter formed the basis for the following publication and was reproduced with permission from 2011 American Chemical Society:

Robinson, S. A., Forbes, M. R., Hebert, C. E. and Scheuhammer, A. M. 2011. Evidence for sex differences in mercury dynamics in double-crested cormorants. Environmental Science and Technology 45: 1213-1218. 


\begin{abstract}
Piscivorous birds can demethylate methylmercury in their livers. In this study, I determined whether a previously documented sex difference in mercury concentration (males had higher mercury concentrations) in double-crested cormorants Phalacrocorax antritus (Lesson 1831) was due entirely to the depuration of mercury into eggs or might also in part be related to sex differences in methylmercury demethylation or biliary excretion capability in the liver. I found egg depuration accounted for less than a fifth of the mercury concentration difference between males and females, hence not entirely explaining the sex difference. Females had a significantly steeper slope for the negative relationship between percent methylmercury (i.e., percentage of total mercury that is methylmercury) and total mercury concentration than did males. This suggests that females have a greater capacity to demethylate methylmercury which might be reducing the amount of methylmercury available for depuration to eggs. I also found a significant negative relationship between methylmercury concentration and liver mass for females only; thus females might also have a greater capability to excrete methylmercury compared to males. Therefore, I conclude that the sex differences in mercury concentration might also result from females having a greater capability to excrete mercury compared to males.
\end{abstract}




\section{Introduction}

Mercury is a natural trace metal in the environment with no essential function for life; however, it is of environmental concern because levels are increasing globally due to industrial releases, especially from coal combustion for energy production (Weiner et al. 2003). The methylated form of mercury is toxic and biomagnifies through food webs, resulting in high trophic level consumers, such as piscivorous waterbirds, being exposed to relatively high dietary methylmercury concentrations (Weiner et al. 2003).

Toxic effects from methylmercury, such as reduced reproduction, suppressed immune function, or central nervous system dysfunction have been reported in waterbirds (Scheuhammer et al. 2007): however, there is considerable interspecific variability in the levels of methylmercury exposure required to produce these and other toxic effects (Wolfe et al. 1998). It has been suggested that some piscivorous waterbird species may have a greater ability to demethylate methylmercury than other species (Thompson $\&$ Furness 1989a; Kim et al. 1996a; Scheuhammer et al. 2008).

The liver is the primary filtering and detoxifying organ in birds (Duke 1986). It has been suggested that methylmercury is demethylated in the liver, thereby resulting in the production of inorganic mercury, which may associate with selenium in an approximate 1:1 molar ratio, hence detoxifying methylmercury (Kim et al. 1996b:

Scheuhammer et al. 2008). There is evidence to suggest that selenium is involved in detoxification of methylmercury because it is often positively correlated with concentrations of inorganic mercury in the liver (and kidney; Cuvin-Aralar \& Furness 
1991; Scheuhammer et al. 1998b) and has been found to decrease the toxic effects of mercury (Yang et al. 2010).

Several studies have found a negative correlation between methylmercury and total mercury in the liver. such that as levels of total mercury increase the percentage of methylmercury decreases (Thompson \& Furness 1989a; Kim et al. 1996a; Scheuhammer et al. 1998b; Henny et al. 2002; Eagles-Smith et al. 2009). Recent studies have indicated the possibility for a threshold value of total mercury in the liver before the demethylation process is activated fully (Scheuhammer et al. 2008; Henny et al. 2002; Eagles-Smith et al. 2009). Furthermore, there is evidence to suggest different demethylation thresholds among waterbird species and between chicks and adults (Eagles-Smith et al. 2009). The energetic costs of demethylation are not known; however. it is conceivable that demethylation is costly and would be activated only when potential toxic effects outweigh the costs of demethylation. Caspian and Forster's terns (Hydroprogne caspia (Pallas 1770) and Sterna forsteri (Nuttall 1834), respectively), that are exposed to fairly high levels of methylmercury from their fish diet, have a lower threshold value at which demethylation in the liver begins compared to American avocets Recurvirostra americana (Gmelin 1789) and black-necked stilts Himantopus mexicamus (Muller 1776), that generally accumulate methylmercury to lower levels because of their invertebrate diet (Eagles-Smith et al. 2009). Therefore, it is plausible that bird species that are exposed to higher dietary levels of methylmercury have evolved mechanisms to demethylate mercury more readily than other species. 
Although female birds can reduce their body burden of methylmercury by depositing it into their eggs (Braune \& Gaskin 1987; Lewis et al. 1993), it would be reproductively advantageous for females to reduce the amount of methylmercury transferred to eggs, thereby reducing the risk for methylmercury-induced embryonic toxicity (Weiner et al. 2003). The occurrence of higher mercury levels in male birds during the breeding season often has been attributed to females depurating some of their methylmercury into their eggs (Braune \& Gaskin 1987; Lewis et al. 1993). However, it is also plausible that females are able to reduce the amount of methylmercury available for depuration by demethylating methylmercury and/or increasing their biliary excretion of mercury and thus reducing their overall mercury burden. In rats, methylmercury and inorganic mercury were excreted from the liver and into the bile at a greater rate in females than in males, and this was associated with females tending to have lower liver mercury concentrations than males (Ballatori \& Clarkson 1983, 1984).

In previous work, male double-crested cormorants had higher mercury concentrations than females (Chapter 3). In this study, I explored whether the sex difference was entirely due to egg depuration of mercury or in part related to sex differences in methylmercury demethylation and/or excretion in the liver. I first analysed the amount of mercury in cormorant eggs to determine the degree to which depuration of mercury into eggs can explain lower mercury burdens in female cormorants. I also measured the size of the liver as a proxy of liver demethylation capability, based on the finding that detoxification capacity increased with an increase in liver mass and detoxifying enzymes in mammals exposed to plant chemical toxins compared to controls 
(Harju \& Tahvanainen 1994). I then determined the relationship between methylmercury and inorganic mercury in the liver of males and females and examined whether the relationship (i.e.. demethylation) was different between males and females. I also determined if larger livers could be excreting more mercury and if this relationship was different for males and females. Finally, I measured the concentration of selenium in male and female livers to determine if either sex had a greater concentration of selenium available to bind with inorganic mercury.

\section{Methods}

I used tissues from 193 breeding cormorants that were collected for another study from Lake Erie at Point Pelee National Park of Canada-Middle Island $\left(41^{\circ} 41^{\prime} \mathrm{N}, 82^{\circ} 41^{\prime} \mathrm{W}\right)$ during May 2008 [refer to Chapter 4, for collection details]. The samples were collected two weeks after a full clutch was laid. Whole livers were excised by use of clean, acetone-rinsed and then hexane-rinsed stainless steel scalpels and forceps. I removed any connective tissue, placed each liver into a separate chemically clean glass jar, recorded the wet mass on a Mettler toledo balance $( \pm 0.1 \mathrm{~g})$ and stored them at $-40^{\circ} \mathrm{C}$ until they were processed for metals analysis. There were no obvious lesions or abnormalities on any of the livers I collected, and I assume that all livers were likely functioning optimally when the birds were sampled.

I measured total mercury concentration in eight cormorant eggs randomly collected from different clutches from Lake Erie at East Sister Island $\left(41^{\circ} 49^{\prime} \mathrm{N}, 82^{\circ}\right.$ $5 \mathrm{l}$ 'W) during May 2006. Total egg contents (albumen plus yolk. wet mass) were 
measured to $0.1 \mathrm{~g}$. I also randomly selected a sub-sample of 36 cormorant ( 18 male and 18 female) livers for total mercury and methylmercury analysis and 20 (10 of each sex) of these liver samples for selenium analysis. Egg contents and thawed liver tissue were individually homogenized into a uniform paste (by use of Ultraturrax homogenizer) and samples were weighed into acid-washed polypropylene vials. Homogenized tissue was then freeze-dried for at least $48 \mathrm{~h}$ and the dry mass was recorded. I crushed the freezedried tissue into a fine powder with the blunt end of a microspatula and analysed it for total mercury on a Milestone DMA-80 direct mercury analyzer (Shelton, CT). For methylmercury analysis I followed the extraction and analysis procedure described in Scheuhammer et al. (1998a). I determined selenium content in nitric acid-digested liver tissue by graphite furnace atomic absorption spectrophotometry on a Perkin-Elmer AAnalyst 800 (Norwalk, CT) equipped with Zeeman background correction and electrodeless discharge lamps. Calibration was done by the method of standard additions. Quality control for all determinations of total mercury. methylmercury and selenium was maintained by analyzing procedural blanks, appropriate certified reference material (dogfish liver certified reference material for trace metals [DOLT-3], Metals Toxicology Laboratory, National Wildlife Research Centre, Ottawa. ON, Canada) and sample replicates. The mean $( \pm S E$ ) values for certified reference material DOLT-3 recoveries was $99.1 \pm 1.5 \%(n=9)$ for total mercury analyses, $93.1 \pm 1.2 \%(n=14)$ for methylmercury analyses, and $96.5 \pm 6.9 \%(n=3)$ for selenium analyses. The relative percent standard deviation for sample replicates for total mercury analyses was $4.8 \pm 1.3$ $\%(\mathrm{n}=3)$, for methylmercury analysis was $2.9 \pm 1.0 \%(\mathrm{n}=7)$, and for selenium analyses 
was $4.9 \pm 0.9 \%(\mathrm{n}=2)$. Cormorant tissue values are expressed as a dry mass concentration (unless otherwise indicated), and mean values are reported for sample replicates. For comparison of my results to wet mass values reported in other studies, I found the mean percent moisture $( \pm \mathrm{SE}$ ) for cormorant liver tissue was $68.5 \pm 0.3 \%$. There was no difference in the percent moisture content in male and female livers (males: $68.9 \pm 0.3 \%$, females: $\left.68.2 \pm 0.4 \%, \mathrm{~F}_{1.35}=2.2, \mathrm{P}=0.15\right)$. The mean percent moisture $( \pm$ SE) for cormorant egg tissue was $83.7 \pm 0.3 \%$.

I tested the data for normality using the Shapiro-Wilk test and transformed the data to meet the assumption of normality when necessary. I used analysis of variance (ANOVA) tests to determine if males and females had significantly different concentrations of total mercury, methylmercury, inorganic mercury (i.e., total mercury minus methylmercury concentration), or selenium in their livers. I then used a series of calculations from Lewis et al. (1993) to estimate the percentage of mercury depurated into a clutch and compared this to the percent difference in mercury concentration in liver tissue between male and female cormorants. I controlled the influence of body mass on liver mass by using three different methods suggested by Sol et al. (2007). I used an analysis of covariance (ANCOVA) to investigate if sex influenced liver mass once the influence of body mass was controlled. I then compared male and female residuals (from least squares regression analysis between liver mass and body mass) using ANOVA. I report normalized liver mass values by adding the grand geometric mean liver mass to residuals from the regression (see Hebert \& Keenleyside 1995). Finally I compared the 
fraction of body mass that corresponds to liver mass between males and females by an ANOVA.

I then used linear regressions to determine the slope of the relationship between inorganic mercury and methylmercury and between percent methylmercury (i.e.. methylmercury divided by total mercury) and total mercury for each sex. I used t-tests to determine if males and females had different regression slopes (Zar 1999). I used this approach instead of an ANCOVA because the covariates (i.e., methylmercury and total mercury) did not have the same range of values (i.e., minimal overlap) between males and females and therefore violated an assumption of the ANCOVA (Quinn \& Keough 2002). I used linear regressions to determine the relationship between methylmercury concentration and body mass (and liver mass). Finally, I used Pearson's correlation to determine if there was a relationship between inorganic mercury and selenium for males and females. All statistical analyses were done using JMP (v. 4) statistical software (SAS Institute Inc.. 1989-2000). I report mean values that the statistical test was based on (either the arithmetic mean \pm SE or geometric mean (antilog of mean from log transformed data) with its antilog $95 \%$ confidence intervals (CI)).

\section{Results}

\section{Host sex and total mercury, methylmercury and selenium concentrations}

Total mercury, methylmercury and selenium were detected in all liver tissue samples.

Males had significantly greater total mercury and methylmercury concentrations in liver than females (total mercury in males $9.89 \mu \mathrm{g} / \mathrm{g}$ dry mass $(95 \% \mathrm{Cl} 6.73-14.83 \mu \mathrm{g} / \mathrm{g}$ dry 
mass), total mercury in females $4.42 \mu \mathrm{g} / \mathrm{g}$ dry mass (95\% CI $3.61-5.42 \mu \mathrm{g} / \mathrm{g}$ dry mass), $F_{1.34}=13.89, \mathrm{P}<0.001:$ methylmercury in males $3.62 \pm 0.31 \mu \mathrm{g} / \mathrm{g}$ dry mass, methylmercury in females: $2.17 \pm 0.11 \mu \mathrm{g} / \mathrm{g}$ dry mass, $\left.F_{134}=19.02, P<0.001\right)$. Likewise, inorganic mercury concentrations were greater in males than females (males $5.91 \mu \mathrm{g} \cdot \mathrm{g}$ dry mass $(95 \% \mathrm{CI} 3.53-9.90 \mu \mathrm{g} / \mathrm{g}$ dry mass), females $2.17 \mu \mathrm{g} / \mathrm{g}$ dry mass $(95$ $\%$ CI 1.59-2.95 $\mu \mathrm{g} / \mathrm{g}$ dry mass), $\mathrm{F}_{1.34}=11.44, \mathrm{P}=0.002$ ). In females, methylmercury comprised a greater proportion of total mercury than in males, males $38.7 \pm 3.9 \%$ and females $49.6 \pm 2.8 \%\left(F_{134}=5.14, \mathrm{P}=0.03\right)$; however, this difference was no longer detectable when two male outliers $\left(8.5 \%\right.$ and $9.4 \%$ methylmercury) were removed $\left(\mathrm{F}_{1,32}\right.$ $=2.75, \mathrm{P}=0.11)$. There were no differences in selenium concentrations between males and females (males $9.18 \mu \mathrm{g} / \mathrm{g}$ dry mass (95\% CI 7.07-11.92 $\mu \mathrm{g}^{\prime} \mathrm{g}$ dry mass), females $8.25 \mu \mathrm{g} / \mathrm{g}$ dry mass $(95 \% \mathrm{CI} 7.13-9.55 \mu \mathrm{g} / \mathrm{g}$ dry mass $), \mathrm{F}_{1.18}=0.56, \mathrm{P}=0.46$ ).

\section{Estimation of depuration of methylmercury into eggs}

I measured total mercury in egg tissue (three egg samples were measured for methylmercury, where the mean $( \pm \mathrm{SE})$ percentage of total mercury that was methylmercury was $99.3 \pm 1.6 \%$ ) and applied a series of calculations to determine the likelihood that the difference in mercury concentration between males and females was the result of depuration of methylmercury into eggs. All eight cormorant egg tissue samples had detectable concentrations of total mercury. The mean total mercury concentration was $1.08 \pm 0.10 \mu \mathrm{g} / \mathrm{g}$ (dry mass; range $0.76-1.53 \mu \mathrm{g} / \mathrm{g}$ dry mass). The amount of mercury depurated into a clutch was calculated by multiplying the full clutch 
mass by the total mercury concentration in the egg tissue. A full clutch typically contains four eggs (Hatch and Weseloh 1999) with a mean dry egg mass of $6.7 \mathrm{~g}$ (Dzialowski et al. 2009) (range in my sample of eight eggs was 5.7-7.6 g dry mass), which results in a full clutch mass of $-26.8 \mathrm{~g}$ (range $22.8-30.2 \mathrm{~g}$ ): therefore, approximately $0.03 \mathrm{mg}$ of mercury could be depurated into a clutch. However, cormorant egg mercury concentrations within a clutch may vary by 3.9 to $16.9 \%$ (Caldwell et al. 1999). Often, the first laid egg has a significantly greater mercury concentration, with successively laid eggs being more or less similar to one another (Becker \& Sperveslage 1989; Becker 1992). Therefore, I calculated the range of mercury that could be depurated to a clutch by applying the above variability in egg mercury concentrations to my sample, where I performed separate calculations assuming the egg collected was the first laid or a later laid egg. I found the range of mercury that could be depurated to a clutch was 0.02-0.05 mg. I then calculated the amount of mercury in the female cormorant liver by multiplying each female liver mass (range 38.7-74.1 g) by its corresponding total mercury concentration (range $0.8-3.8 \mu \mathrm{g} g$ wet mass); therefore, the female cormorant liver contained from 0.05 to $0.2 \mathrm{mg}$ of mercury. Braune \& Gaskin (1987) found that $36 \%$ of the mercury body burden in Bonaparte`s gulls Larus philadelphia (Ord 1815) was stored in the liver; therefore, an estimated mean of $0.2 \mathrm{mg}$ (range $0.1-0.5 \mathrm{mg}$ ) of mercury was in the body of a female cormorant. Finally, the percentage of the body burden of mercury that could be depurated by a female into her clutch was $0.03 \mathrm{mg} /(0.2 \mathrm{mg}+0.03 \mathrm{mg})=$ $13.0 \%$ (range $9.1-16.7 \%$ ). In my sample. female cormorants had a mean of $71.4 \%$ (range 1.4-82.8\%) less total mercury body burden than males, which suggests depuration 
of mercury to eggs is not the only explanation for the lower mercury concentrations in female cormorants.

\section{Host sex and liver mass}

Males were previously reported as being heavier and structurally larger than females (see Chapters $2 \& 4$ ); despite this, absolute geometric mean liver mass did not significantly differ between males and females (males $54.5 \mathrm{~g}(95 \% \mathrm{CI} 52.8-56.2 \mathrm{~g}$ ), females $\left.55.3 \mathrm{~g}(95 \% \mathrm{CI}: 53.6-57.1 \mathrm{~g}), \mathrm{F}_{1,191}=0.45, \mathrm{P}=0.50\right)$. I found a significant effect of sex and body mass on liver mass but no significant interaction (sex, $F_{1,188}=9.34$ and $P$ $=0.003:$ body mass, $F_{1.188}=17.76$ and $P<0.001 ;$ sex $*$ body mass, $F_{1.188}=2.28$ and $P=$ 0.13 ). I followed with a regression analysis of liver mass versus body mass and found a significant sex difference in the residuals (males $-0.01 \pm 0.007$, females $0.02 \pm 0.007$, $\mathrm{F}_{1,190}=8.08, \mathrm{P}=0.005$ ); however, normalized residual liver mass was not noticeably different (males $54.8 \pm 0.01 \mathrm{~g}$, females $54.8 \pm 0.01 \mathrm{~g}$ ). I further compared male and female liver mass using the fraction of body mass that corresponds to liver mass and found a sex difference where females had a higher percent liver mass than males (males $2.8 \%(95 \%$ CI $2.7-2.9 \%)$, females $3.2 \%(95 \%$ CI $3.1-3.3 \%), F_{1.190}=33.35, \mathrm{P}<$ $0.001)$

\section{Host sex and mercury species relationships}

I found significant linear regressions between inorganic mercury concentrations and methylmercury concentrations for males and females (males $\log _{10} \mathrm{IoHg}=-0.2+$ 
$0.3 \mathrm{MeHg}, \mathrm{R}^{2}=0.60, \mathrm{~F}_{1.16}=23.79, \mathrm{P}=0.0002 ;$ females $\log _{10} \mathrm{IoHg}=-0.7+0.5 \mathrm{MeHg}, \mathrm{R}^{2}$ $=0.65, \mathrm{~F}_{1.16}=29.92, \mathrm{P}<0.001$ ), with females having an almost significantly steeper slope than males $\left(t_{1.35}=1.98, P=0.06\right.$; Figure 7.1$)$. Furthermore, upon comparison of percent methylmercury with total mercury concentrations, both sexes had significant linear regressions (males $\% \mathrm{MeHg}=49.2-0.7 \mathrm{TotHg} . \mathrm{R}^{2}=0.58, \mathrm{~F}_{1.16}=22.33, \mathrm{P}<0.001$; females $\left.\% \mathrm{MeHg}=69.4-4.1 \mathrm{TotHg}, \mathrm{R}^{2}=0.73, \mathrm{~F}_{1.16}=42.80, \mathrm{P}<0.001\right)$ and the female slope was significantly steeper than that for the males $\left(t_{1,35}=-5.26, P<0.001\right.$; Figure 7.2). I also found significant correlations between $\log _{10}$ selenium and $\log _{10}$ inorganic mercury for males but not for females (males, $\mathrm{R}_{\text {Pearson }}=0.90, \mathrm{P}<0.00 \mathrm{I}$; females, $\mathrm{R}_{\text {Pearson }}$ $=0.28, P=0.44)$. Finally, I found the relationship between methylmercury concentration and body mass was significantly negative for females but was non-significantly positive for males (males, $\left[\right.$ OrgHg] $=-28.4+9.7 \log _{10}$ (bodymass), $\mathrm{R}^{2}=0.06, \mathrm{~F}_{1.16}=0.98, \mathrm{P}=$ 0.34 ; females. $\left[\right.$ OrgHg] $=34.5-9.9 \log _{10}$ (bodymass), $\mathrm{R}^{2}=0.25, \mathrm{~F}_{1,16}=5.35, \mathrm{P}=0.03$ ). The significant negative relationship for females persisted when I compared methylmercury concentration versus absolute liver mass $\left([\mathrm{OrgHg}]=11.3-5.2 \log _{10}\right.$ (liver mass), $\mathrm{R}^{2}=0.46, \mathrm{~F}_{1,16}=13.47, \mathrm{P}=0.002$ ), but there was much more variation for males, resulting in a nonsignificant negative relationship $\left([\mathrm{OrgHg}]=16.3-7.4 \log _{10}\right.$ (liver mass), $\mathrm{R}^{2}=0.06, \mathrm{~F}_{1.16}=1.08, \mathrm{P}=0.31$ ).

\section{Discussion}

Sex differences in mercury concentration have been reported for several avian species, where male mercury concentrations ranged from 1.1 to 7.8 times greater than females 


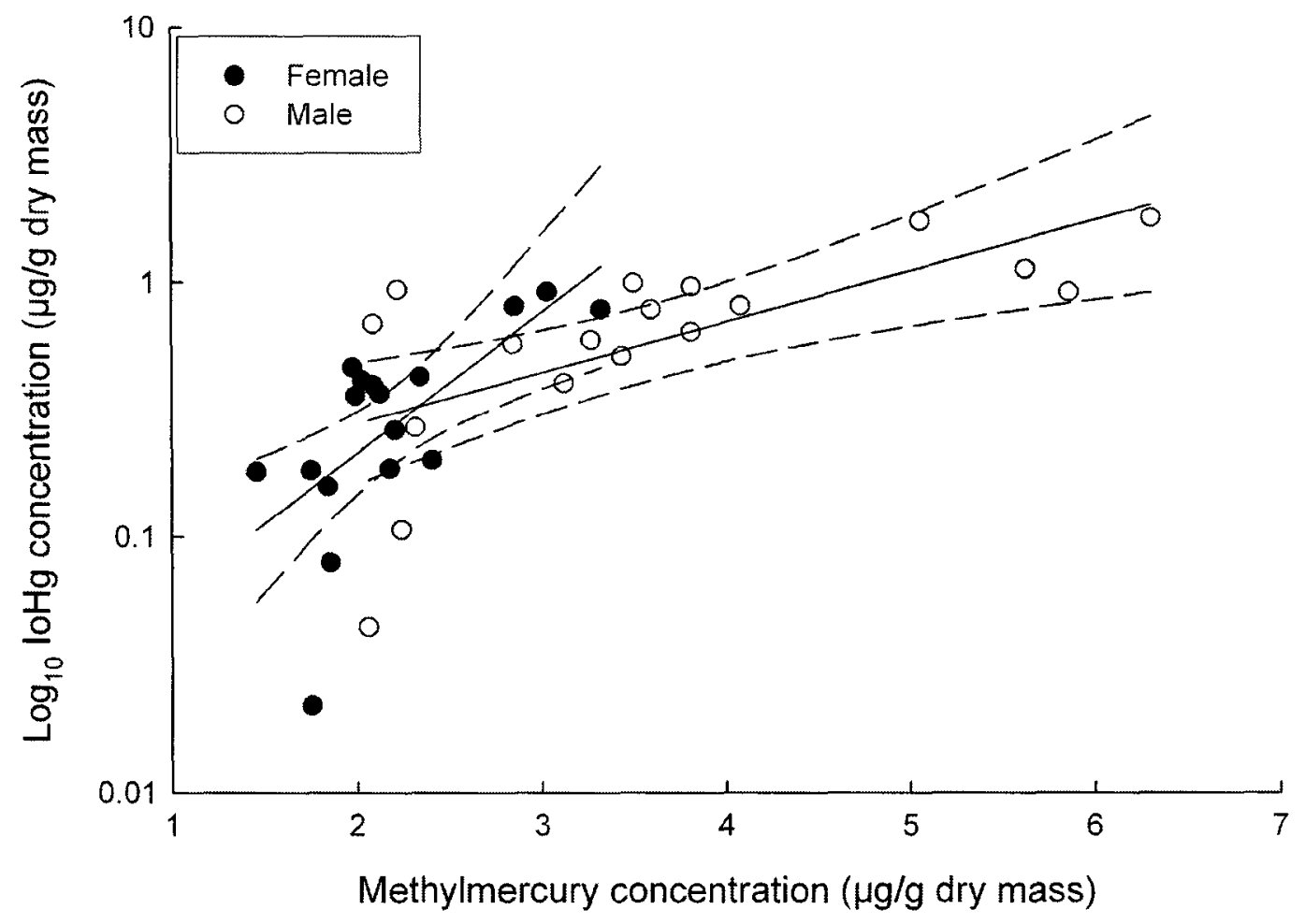

Figure 7.1. Relationships between $\log _{10}$ inorganic mercury $(\mathrm{IoHg})$ concentration and methylmercury concentration in liver tissue of male and female double-crested cormorants (Phalacrocorax auritus). Dashed lines indicate $95 \%$ confidence interval. Reprinted with permission from (c) 2011 American Chemical Society. 


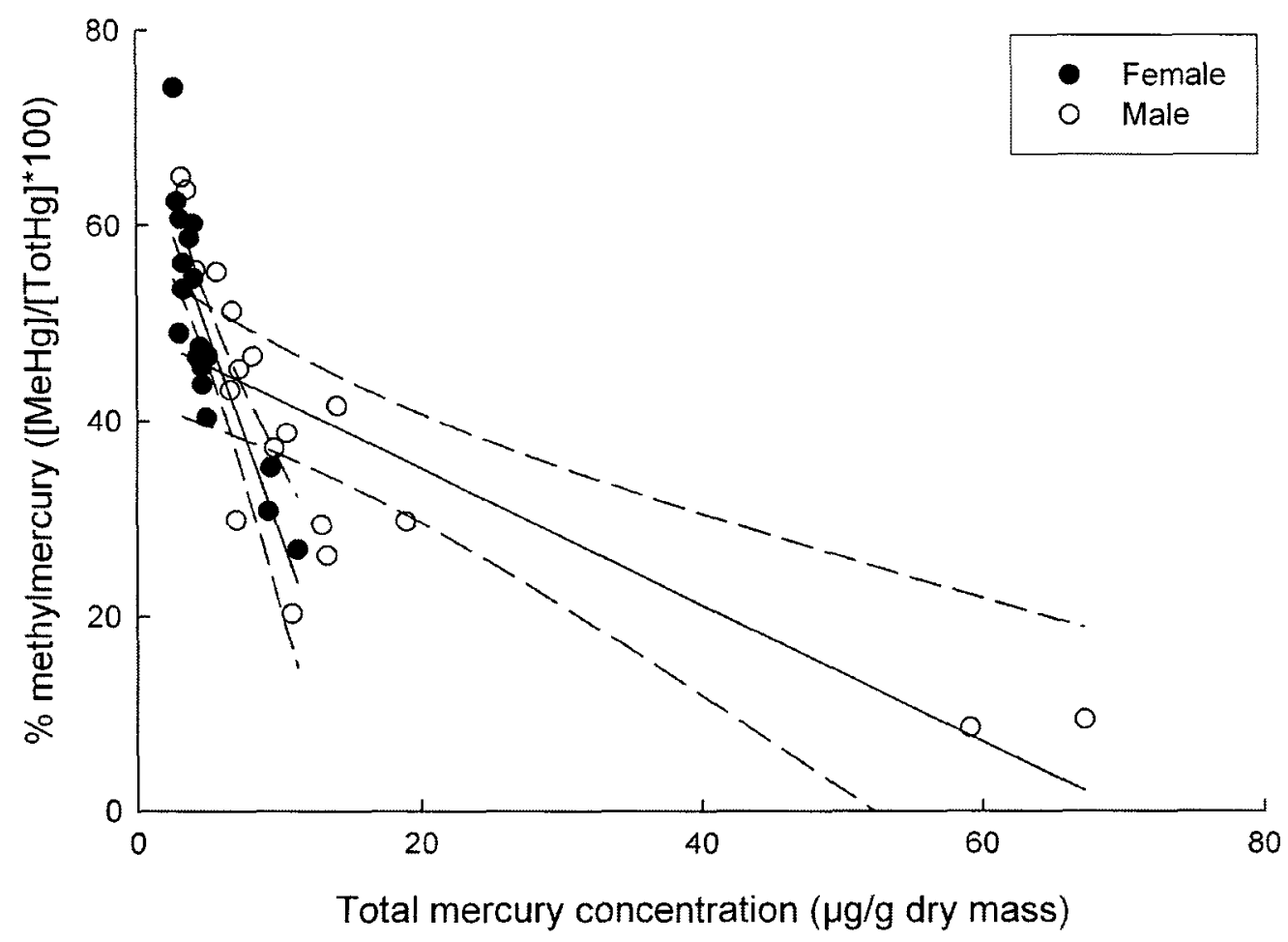

Figure 7.2. Relationships between proportion of total mercury that is methylmercury $(\% \mathrm{MeHg})$ and total mercury concentration in liver tissue of male and female doublecrested cormorants (Phalacrocorax aurtus). Dashed lines indicate $95 \%$ confidence interval. Reprinted with permission from (C) 2011 American Chemical Society. 
(see Table 7.1). My study found males had 2.3 times more total mercury than females. A common suggested explanation for sex differences in mercury concentration is that females depurate some of their methylmercury body burden into their eggs (Braune \& Gaskin 1987; Lewis et al. 1993). Monteiro \& Furness (2001) attempted to corroborate this explanation; however, similar to the results of the current study, they found that egg depuration of mercury by females could not account fully for the difference in mercury concentration between male and female Cory's shearwaters Calonectris diomedea (Scopoli 1769). The shearwaters studied by Monteiro \& Furness (2001) were experimental subjects and therefore had controlled exposure to mercury; whereas in wild birds the sexes could be differentially exposed to mercury due to foraging specializations (see Burger 2007). My cormorant samples were collected from a wild colony and therefore the sexes might be differentially exposed to mercury; however. I did not find a relationship between mercury concentration and foraging ecology (measured by use of $\delta^{13} \mathrm{C}$ and $\delta^{15} \mathrm{~N}$ ) in males and females from this Lake Erie colony (unpublished data) or in a second cormorant colony from Lake Ontario (Chapter 3). I cannot rule out the additional possibility that males are consuming more and or larger fish than females and thus increasing their exposure to mercury. In fact, male cormorants often have a greater mass of fish in their stomachs ( -1.2 times more) than females (Bur et al. 1999), and therefore I expect that most of the difference in mercury concentration between male and female cormorants is a result of differences in dietary exposure to mercury.

Female cormorants tended to have larger livers than males once adjusted for body mass. Sex differences in liver mass were also found for fish (Casselman \& Schulte- 
Table 7.1. Examples of studies that have found significant differences in mercury concentration between adult male and female birds $(\mathrm{wm}=$ wet mass, $\mathrm{dm}=$ dry mass, $\mathrm{fm}=$ fresh mass $)$. Reprinted with permission from 011 American Chemical Society.

\begin{tabular}{|c|c|c|c|c|}
\hline \multirow[t]{2}{*}{ Species } & \multirow[t]{2}{*}{ Tissue } & \multicolumn{2}{|c|}{ Mercury concentration } & \multirow[t]{2}{*}{ Ref } \\
\hline & & Male & Female & \\
\hline Black-necked stilts Himantopus mexicanus & blood & $1.3 \mu \mathrm{g} / \mathrm{g} \mathrm{wm}$ & $1.2 \mu \mathrm{g} / \mathrm{g} \mathrm{wm}$ & (l) \\
\hline Northern Giant Petrel Macronectes halli & blood & $2.9 \mu \mathrm{g} / \mathrm{g} \mathrm{dm}$ & $2.3 \mu \mathrm{g} / \mathrm{g} \mathrm{dm}$ & (2) \\
\hline \multicolumn{5}{|l|}{ Cory's shearwaters Calonectris spp. } \\
\hline Cape Verde & feathers & $\sim 3162 \mathrm{ng} / \mathrm{g} \mathrm{fm}$ & $-2512 \mathrm{ng} / \mathrm{g} \mathrm{fm}$ & (3) \\
\hline Azores Is. & feathers & $\sim 3981 \mathrm{ng} / \mathrm{g} \mathrm{fm}$ & $-3162 \mathrm{ng} / \mathrm{g} \mathrm{fm}$ & (3) \\
\hline Canary Is. & feathers & $-4169 \mathrm{ng} / \mathrm{g} \mathrm{fm}$ & $-3020 \mathrm{ng} / \mathrm{g} \mathrm{fm}$ & (3) \\
\hline Chafarinas Is. & feathers & $-7943 \mathrm{ng} / \mathrm{g} \mathrm{fm}$ & $-6026 \mathrm{ng} / \mathrm{g} \mathrm{fm}$ & (3) \\
\hline Bonaparte's Gulls Larus philadelphia & \multicolumn{2}{|c|}{ Primaries $(1-5) \sim 5.5$ to $13.5 \mu \mathrm{g} / \mathrm{g}$} & $\sim 3.8-9.2 \mu \mathrm{g} / \mathrm{g}$ & (4) \\
\hline American avocets Recurvirostra americana & blood & $0.3 \mu \mathrm{g} / \mathrm{g} w \mathrm{~m}$ & $0.2 \mu \mathrm{g} / \mathrm{g} \mathrm{wm}$ & $(l)$ \\
\hline Herring Gulls Larus argentatus & Primary 1 & $9.6 \mu \mathrm{g} / \mathrm{g} \mathrm{dm}$ & $5.8 \mu \mathrm{g} / \mathrm{g} \mathrm{dm}$ & $(5)$ \\
\hline King Eiders Somateria spectabilis & blood & $0.3 \mu \mathrm{g} / \mathrm{g} w \mathrm{~m}$ & $0.2 \mu \mathrm{g} / \mathrm{g} \mathrm{wm}$ & $(6)$ \\
\hline Spectacled Eiders Somateria fischeri & blood & $0.20 \mu \mathrm{g} / \mathrm{g} \mathrm{wm}$ & $0.12 \mu \mathrm{g} / \mathrm{g} \mathrm{wm}$ & $(6)$ \\
\hline
\end{tabular}


Table 7.1 Continued

\begin{tabular}{|c|c|c|c|c|}
\hline \multirow[t]{2}{*}{ Species } & \multirow[t]{2}{*}{ Tissue } & \multicolumn{2}{|c|}{ Mercury concentration } & \multirow[t]{2}{*}{ Ref } \\
\hline & & Male & Female & \\
\hline \multicolumn{5}{|l|}{ Common goldeneye Bucephala clangula } \\
\hline Early winter & liver & $4.4 \mu \mathrm{g} / \mathrm{g} \mathrm{wm}$ & $3.1 \mu \mathrm{g} / \mathrm{gwm}$ & $(7)$ \\
\hline Mid winter & liver & $14.6 \mu \mathrm{g} / \mathrm{g} \mathrm{wm}$ & $14.0 \mu \mathrm{g} / \mathrm{g} \mathrm{wm}$ & $(7)$ \\
\hline Late winter & liver & $13.7 \mu \mathrm{g} / \mathrm{g} \mathrm{wm}$ & $8.5 \mu \mathrm{g} / \mathrm{g} w \mathrm{~m}$ & $(7)$ \\
\hline \multirow[t]{2}{*}{ California Black RailsLaterallus jamaicensis } & feathers & $8.2 \mathrm{ug} / \mathrm{g} \mathrm{dm}$ & $6.6 \mathrm{ug} / \mathrm{g} \mathrm{dm}$ & $(8)$ \\
\hline & blood & $0.6 \mu \mathrm{g} / \mathrm{g} \mathrm{wm}$ & $0.2 \mu \mathrm{g} / \mathrm{g} \mathrm{wm}$ & $(8)$ \\
\hline \multicolumn{5}{|l|}{ Common loon Gavia immer } \\
\hline \multirow[t]{2}{*}{ New England } & blood & $\sim 2.0 \mu \mathrm{g} / \mathrm{g} \mathrm{wm}$ & $\sim 1.2 \mu \mathrm{g} / \mathrm{g} \mathrm{wm}$ & (9) \\
\hline & feathers & $\sim 13 \mu \mathrm{g} / \mathrm{g} \mathrm{fm}$ & $\sim 8.5 \mu \mathrm{g} / \mathrm{g} \mathrm{fm}$ & (9) \\
\hline \multirow[t]{2}{*}{ Wisconsin } & blood & $-1.5 \mu \mathrm{g} / \mathrm{g} \mathrm{wm}$ & $-1.0 \mu \mathrm{g} / \mathrm{g} \mathrm{wm}$ & $(9)$ \\
\hline & feathers & $\sim 12 \mu \mathrm{g} / \mathrm{g} \mathrm{fm}$ & $-10 \mu \mathrm{g} / \mathrm{g}$ fm & $(9)$ \\
\hline American white pelican Pelecantis ervthrorhyncos & liver & $10.9 \mathrm{mg} / \mathrm{kg} \mathrm{dm}$ & $4.2 \mathrm{mg} / \mathrm{kg} \mathrm{dm}$ & $(10)$ \\
\hline Gentoo Penguin Pygoscelis papua & feathers & $1191 \mathrm{ng} / \mathrm{g} \mathrm{fm}$ & $340 \mathrm{ng} / \mathrm{g} \mathrm{fm}$ & $(l l)$ \\
\hline Ospreys Pandion haliaetus & liver & $9.3 \mathrm{ppm} \mathrm{wm}$ & $1.2 \mathrm{ppm} w \mathrm{~m}$ & $(12)$ \\
\hline
\end{tabular}


References: (1) Ackerman et al. 2007; (2) Gonzalez-Solis et al. 2002; (3) Ramos et al. 2009; (4) Braune \& Gaskin 1987; (5) Lewis et al. 1993; (6) Wilson et al. 2004; (7) Vest et al. 2009; (8) Tsao et al. 2009; (9) Mitro et al. 2008; (10) Donaldson \& Braune 1999; (11) Becker et al. 2002; (12) Wiemeyer et al. 1987. 
Hostedde 2004), snakes (Bonnet et al. 1998), voles (Klemola et al. 1997) and house sparrows (Chappell et al. 1999). The liver is the primary organ responsible for processing and transferring proteins and lipids to eggs (Sturkie 1986): therefore, it may be advantageous for females to invest more into the development of the liver than males because a female's reproductive role is to produce energy-rich eggs. The liver also playsa significant role in detoxifying xenobiotics. including methylmercury (Thompson \& Furness 1989a; Kim et al. 1996a; Scheuhammer et al. 1998b; Henny et al. 2002). The exact biochemical mechanism by which methylmercury is demethylated in liver is not well understood, but there is evidence to suggest an enzyme system is involved (Scheuhammer et al. 2007: Norseth \& Clarkson 1970). Therefore, enzymatic activity might be enhanced in the liver of females, which would increase the females' capability to demethylate methylmercury compared to males. It is possible that females have evolved a greater demethylation capability specifically to reduce the amount of mercury transferred into their eggs, as only methylmercury is transferred to eggs.

The mercury concentrations in cormorants were well below lethal levels and many sublethal levels for adult birds, except for two males where the liver mercury concentrations were 17 and $22 \mu \mathrm{g} / \mathrm{g}$ wet mass (or 59.1 and $67.2 \mu \mathrm{g} / \mathrm{g}$ dry mass) and therefore within the range where overt signs of mercury intoxication and death have been reported for birds (Weiner et al. 2003). Most of the total mercury concentration in these two birds was in the inorganic form (54.1 and $60.9 \mu \mathrm{g} / \mathrm{g}$ dry mass) and was associated with a relatively high selenium concentration $(23.4 \mu \mathrm{g} / \mathrm{g}$ dry mass, next nearest value was $10.7 \mu \mathrm{g} / \mathrm{g}$ dry mass) for the one bird from this pair that was analysed for selenium 
concentration. The low concentration of methylmercury in these two male livers suggests they might have been older males that gradually accumulated methylmercury, demethylated a large portion of it, and were storing the resulting inorganic mercury as toxicologically inert inorganic mercury - selenium complex (Cuvin-Aralar \& Furness 1991: Scheuhammer et al. 1998b; Ikemoto et al. 2004). The mercury concentrations in cormorant eggs were also below generally accepted adverse effect levels (Weiner et al. 2003). By my calculations, less than a fifth of the difference in mercury concentration between males and females can be explained by females depurating mercury into their clutch. However, if females had reduced their body burden of mercury by $71 \%$ by depurating mercury into their clutch, then the mercury concentration in the eggs $(\sim 2.5$ $\mu \mathrm{g} / \mathrm{g}$ wet mass) would be above adverse effect levels $(>1 \mu \mathrm{g} / \mathrm{g}$ wet mass associated with impaired hatchability (Weiner et al. 2003)).

Piscivorous birds are more exposed to and therefore might have evolved a higher tolerance for methylmercury than birds that feed on invertebrates or vegetation (Weiner et al. 2003; Scheuhammer et al. 2007). It is thought that fish-eating birds have adapted to higher dietary methylmercury exposure by detoxifying (i.e., demethylating) absorbed methylmercury (Thompson \& Furness 1989a; Kim et al. 1996a). However, it was also noted that demethylation required a threshold concentration of methylmercury to be reached (Eagles-Smith et al. 2009). In my study, I found that females had a greater potential capability at reducing methylmercury concentrations than males when I compared the relationship between the percent methylmercury and total mercury concentration (Figure 7.2). I also found suggestive evidence that females were more 
capable of metabolizing methylmercury into inorganic mercury (Figure 7.1). Henny et al. (2002) found a dose-dependent relationship between percentage of total mercury that was methylmercury and total mercury concentrations at total mercury concentrations above 20-25 $\mu \mathrm{g} / \mathrm{g}$ dry mass, whereas I found a significant relationship below this threshold. The threshold concentration found by Henny et al. (2002) was greater than almost all my total mercury concentrations in males and females; where only one of the data points was above their threshold.

The rate at which hepatic mercury can be eliminated from the body through the feces is also important in addition to demethylation of methylmercury in the liver (Clarkson 1997; Clarkson et al. 2007). The mechanism for transport of mercury from the liver is biliary secretion bound to glutathione (GSH) and other thiols that are synthesized in the liver (Ballatori \& Clarkson 1984, 1985). Both methylmercury and inorganic mercury bind to the sulfhydryl groups on GSH and thus form a mercury-GSH complex that is secreted into the bile and thereby into the intestine, where it is excreted in the feces after a portion is reabsorbed (Ballatori \& Clarkson 1984). In rats, the rate of secretion of methylmercury, inorganic mercury and GSH into the bile is greater in females than males (Ballatori \& Clarkson 1983, 1984). The increased rate of biliary secretion of mercury and GSH in rats was associated with females tending to have lower liver mercury concentrations than males and was suggested as an explanation for the shorter half-life of mercury in females (Ballatori \& Clarkson 1983 1984). This hepatobiliary excretion of methylmercury and total mercury via GSH complexes also appears to occur in mallards Anas platyrhynchos (Linnaeus 1758), diving ducks (Aythya marila (Limnaeus 1761), 
Melanitta perspicullata (Linnaeus 1758), and Oxyura jamaicensis (Gmelin 1789)) and great blue herons Ardea herodhas ((Linnaeus 1758); Custer et al. 1997; Hoffman \& Heinz 1998; Hoffman et al. 1998); however, the rate of secretion has never been studied as a possible explanation for sex differences in mercury concentrations in wild birds. This is surprising given that Engstrom et al. (2008) found that differences in the metabolism of mercury are influenced by hereditary differences in the genes that are responsible for the production of GSH. Hence the differences in mercury accumulation and toxicity observed between bird species might be a result of differences in genetics or expression of hepatobiliary excretion and/or other processes related to GSH synthesis and between sexes due to developmental differences. Although I did not measure excretion, the negative relationship between methylmercury concentration and liver mass (and body mass) for females suggests females might be more capable of reducing their mercury body burden than males. Furthermore, if methylmercury is being converted to inorganic mercury and stored in the liver as inorganic mercury - selenium complex, I would expect a strong relationship between inorganic mercury and selenium in females: however, a significant relationship was found only for males. This suggests that perhaps females are not storing inorganic mercury as well as males and perhaps females are excreting mercury species more through bile secretions than males.

In summary, female cormorants had less mercury in their liver tissues compared to males. Mercury depuration to eggs could not explain all of the difference in mercury concentrations between male and female cormorants. The liver is the main detoxifying organ in vertebrates and therefore females might have a greater capability to demethylate 
and thus reduce the amount of methylmercury depurated to eggs and/or excrete more mercury compared to males. particularly during the breeding season when liver function is likely optimal in females. I suggest that future studies investigate sex differences in mercury concentration and consider examining differences in excretion of mercury between sex and species. 
Chapter 8

\section{CHAPTER EIGHT}

General Discussion 


\section{General Discussion}

Linkages between contaminant burdens and degree of parasitism have been documented for fish (Khan \& Thulin 1991), birds (Sagerup et al. 2000, 2009, Wayland et al. 2001, but see Mallory et al. 2007) and other taxa (e.g. Aguilar \& Borrell 1994). Such studies are useful in evaluating the combined influences of stressors on the health of hosts and perhaps to their populations. I was specifically interested in determining the factors or circumstances promoting relationships between stressors to understand better which hosts and populations are at the greatest risk from these multiple stressors. My research addressed key gaps in the understanding of linkages between contaminants and parasitism in wildlife. Research focused on evaluating the effects of multiple stressors on wildlife may have important implications for conservation and management/policy decisions. For example, it can inform risk assessment activities by identifying at-risk wildlife. My research was fundamental in its scope in attempting to understand linkages between various measures of host health and how evolved sex differences in ecology may influence sex differences in parasitism. However, my research was also applied in its scope as mercury is a major issue for wildlife because it is not biodegradable, is toxic to wildlife and levels in the environment are increasing because of human activities (Weiner et al. 2003). Below, I discuss the salient findings of each chapter, the novelty of my research and specific areas for future research.

Previous studies on contaminant-parasite linkages in birds have tested for relationships from the viewpoint that contaminants reduce immune function which results in a greater susceptibility to parasites (Sagerup et al. 2000, 2009: Wayland et al. 200 1; 
Mallory et al. 2007). Initially. I set out to test a novel alternative hypothesis for a positive relationship between parasites and contaminants: co-ingestion. However. I found male cormorants had high abundance of Contracaecum spp. (Chapter 2) and high mercury concentration (Chapter 3); but these two stressors did not occur in the same individuals. That is, the males responsible for the sex difference in abundance of ('ontracaecum spp. were different from the males responsible for the sex difference in mercury concentration (i.e.. male (or female) cormorants rarely had high levels of both stressors). Therefore, I did not find evidence to suggest the occurrence of parasites was dependent on mercury. My research challenges the supposition that positive relationships should be expected between mercury (an immunosuppressive contaminant) and levels of parasitism in birds. The independent sex differences in parasitism and mercury concentration required that I investigate other explanations for these patterns separately and that a co-ingestion hypothesis need not be invoked.

I first determined if there were sex differences in parasitism in breeding cormorants and tested conventional explanations related to body size and immune function for sex differences in parasitism (Chapter 2). I found an extreme example of sex differences in parasitism (Poulin 1996) where male cormorants had more than twice the abundance of Contracaecum spp. (nematodes) compared to females. Nematodes are the most common parasite to be associated with sex differences in parasitism in birds (Poulin 1996); however the magnitude of the sex difference is usually much lower than what I found in the cormorants from Lake Ontario. Conventional hypotheses for sex differences in parasitism pertain to sex differences in physiological susceptibility stemming from 
sexual size dimorphism and 'or circulating androgens (Folstad \& Karter 1992; Zuk \& McKean 1996; Sheldon \& Verhulst 1996; Moore \& Wilson 2002). I did not find supportive evidence for conventional hypotheses often proposed for sex differences in parasitism. In fact, although the male cormorants were larger than females (Glahn \& McCoy 1995; Chapter 2.4) and had greater parasite burdens than females, I did not find positive relationships between body mass or size and abundance of helminths in male or female cormorants. I also did not find supportive evidence for reduced immune function (based on spleen mass) in males compared to females and abundance of parasites and spleen mass were unrelated in both sexes. However, I note (in Chapter 2) that other measures of immunological function should be tested to confirm this finding in cormorants because spleen mass might not be the best measure of immune function for a diving bird.

Notwithstanding the caveat above, I focused on exploring the sex difference in parasitism by addressing a less often investigated explanation: sex differences in exposure to infective stages of parasites via prey selection, rather than continuing to investigate conventional hypotheses pertaining to immunology (Chapters 3 to 5 ). When investigating sex differences in parasitism, less emphasis has been placed on examining sex differences in exposure compared to sex differences in susceptibility (i.e., immunity); however, both are important in understanding overall sex differences (Forbes 2007). I used stable isotopes of carbon and nitrogen as a measure of foraging ecology to determine if males and females were differentially exposed to infective stages of parasites and concentrations of mercury. Stable isotope analysis offers a measure of assimilated 
diet and is not a snapshot of a recent feeding event (e.g., stomach content analysis; Barrett et al. 2007), thus better coinciding with the established parasite fauna.

I detected a consistent difference in carbon isotopes between breeding males and females from Lake Ontario (Chapter 3) and Lake Erie (Chapter 4). In both samples, abundance of Contracaecum spp. increased with more negative $\delta^{13} \mathrm{C}$ signatures, which is consistent with a hypothesis of more pelagic foraging (Hobson et al. 1994: France 1995). Although I could not use stable isotope analysis to distinguish specific diet items, the trend for sex differences in foraging location suggests different exposure to infective parasitic stages. I consistently documented the relative importance of resource partitioning by males and females for sex differences in parasitism in two colonies, separated spatially and temporally. Collectively, this suggests exposure might be more important than physiological differences between the sexes in determining instances and magnitude of sex differences in parasitism. My studies pertaining to dietary exposure are novel in that I establish the relative importance of sex differences in dietary exposure to infective stages as a general explanation for sex differences in parasitism of cormorants. This work challenges the often invoked general hypothesis that sex differences in parasitism, where males have greater burdens of parasites, is primarily related to reduced immune function of males mediated by androgens.

I used a sample of nestlings to further test this exposure hypothesis, where I predicted no sex difference in parasitism (or mercury concentration) because I did not expect male and female nestlings to differ in provisioning ecology (Chapter 5). However. I found that carbon signatures were significantly different between males and females and 
followed a similar pattern as the adult sample. That is, carbon signatures of male nestlings resembled adult male stable carbon isotope signatures and female nestlings resembled adult female stable carbon isotope signatures. Furthermore, male nestlings were more often infected by Contracaecum spp., which suggests that fathers might be transferring their parasites when regurgitating fish or providing infected fish more often to male nestlings than female nestlings. Future work should test for sex differences in provisioning ecology in multi-chick broods and determine if male or female chicks are fed more often or different prey by a specific parent. The gape-size constraint hypothesis proposed by Slagsvold \& Wiebe (2007) and Wiebe \& Slagsvold (2009) might be a fruitful direction to pursue in piscivorous birds. However, investigations into sex differences in provisioning would require a labour intensive observational study, where the sex of the adult and nestlings needs to be easily identifiable during feeding events. Furthermore, stable isotopes are informative in many instances: however, fractionation patterns in actively growing chicks require further study. Therefore, other methods for measuring provisioning should be used to further inform the observed patterns (e.g.. stomach content analysis, fatty acid analysis).

The final two chapters of my thesis were directed at investigating mechanisms for the sex difference in mercury concentration (Chapters 6 and 7). I did not find any evidence that dietary exposure to mercury was affecting sex differences in mercury concentration (Chapter 3); therefore, I investigated other explanations. I first tested an explanation for the independent sex differences in parasitism and mercury concentration found in cormorants from a new angle. I determined whether ('ontracaecum spp. were 
altering their host's mercury concentration by sequestering mercury in their own tissues, thereby driving the difference in mercury concentration between the males with high abundance of nematodes and those males with low abundance of nematodes (Chapter 6). Endoparasites may sequester heavy metals and thereby reduce the accumulation in their fish host tissues (Sures \& Siddall 1999: Sures et al. 2003): however, there are no published accounts of this parasite-associated reduction in mercury concentration in host tissues being tested in birds. I found that nematodes accumulated methylmercury in their tissues to concentrations above their cormorant host tissue concentrations. This is consistent with acanthocephalan and cestode contaminant accumulation patterns found in fish (Sures \& Siddall 1999), mammals (Sures et al. 1998: Sures et al. 2003) and birds (Barus et al. 2000a. b: Barus et al. 2001). However, I calculated that the amount of mercury sequestered by the nematodes represented a small amount of the total host burden, and thus could not account for major differences in host tissue concentrations. In fish hosts, parasites that reduce fish host tissue concentrations acquire their mutrients from the fish host digestive products (i.e., acanthocephalans; Roberts \& Janovy 2005). Nematodes feed on host tissues and can cause large ulcerations (Huizinga 1971); however, nematodes in cormorants could be feeding on the fish tissue in the cormorant stomach (Anderson 2000). I used stable isotope analysis to determine if the nematodes were accumulating mercury from fish in the cormorant stomach (i.e., similar carbon and nitrogen profiles between host and parasite) or from cormorant tissue (i.e., enriched ${ }^{13} \mathrm{C}$ and ${ }^{15} \mathrm{~N}$ in parasite compared to host). This was an approach not previously applied with avian parasites. I found evidence to suggest that Contracciecum spp. were consuming host 
tissues based on stable carbon isotope signatures of the nematodes compared to host signatures. More research is needed on fractionation patterns of stable isotopes in parasites (particularly assimilation and excretion of nitrogenous compounds) to better understand feeding relationships between parasites and their host. Also, we require better information on the role specific taxonomical or functional groups of parasites play in host accumulation of contaminants to understand if certain parasites have a uniquely important role in contaminant sequestration.

In the final data chapter of my thesis I addressed a different avenue of investigation for the sex difference in mercury concentration in cormorants: sex differences in methylmercury demethylation or biliary excretion capability in the liver. I first documented that the sex difference could not be entirely explained by the conventional hypothesis that mercury is depurated into eggs by females (Braune \& Gaskin 1987; Lewis et al. 1993). Egg depuration accounted for less than a fifth of the mercury concentration difference between males and females, therefore egg depuration does account for some of the sex difference in cormorants. but not all of it. There are no detailed or validated avian mercury dynamics models to accurately calculate the amount of mercury that is ingested and excreted (Monteiro \& Furness 2001). However, it is known that the main exposure route for birds is through food (Scheuhammer 1987). Fisheating birds are exposed to high concentrations of methylmercury because fish accumulate and store predominantly $(\sim 100 \%)$ methylmercury in their tissues (Scheuhammer 1987). It is this methylated form of mercury that is readily absorbed $(-100 \%)$ in the avian intestine and then distributed throughout the body (Scheuhammer 
1987). The main elimination pathways for mercury are feathers $(-100 \%$ is

methylmercury; Thompson \& Furness 1989b), feces and urine (minimal methylmercury; Scheuhammer 1987) and in females, the eggs (predominantly in the albumin where $\sim 100$ $\%$ is methylmercury; Cappon \& Smith 1981). During annual molts, as much as $93 \%$ of the mercury body burden was excreted into the feathers of Bonaparte's Gulls (Braune \& Gaskin 1987). The percentage of methylmercury or inorganic mercury excreted in feces and urine is not known for birds, but is expected to be quite low (Scheuhammer 1987: Leonzio et al. 2009). Females can depurate a portion of their mercury body burden to their eggs, where approximately $20 \%$ was calculated for Herring gulls (Lewis et al. 1993). Therefore, females have an additional excretion pathway that males lack, and the degree to which this likely influences mercury body burden differences between males and females depends on the amount of body resources females invest into a clutch (i.e., likely differs by species).

Sex differences in mercury concentration are not likely a function of increasing differences between males and females as a result of females depurating mercury to eggs on an annual basis. There are documented differences in mercury concentrations between age groups, where adults have greater concentrations than chicks or juveniles (e.g., Platteeuw et al. 1995). However, there are often no relationships between mercury concentration and adult age in birds (Hutton 1981; Furness et al. 1990; Thompson et al. 1991). This might be a result of the large percentage of the mercury body burden that is excreted during annual molts (e.g., Braune \& Gaskin 1987). The first couple of primary feathers replaced during annual molts sequester a large proportion of the mercury body 
burden and likely result in an annual equilibration in mercury body burden between males and females. Indeed, sex differences in mercury are found in the first couple of primaries, with the remaining molted feathers showing no significant differences between the sexes (Lewis et al. 1993). However, more research is needed on determining the relationship between mercury concentration and adult age and how annual egg production might influence sex differences in mercury concentration, particularly for birds that do not complete a full annual molt. Studies pertaining to relationships with adult age will require long-term monitoring databases because it is often not possible to accurately age adult birds if they were not banded as chicks.

Experimental studies on birds found that egg depuration could not explain the entire sex difference in mercury concentration (Monteiro \& Furness 2001) and proposed that some unidentified physiological difference must exist between the sexes. My research was the first to test for such a physiological difference in metabolism of ingested methylmercury. I found that females may have a greater capacity to demethylate methylmercury in their liver tissue compared to males, which might be reducing the amount of methylmercury available for depuration to eggs. Furthermore, in females, a larger liver was associated with lower methylmercury concentrations, suggesting the larger liver was able to excrete more methylmercury than a smaller liver. Males tended to have relatively smaller livers than females hence males might be less able to excrete ingested methylmercury resulting in elevated mercury concentrations compared to females. Future work is needed to test my supposition that a larger liver relates to greater demethylation capability. Secondly, differences in liver functioning rate between males 
and females and its relationship to mercury metabolism needs to be tested. One method would be to use radio-labelled methylmercury and measure its rate of excretion in males and females (including eggs) and accumulation in internal organs.

In summary. the two most important patterns I found were the consistent sex differences in parasitism and mercury concentration. where male cormorants had higher burdens of both (Chapter 2-4); however, the sex differences were independent (Chapter 3). The independent sex differences required that I investigate explanations for these patterns separately. I documented an extreme example of sex differences in parasitism in birds (Chapter 2) and found evidence to support the sex difference was most likely influenced by exposure differences between males and females to infective parasitic stages in prey 1tems (Chapters 2-5). For the sex difference in mercury concentration, I found new evidence for a mechanism for the difference, where males and females might differ in their capability to demethylate and/or excrete methylmercury from the liver and that egg depuration is not likely the entire explanation for sex differences in contaminant levels (Chapter 7).

\section{Future Directions}

\section{Sex differences in parasitism}

Although I found evidence that agrees with the observation that the larger sex is more often parasitised: the occurrence of sex differences in parasitism in non-sexually size dimorphic species (e.g., hazel grouse Bonasa bonasia (Linnaeus 1758); Isomursu et al. 2006) and greater burdens of parasites in females of some species (McCurdy et al. 
1998) suggests more research on behavioural differences between the sexes is warranted.

Based on my results, I suggest first looking at foraging differences between the sexes.

Males and females may have different nutritional requirements (Carey 1996), particularly

during the breeding season, and hence select different prey for which differences in

exposure to infective parasitic stages might occur. These differences in nutritional

requirements during the breeding season might also explain the absence of a sex

difference in adults outside the breeding season (Dezfuli et al. 2002). Future studies

could focus on describing the variation in parasitism in the same host species from the

same location during and outside the breeding season in association with measures of foraging ecology. By investigating patterns of parasitism in association with measures of exposure during and outside the breeding season the variation in the taxonomical or functional group of parasite displaying the sex difference might be uncovered. That is, if prey items change seasonally, likely based on prey availability as a result of prey phenology, then there might be a change in the taxonomical group of parasite displaying the sex difference. Hence, exposure might be a bigger player in explaining parasitism than previously considered.

\section{Contaminant-parasite relationships}

My work highlights the need to identify sex when investigating the relationship between parasites and contaminants. If sex had not been identified, I might have simply reported there was no association in cormorants, instead of reporting the intriguing independent sex differences in parasitism and mercury concentration. Future research 
should address the cause of independent sex differences in cormorants. I do not have an explanation for the independent patterns of parasitism and mercury concentration in male cormorants. However, there are reports that cormorants will forage in flocks or individually (Hatch \& Weseloh 1999). Perhaps this difference in social or individual foraging behaviour influences exposure to parasites and mercury differently and in a way that is not identifiable with stable isotope analysis. Individual feeding preferences or specialisations could significantly increase the variability in levels of parasites and contaminants, thus necessitating the collection of large sample sizes.

My research suggests the influence of immunity on levels of parasitism might be minimal in host populations or seasons when exposure to parasites is high for certain individuals (e.g., males). This greater role of exposure to parasites in explaining parasitism might also reduce the occurrence of uncovering relationships between contaminants and parasitism, because any contaminant-induced effects on immune function might be overridden by exposure. Other studies on contaminant-parasite linkages that found positive relationships used seabirds that do not show sex differences in foraging based on stable carbon and nitrogen isotope analysis (see Sagerup et al. 2002) or stomach content analysis (e.g., Merkel et al. 2007). Sex differences in foraging or prey selection are well documented in a variety of cormorant species (Watanuki et al. 1996; Casaux et al. 2001). I suggest future studies on contaminant-parasite linkages need to address host foraging ecology and diet specialisation. 


\section{Stable isotope analysis and ecology}

Stable isotope analysis has become a valuable tool in ecology because it allows researchers to quantify the foraging ecology of their study species which is often difficult to do for free-ranging aquatic animals, such as seabirds. The two central tenets of stable isotope analysis are: (1) that the consumers' isotopic signature is a proportional representation of the prey consumed and (2) that prey items differ in their isotopic ratio's (DeNiro \& Epstein 1978, 1981). However, there are some inherent assumptions and limitations that need to be recognized and ultimately tested to accurately interpret stable isotope analyses from field studies (Gannes et al. 1997; Bond \& Jones 2009; Martinez del Rio et al. 2009).

Often avian field studies assume that the rates of isotopic incorporation and discrimination factors between consumer and prey of laboratory animals can be extrapolated to free-ranging species. How'ever, there is increasing evidence that assimilation efficiency and hence rate of isotopic incorporation and discrimination factors might be unique for each tissue-consumer-prey combination (Bearhop et al. 2002; Cherel et al. 2005; Caut et al. 2009). It has been hypothesized that species-specific and tissuespecific differences in metabolic rate, nutritional condition and carbohydrate, protein and lipid content could differentially affect the ratio of stable isotopes in tissues (Gannes et al. 1997: Bond \& Jones 2009). Therefore, controlled laboratory experiments in combination with field studies (to adjust for possible physiological differences between captive and free-ranging individuals) are needed to accurately interpret stable isotope analysis in ecological studies (Gannes et al. 1997). 
In addition, the isotopic profiles of prey in ecosystems under study are necessary because baseline isotopic values might vary within and between habitats (Post 2002). If baseline isotopic profiles are documented then isotopic ratios in consumer tissues can be compared between studies. Therefore, to more accurately assess the diet composition of male and female cormorants using stable isotope analysis, the isotopic composition of their prey fish is necessary. Furthermore, to compare between Lake Ontario and Lake Erie cormorant colonies the baseline primary consumer $\delta^{13} \mathrm{C}$ and $\delta^{15} \mathrm{~N}$ signatures are required.

\section{Sex differences in contaminants}

Finally, my correlative work on sex differences in demethylation capability of methylmercury is a promising avenue for further research. There is considerable interspecific variability in the levels of methylmercury exposure required to produce toxic effects (Wolfe et al. 1998). It has been suggested that some piscivorous waterbird species may have a greater ability to demethylate methylmercury than other species (Thompson \& Furness 1989a; Kim et al. 1996a; Scheuhammer et al. 2008). Knowing more about the circumstances favouring such occurrences would help risk assessors predict situations in which negative effects might occur in wildlife populations (i.e., when to expect toxicity of a contaminant in a population). Furthermore, understanding species differences in demethylation would have great implications for the development of ecological and evolutionary theories pertaining to the dynamics of contaminants in birds and other animals. I suggest the use of a meta-analysis to analyse all documented studies 
of sex differences in mercury concentration (and other contaminants) in birds to establish the common pattern. This will help determine whether sex differences in mercury concentration is the common pattern. and whether its direction (i.e., greater concentrations in males or females) and its incidence is dependent upon the reproductive stage of the bird samples (i.e., breeding or non-breeding); the tissue analysed; or the feeding guild of the birds. This proposed research will establish the generality of sex differences in mercury concentration in birds. Furthermore, if other contaminants are included in the meta-analysis, generalizations based on chemical structure might be possible. This area of research will provide a baseline of information for controlled dosing studies to test the mechanisms for sex differences in mercury concentration and also other toxic, biomagnifying contaminants. This exciting research on mercury promises to make an important contribution to understanding the dynamics of toxic contaminants in individuals and ultimately their effects on wildlife health.

Mercury levels are expected to increase due to continued emissions from industrializing countries, such as China and India (Pacyna et al. 2006). There is reason for international concern about mercury because its propensity for long range atmospheric transport means that mercury will continue to increase in areas where there are no local sources (i.e., the Arctic) or where emissions have been reduced recently such as North America (Pacyna et al. 2006). Top consumers in aquatic ecosystems are expected to continue to be most at risk of mercury contamination because they are exposed to high concentrations through their diet (Scheuhammer et al. 2007). In addition. wildlife from environments previously considered to be pristine, such as the Arctic, are 
likely to be at increased risk because mercury levels are increasing there (Braune 2007). We must be vigilant in monitoring mercury bioaccumulation and its effects in wildlife to understand fully the effects of mercury on individuals and thus possible effects on wildlife populations. Furthermore, we might be able to more definitely document clinical signs of mercury toxicity in free-ranging wildlife if we are prepared to monitor focal wildlife species in targeted environments. 


\section{Literature Cited}

Ackerman, J. T., Eagles-Smith, C. A., Takekawa, J. Y., Demers, S. A., Adelsbach, T. L., Bluso, J. D., Miles, A. K., Warnock, N., Suchanek, T. H. and Schwarzbach, S. E. 2007. Mercury concentrations and space use of pre-breeding American avocets and black-necked stilts in San Francisco bay. Science of the Total Environment 384: $452-466$.

Aguilar, A. and Borrell, A. 1994. Abnormally high polychlorinated biphenyl levels in striped dolphins (Stenella coentleoalba) affected by the 1990-1992 Mediterranean epizootic. Science of the Total Environment 154: 237-247.

Anderson, C. D., Roby, D. D. and Collis, K. 2004. Foraging patterns of male and female double-crested cormorants nesting in the Columbia River estuary. Canadian Journal of Zoology 82: $541-554$.

Anderson, R. C. 2000. Nematode parasites of vertebrates: Their development and transmission. New York, CABI Publishing.

Apanius, V. 1998. The immune system. In: Starck, J. M. and Ricklefs, R. E. (eds.) Avian growth and development: Evolution within the altricial-precocial spectrum. Oxford University Press, New York, pp. 203-222.

Ballatori, N. and Clarkson, T. W. 1985. Biliary-secretion of glutathione and of glutathione metal-complexes. Fundamental and Applied Toxicology 5: 816-831. 
Ballatori, N. and Clarkson. T. W. 1984. Dependence of biliary-secretion of inorganic mercury on the biliary transport of glutathione. Biochemical Pharmacology 33: 1093-1098.

Ballatori, N. and Clarkson. T. W. 1983. Biliary transport of glutathione and methylmercury. American Journal of Physiology 244: G435-G441.

Barrett, J. 1981. Biochemistry of parasitic helminths. London, MacMillan Publishers Ltd.

Barrett, R. T.. Camphuysen, K., Anker-Nilssen. T., Chardine, J. W., Furness. R. W., Garthe, S.. Huppop, O.. Leopold, M. F.. Montevecchi, W. A. and Veit, R. R. 2007. Diet studies of seabirds: A review and recommendations. ICES Journal of Marine Science 64: 1675-1691.

Barton, D. R., Johnson, R. A., Campbell. L., Petruniak, J. and Patterson. M. 2005. Effects of round gobies (Neogobius melanostomus) on dreissenid mussels and other invertebrates in eastern Lake Erie, 2002-2004. Journal of Great Lakes Research 31 : 252-261.

Barus. V., Tenora, F. and Kracmar, S. 2000b. Heavy metal (Pb, Cd) concentrations in adult tapeworms (Cestoda) parasitizing birds (Aves). Helminthologia 37: 131-136.

Barus, V., Tenora, F., Kracmar. S. and Prokes, M. 2001. Cadmium and lead concentrations in Contracaecum rudolphni (Nematoda) and its host, the cormorant Phalacrocorax carbo (Aves). Folia Parasitologica 48: 77-78. 
Barus, V., Tenora. F., Kracmar, J., Hedvabny, J., Prokes, M. and Sitko, J. 2000a. Heavy metals $(\mathrm{Pb}, \mathrm{Cd})$ concentrations in the Ligula intestinalis (Cestoda) and the host Phalacrocorax carbo (Aves). Helminthologia 37: 178-179.

Barus, V., Jarkovsky, J. and Prokes, M. 2007. Philometra ovata (Nematoda: Philometroidea): A potential sentinel species of heavy metal accumulation. Parasitology Research 100: 929-933.

Bearhop, S., Phillips, R. A., McGill, R., Cherel, Y., Dawson, D. A. and Croxall, J. P. 2006. Stable isotopes indicate sex-specific and long-term individual foraging specialisation in diving seabirds. Marine Ecology-Progress Series 311: 157-164.

Bearhop, S., Waldron, S., Voiter, S. C. and Furness, R. W. 2002. Factors that influence assimilation rates and fractionation of nitrogen and carbon stable isotopes in avian blood and feathers. Physiological and Biochemical Zoology 75: 451-458.

Beaulieu, M., Thierry, A. M., Raclot, T., Maho, Y., Ropert-Coudert, Y., Gachot-Neveu, H. and Ancel, A. 2009. Sex-specific parental strategies according to the sex of offspring in the Adelie penguin. Behavioral Ecology 20:878-883.

Becker, P. H. 1992. Egg mercury levels decline with the laying sequence in Charadriiformes. Bulletin of Environmental Contamination and Toxicology 48: 762767. 
Becker, P. H. and Sperveslage. H. 1989. Organochlorines and heary-metals in herring gull (Larus argentatus) eggs and chicks from the same clutch. Bulletin of Environmental Contamination and Toxicology 42: 721-727.

Becker, P. H.. Gonzalez-Solis, J., Behrends, B. and Croxall, J. 2002. Feather mercury levels in seabirds at South Georgia: Influence of trophic position, sex and age. Marine Ecology-Progress Series 243: 261-269.

Bergey, L.. Weis, J. S. and Weis. P. 2002. Mercury uptake by the estuarine species Palaemonetes pugio and Fundulus heterochitus compared with their parasites, Probopyrus pandalicola and Eustrongylides sp. Marine Pollution Bulletin 44: 10461050.

Bertrand, M., Marcogliese, D. J. and Magnan, P. 2008. Trophic polymorphism in brook charr revealed by diet, parasites and morphometrics. Journal of Fish Biology 72: $555-572$.

Boag, B., Neilson, R., Robinson, D., Scrimgeour, C. M. and Handley, L. L. 1998. Wild rabbit host and some parasites show trophic-level relationships for $\delta^{13} \mathrm{C}$ and $\delta^{15} \mathrm{~N}$ : A first report. Isotopes in Envirommental and Health Studies 34: 81-85.

Bond, A. L. and Jones, I. L. 2009. A practical introduction to stable-isotope analysis for seabird biologists: approaches, cautions and caveats. Marine Ornithology 37: 183188. 
Bonnet. X., Shine. R., Naulleau, G. and Vacher-Vallas, M. 1998. Sexual dimorphism in snakes: Different reproductive roles favour different body plans. Proceedings of the Royal Society of London Series B-Biological Sciences 265: 179-183.

Boroskova, Z., Soltys, J. and Benkova, M. 1995. Effect of mercury on the immuneresponse and mean intensity of Ascarts suum infection in guinea pigs. Journal of Helminthology 69: 187-194.

Braune, B. M. and Gaskin, D. E. 1987. Mercury levels in Bonaparte's gulls (Larns philadelphia) during autumn molt in the Quoddy region, New Brunswick, Canada. Archives of Environmental Contamination and Toxicology 16: 539-549.

Braune, B. M., Outridge, P. M.. Fisk, A. T., Muir. D. C. G., Helm, P. A., Hobbs, K., Hoekstra, P. F., Kuzyk, Z. A., Kwan, M., Letcher, R. J., Lockhart, W. L., Norstrom, R. J., Stern, G. A. and Stirling, I. 2005. Persistent organic pollutants and mercury in marine biota of the Canadian arctic: An overview of spatial and temporal trends. Science of the Total Environment 351: 4-56.

Braune, B. A. 2007. Temporal trends of organochlorines and mercury in seabird eggs from the Canadian arctic, 1975-2003. Environmental Pollution 148: 599-613. 
Bur, M. T.. Tinnirello. S. L., Lovell, C. D. and Tyson, J. T. 1999. Diet of the doublecrested cormorant in western Lake Erie. In: Tobin, M. E. (ed.) Symposium on double-crested cormorants: Population status and management issues in the Midwest. USDA Technical Bulletin No. 1879, pp. 78-85.

Burger, J. 2007. A framework and methods for incorporating gender-related issues in wildlife risk assessment: Gender-related differences in metal levels and other contaminants as a case study. Environmental Research 104: 153-162.

Burgess, N. M., Evers, D. C. and Kaplan, J. D. 2005. Mercury and other contaminants in common loons breeding in Atlantic Canada. Ecotoxicology 14: 241-252.

Bush, A. O., Fernandez, J. C., Esch, G. W. and Seed, J. R. 2001. Parasitism: The diversity and ecology of animal parasites. Cambridge, U.K., Cambridge University Press.

Bush, A. O., Lafferty. K. D., Lotz, J. M. and Shostak. A. W. 1997. Parasitology meets ecology on its own terms: Margolis et al. revisited. Journal of Parasitology 83: 575 583.

Cabana, G. and Rasmussen. J. B. 1994. Modeling food-chain structure and contaminant bioaccumulation using stable nitrogen isotopes. Nature 372: 255-257. 
Caldwell, C. A., Arnold, M. A. and Gould, W. R. 1999. Mercury distribution in blood, tissues, and feathers of double-crested cormorant nestlings from arid-lands reservoirs in south central New Mexico. Archives of Environmental Contamination and Toxicology 36: 456-461.

Callum, G. I., Ferguson, M. M. and Lenihan, J. M. A. 1981. Determination of methylmercury in tissue using enzyme proteolysis. Analyst 106: 1009-1013.

Cameron-MacMillan, M. L., Walsh, C. J., Wilhelm, S. I. and Storey, A. E. 2007. Male chicks are more costly to rear than females in a monogamous seabird, the common murre. Behavioral Ecology 18: 81-85.

Camp, J. W., Blaney, L. M. and Barnes, D. K. 1999. Helminths of the round goby, Neogobinis melanostomus (Perciformes: Gobiidae), from southern Lake Michigan, Indiana. Journal of the Helminthological Society of Washington 66: 70-72.

Cappon, C.J. and Smith, J. C. 1981. Chemical form and distribution of mercury and selenium in eggs from chickens fed mercury-contaminated grain. Bulletin of Environmental Contamination and Toxicology 26: 472-478.

Carey, C. 1996. Female reproductive energetics. In: Carey, C. (ed.) Avian energetics and nutritional ecology. Chapman \& Hall, New York, pp. 324-374. 
Casaux, R., Favero. M., Silva, P. and Baroni, A. 2001. Sex differences in the diving depths and diet of Antarctic shags at the South Shetland Islands. Journal of Field Ornithology 72: 22-29.

Casselman, S. J. and Schulte-Hostedde, A. I. 2004. Reproductive roles predict sexual dimorphism in internal and external morphology of lake whitefish, Coregonus clupeaformis. Ecology of Freshwater Fish 13:217-222.

Caut, S., Angulo, E. and Courchamp, F. 2009. Variation in discrimination factors $\left(\Delta^{15} \mathrm{~N}\right.$ and $\Delta^{13} \mathrm{C}$ ): the effect of diet isotopic values and applications for diet reconstruction. Journal of Applied Ecology 46: 443-453.

Chappell, M. A., Bech, C. and Buttemer. W. A. 1999. The relationship of central and peripheral organ masses to aerobic performance variation in house sparrows. Journal of Experimental Biology 202: 2269-2279.

Cherel. Y., Hobson, K. A. and Hassanı, S. 2005. Isotopic discrimination between food and blood and feathers of captive penguins: implications for dietary studies in the wild. Physiological and Biochemical Zoology 78: 106-115.

Clarkson, T. W. 1997. The toxicology of mercury. Critical Reviews in Clinical Laboratory Sciences 34: 369-403.

Clarkson, T. W., Vyas, J. B. and Ballatori, N. 2007. Mechanisms of mercury disposition in the body. American Journal of Industrial Medicine 50: 757-764. 
Connors, V. A. and Nickol, B. B. 1991. Effects of Plagiorhynchus cylindraceus (Acanthocephala) on the energy-metabolism of adult starlings, Sturnus vulgaris. Parasitology 103: 395-402.

Coon, T. G. 1999. Icthyofauna of the Great Lakes. In: Taylor, W. W. and Ferrari, C. P. (eds.) Great Lakes fisheries policy and management. Michigan State University Press. East Lansing. Michigan, pp. 55-72.

Courtney, P. A. and Blokpoel, H. 1980. Food and indicators of food availability for common terns on the lower Great Lakes. Canadian Journal of Zoology 58: 13181323.

Cristol, D. A., Baker, M. B., Carbone. C. 1999. Differential migration revisited: Latitudinal segregation by age and sex class. Current Ornithology 15: 33-88.

Custer, T. W., Hines, R. K., Melancon, M. J., Hoffman, D. J., Wickliffe, J. K., Bickham, J. W., Martin, J. W. and Henshel. D. S. 1997. Contaminant concentrations and biomarker response in great blue heron eggs from 10 colonies on the upper Mississippi ruver, USA. Environmental Toxicology and Chemistry 16:260-271.

Cuvin-Aralar, M. L. A. and Furness, R. W. 1991. Mercury and selenium interaction - a review. Ecotoxicology and Environmental Safety 21: 348-364. 
Daunt, F., Monaghan, P., Wanless, S.. Harris, M. P. and Griffiths, R. 2001. Sons and daughters: Age-specific differences in parental rearing capacities. Functional Ecology 15: 211-216.

Delahay, R. J., Speakman, J. R. and Moss, R. 1995. The energetic consequences of parasitism. Effects of a developing infection of Trichostrongylus tenuis (nematode) on red grouse (Lagopus lagopus-scoticus) energy balance, body weight and condition. Parasitology 1 10: 473-482.

DeNiro, M. J. and Epstein, S. 1978. Influence of diet on distribution of carbon isotopes in animals. Geochimica et Cosmochimica Acta 42: 495-506.

DeNiro, M. J. and Epstein, S. 1981. Influence of diet on the distribution of nitrogen isotopes in animals. Geochimica et Cosmochimica Acta 45:341-351.

Dezfuli, B. S., Volponi, S., Beltrami, I. and Poulin, R. 2002. Intra- and interspecific density-dependent effects on growth in helminth parasites of the cormorant, Phalacrocorax auritus. Parasitology 124: 537-544.

Donaldson, G. M. and Braune, B. M. 1999. Sex-related levels of selenium, heavy metals, and organochlorine compounds in American white pelicans (Pelecamus ervthrorhyncos). Archives of Environmental Contamination and Toxicology 37 : $110-114$ 
Dubois, S. Y.. Savoye, N., Sauriau, P. G., Billy, I., Martinez, P. and de Montaudouin, X. 2009. Digenean trematodes-marine mollusc relationships: A stable isotope study. Diseases of Aquatic Organisms 84: 65-77.

Duke, G. E. 1986. Alimentary canal: Secretion and digestion, special digestive functions, and absorption. In: Sturkie, P. D. (ed.) Avian physiology. Springer-Verlag, New York, pp. 289-302.

Dunn, E. H. 1975. Growth, body components and energy content of nestling doublecrested cormorants. Condor 77: 431-438.

Dzialowski, E. M., Reed, W. L. and Sotherland, P. R. 2009. Effects of egg size on double-crested cormorant (Phalacrocorax auritus) egg composition and hatchling phenotype. Comparative Biochemistry and Physiology A-Molecular \& Integrative Physiology 152: 262-267.

Eagles-Smith. C. A., Ackerman, J. T., Yee, J. and Adelsbach. T. L. 2009. Mercury demethylation in waterbird livers: Dose-response thresholds and differences among species. Environmental Toxicology and Chemistry 28: 568-577.

Eira, C., Torres, J., Miquel, J., Vaqueiro, J., Soares, A. M. V. M. and Vingada, J. 2009. Trace element concentrations in Proteocephalus macrocephalus (Cestoda) and Anguillicola crassus (Nematoda) in comparison to their fish host. Anguilla anguilla in Ria de Aveiro, Portugal. Science of the Total Environment 407: 991-998. 
Endo. T., Hisamichi, Y., Kimura, O., Haraguchi, K., Lavery, S., Dalebout, M. L., Funahashi, N. and Baker, C. S. 2010. Stable isotope ratios of carbon and nitrogen and mercury concentrations in 13 toothed whale species taken from the western Pacific Ocean off Japan. Environmental Science \& Technology 44: 2675-2681.

Engstrom, K. S., Stromberg. U., Lundh. T., Johansson, I.. Vessby, B.. Hallmans, G., Skerfving, S. and Broberg, K. 2008. Genetic variation in glutathione-related genes and body burden of methylmercury. Environmental Health Perspectives 116: 734739.

Evans, D. W., Irwin, S. W. B. and Fitzpatrick, S. 2001. The effect of digenean (Platyhelminthes) infections on heavy metal concentrations in Littorina littorea. Journal of the Marine Biological Association of the United Kingdom 81: 349-350.

Fairbairn, D. J. 1997. Allometry for sexual size dimorphism: Pattern and process in the coevolution of body size in males and females. Annual Reviews in Ecological Systems 28: 659-687.

Fargallo, J. A., Martinez-Padilla, J., Toledano-Diaz, A., Santiago-Moreno, J. and Davila, J. A. 2007. Sex and testosterone effects on growth. immunity and melanin coloration of nestling Eurasian kestrels. Journal of Animal Ecology 76: 201-209.

Fimreite, N. 1974. Mercury contamination of aquatic birds in northwestern Ontario. Journal of Wildlife Management 38: 120-131. 
Fimreite, N., Brevik. E. M. and Torp, R. 1982. Mercury and organochlorines in eggs from a Norwegian gannet colony. Bulletin of Environmental Contamination and Toxicology 28: 58-60.

Fisk, A. T., de Wit, C. A., Wayland, M., Kuzyk, Z. Z., Burgess, N., Letcher, R., Braune, B.. Norstrom. R., Blum, S. P., Sandau. C., Lie, E., Larsen, H. J. S., Skaare, J. U. and Muir, D. C. G. 2005. An assessment of the toxicological significance of anthropogenic contaminants in Canadian arctic wildlife. Science of the Total Environment 351-352: 57-93.

Folstad, I. and Karter, A. J. 1992. Parasites, bright males, and the immunocompetence handicap. The American Naturalist 139: 603-622.

Forbes, M. R. 2007. On sex differences in optimal immunity. Trends in Ecology and Evolution 22: 111-113.

Forbes, M. R., Alisauskas, R. T., McLaughlin, J. D. and Cuddington, K. M. 1999. Explaining co-occurrence among helminth species of lesser snow geese (Chen caerulescens) during their winter and spring migration. Oecologia 120: 613-620.

Forero, M. G., Hobson. K. A., Bortolotti, G. R., Donazar, J. A.. Bertellotti, M. and Blanco. G. 2002. Food resource utilisation by the magellanic penguin evaluated through stable-isotope analysis: Segregation by sex and age and influence on offspring quality. Marine Ecology-Progress Series 234: 289-299. 
Forero, M. G., Gonzalez-Solis, J., Hobson. K. A., Donazar, J. A., Bertellotti, M., Blanco, G. and Bortolotti, G. R. 2005. Stable isotopes reveal trophic segregation by sex and age in the southern giant petrel in two different food webs. Marine Ecology-Progress Series 296: 107-113.

France. R., Chandler, M. and Peters, R. 1998. Mapping trophic continua of benthic foodwebs: Body size-delta N-15 relationships. Marine Ecology-Progress Series 174: $301-306$.

France, R. L. 1995. Differentiation between littoral and pelagic food webs in lakes using stable carbon isotopes. Limnology and Oceanography 40: 1310-1313.

Furness, R. W.. Lewis, S. A. and Mills. J. A. 1990. Mercury levels in the plumage of redbilled gulls Larus novaehollandiae scopulimus of known sex and age. Environmental Pollution 63: 33-39.

Gannes, L. Z.. O'Brien, D. M. and Martinez del Rio, C. 1997. Stable isotopes in animal ecology: assumptions, caveats, and a call for more laboratory experiments. Ecology 78: $1271-1276$

Gaye-Siessegger, J., Focken, U., Muetzel, S., Abel, H. and Becker, K. 2004. Feeding level and individual metabolic rate affect delta $\mathrm{C}-13$ and delta $\mathrm{N}-15$ values in carp: Implications for food web studies. Oecologia 138: 175-183. 
Gilliland, S. G. and Ankney. C. D. 1992. Estimating age of young birds with a multivariate measure of body size. Auk 109: 444-450.

Glahn, J. F. and McCoy, R. B. 1995. Measurements of wintering double-crested cormorants and discriminant models of sex. Journal of Field Ornithology 66: 299304.

Glahn, J. F., Dixson, P. J., Littauer, G. A. and McCoy, R. B. 1995. Food habits of doublecrested cormorants wintering in the delta region of Mississippi. Colonial Waterbirds 18: $158-167$.

Gonzalez-Solis, J.. Sanpera, C. and Ruiz, X. 2002. Metals and selenium as bioindicators of geographic and trophic segregation in giant petrels Macronectes spp. Marine Ecology-Progress Series 244: 257-264.

Great Lakes Bathymetry [electronic resource]. Boulder, Colorado: National Geophysical Data Center, Marine Geology \& Geophysics Division. Accessed April 26, 2011, from http:/ www.ngdc.noaa.gov/mgg/greatlakes/greatlakes.html

Gremillet, D., Argentin, G., Schlte, B. and Culik, B. M. 1998. Flexible foraging techniques in breeding cormorants Phalacrocorax carbo and shags Phalacrocorax aristotelis: Benthic or pelagic feeding? Ibis 140: 113-119.

Grime, J. P. 1989. The stress debate - symptom of impending synthesis. Biological Journal of the Linnean Society 37: 3-17. 
Hare, P. E., Fogel, M. L., Stafford, T. W.. Mitchell, A. D. and Hoering, T. C. 1991. The isotopic composition of carbon and nitrogen in individual amino-acids isolated from modern and fossil proteins. Journal of Archaeological Science 18: 277-292.

Harju, A. and Tahvanainen, J. 1994. The effect of silver birch (Betula pendula) powder on physiological performance of field voles (Microtus agrestis). Annales Zoologici Fennici 31: 229-234.

Hatch, J. J. and Weseloh, D. V. 1999. Double-crested cormorant (Phalacrocorax auritus). In: Poole, A. and Gill, F. (eds.) The birds of north America, no. 441. The Birds of North America, Inc., Philadelphia, PA., pp. 1-36.

Hebert, C. E. and Keenleyside, K. A. 1995. To normalize or not to normalize? Fat is the question. Environmental Toxicology and Chemistry 14: 801-807.

Hebert, C. E., Bur, M., Sherman, D. and Shutt, J. L. 2008. Sulfur isotopes link overwinter habitat use and breeding condition in double-crested cormorants. Ecological Applications 18: 561-567.

Henny, C. J., Hill, E. F., Hoffman, D. J., Spalding, M. G. and Grove, R. A. 2002. Nineteenth century mercury: Hazard to wading birds and cormorants of the Carson River, Nevada. Ecotoxicology 11: 213-231.

Hobson, K. A., Piatt, J. F. and Pitocchelli, J. 1994. Using stable isotopes to determine seabird trophic relationships. Journal of Animal Ecology 63: 786-798. 
Hobson, K. A. 1993. Trophic relationships among high arctic seabirds - insights from tissue-dependent stable-isotope models. Marine Ecology-Progress Series 95: 7-18.

Hobson, K. A. and Clark, R. G. 1992. Assessing avian diets using stable isotopes .1. turnover of C-13 in tissues. Condor 94: 181-188.

Hobson, K. A., Alisauskas, R. T. and Clark, R. G. 1993. Stable-nitrogen isotope enrichment in avian-tissues due to fasting and nutritional stress - implications for isotopic analyses of diet. Condor 95: 388-394.

Hodum. P. J. and Hobson, K. A. 2000. Trophic relationships among Antarctic fulmarine petrels: Insights into dietary overlap and chick provisioning strategies inferred from stable-isotope (delta N-15 and delta C-13) analyses. Marine Ecology-Progress Series 198: 273-281.

Hoffman, G. L. 1999. Parasites of North American freshwater fishes. Ithaca, New York, Cornell University Press.

Hoffman, D. J. and Heinz, G. H. 1998. Effects of mercury and selenium on glutathione metabolism and oxidative stress in mallard ducks. Environmental Toxicology and Chemistry 17: 161-166. 
Hoffman, D. J., Ohlendorf, H. M., Marn, C. M. and Pendleton, G. W. 1998. Association of mercury and selenium with altered glutathione metabolism and oxidative stress in diving ducks from the San Francisco bay region, USA. Environmental Toxicology and Chemistry 17: 167-172.

Holmes, J. C. and Price. P. W. 1986. Communities of parasites. In: Anderson, D. J. and Kikkawa, J. (eds.) Community ecology: Pattern and process. Blackwell Scientific Publications, Oxford, pp. 187-213.

Houserova. P., Kuban, V., Kracmar, S. and Sitko, J. 2007. Total mercury and mercury species in birds and fish in an aquatic ecosystem in the Czech Republic. Environmental Pollution 145: 185-194.

Hubbs, C. L. and Lager, K. F. 2007. Fishes of the Great Lakes region. Ann Arbor, The University of Michigan Press.

Hudson, P. J. and Dobson, A. P. 1991. The direct and indirect effects of the caecal nematode, Trichostrongylus tenuis on red grouse. In: Loye, J. E. and Zuk. M. (eds.) Bird-parasite interactions: Ecology, evolution, and behaviour. Oxford University Press, New York, pp. 49-68.

Hudson, P. J., Newborn, D. and Dobson, A. P. 1992. Regulation and stability of a freeliving host-parasite system: Trichostrongylus tenuis in red grouse. I. Monitoring and parasite reduction experiments. Journal of Animal Ecology 61: 477-486. 
Hudson, P. J. 1986. The effect of a parasitic nematode on the breeding production of red grouse. Journal of Animal Ecology 55: 85-92.

Huizinga, H. W. 1971. Contracaeciasis in pelicaniform birds. Journal of Wildlife Disease 7: 198-204.

Hutton, M. 1981. Accumulation of heavy metals and selenium in three seabird species from the United Kingdom. Environmental Pollution (Series A) 26: 129-145.

Ikemoto, T., Kunito, T., Tanaka, H., Baba, N., Miyazaki, N. and Tanabe, S. 2004. Detoxification mechanism of heavy metals in marine mammals and seabirds: Interaction of selenium with mercury, silver, copper, zinc, and cadmium in liver. Archives of Environmental Contamination and Toxicology 47: 402-413.

Ishikawa, K. and Watanuki, Y. 2002. Sex and individual differences in foraging behaviour of Japanese cormorants in years of different prey availability. Journal of Ethology 20: 49-54.

Isomursu, M., Ratti, O., Helle, P. and Hollmen, T. 2006. Sex and age influence intestinal parasite burden in three boreal grouse species. Journal of Avian Biology 37: $516-$ 522.

Jackson, D. A. 1993. Stopping rules in principal components-analysis - a comparison of heuristic and statistical approaches. Ecology 74: 2204-2214. 
John, J. L. 1995. Parasites and the avian spleen: Helminths. Biological Journal of the Linnean Society 54: 87-106.

John, J. L. 1994b. Nematodes and the spleen: An immunological relationship. Experientia 50: 15-22.

John. J. L. 1994a. The avian spleen: A neglected organ. The Quarterly Review of Biology 69: 327-351.

Johnson, J. H., Ross. R. M. and McCullough. R. D. 2002. Little Galloo Island, Lake Ontario: A review of nine years of double-crested cormorant diet and fish consumption information. Journal of Great Lakes Research 28: 182-192.

Johnson, J. H., Ross, R. M., McKenna, J. E. and Lewis, G. E. 2006. Estimating the size of fish consumed by double-crested cormorants: Considerations for better understanding cormorant-fish interactions. Journal of Great Lakes Research 32: 91 101.

Keesing, F., Holt, R. D. and Ostfeld, R. S. 2006. Effects of species diversity on disease risk. Ecology Letters 9: 485-498.

Kelly, J. F. 1999. Stable isotopes of carbon and nitrogen in the study of avian and mammalian trophic ecology. Canadian Journal of Zoology 78: 1-27. 
Kelly, C. D. 2006. Replicating empirical research in behavioral ecology: How and why it should be done but rarely ever is. The Quarterly Review of Biology 81: $221-236$.

Kempster, B., Zanette, L., Longstaffe, F. J., MacDougall-Shackleton, S. A., Wingfield, J. C. and Clinchy, M. 2007. Do stable isotopes reflect nutritional stress? Results from a laboratory experiment on song sparrows. Oecologia 151:365-371.

Keymer, A. E., Gregory, R. D.. Harvey, P. H., Read, A. F. and Skorping. A. 1991. Parasite-host ecology - case-studies in population-dynamics, life-history evolution and community structure. Acta Oecologica-International Journal of Ecology 12: 105 118.

Khan, R. A. and Thulin, J. 1991. Influence of pollution on parasites of aquatic animals. Advances in Parasitology 30: 201-238.

Kim, E. Y., Murakami, K., Saeki, R. and Tatsukawa, R. 1996a. Mercury levels and its chemical form in tissues and organs of seabirds. Environmental Contamination and Toxicology 30: 259-266.

Kim, E. Y.. Saeki, K., Tanabe, S., Tanaka, H. and Tatsukawa, R. 1996b. Specific accumulation of mercury and selenium in seabirds. Environmental Pollution 94: 261265.

Kirkham, I. R. and Morris, R. D. 1979. Feeding ecology of ring-billed gull (Larus delawarensis) chicks. Canadian Journal of Zoology 57: 1086-1090. 
Klein, S. L. 2004. Hormonal and immunological mechanisms mediating sex differences in parasite infection. Parasite Immunology 26: 247-264.

Klein, S. L. 2000. The effects of hormones on sex differences in infection: From genes to behavior. Neuroscience and Biobehavioral Reviews 24: 627-638.

Klemola, T., Koivula, M., Korpimaki, E. and Norrdahl, K. 1997. Size of internal organs and forage quality of herbivores: Are there differences between cycle phases in Microtus voles? Oikos 80: 61-66.

Knudsen, R., Klemetsen, A. and Staldvik. F. 1996. Parasites as indicators of individual feeding specialization in arctic charr during winter in northern Norway. Journal of Fish Biology 48: 1256-1265.

Koch, P. L. 2007. Isotopic study of the biology of modern and fossil vertebrates. In: Lajtha, K. and Michener, R. (eds.) Stable isotopes in ecology and environmental science. Blackwell, Oxford, pp. 63-92.

Kojadinovic, J., Richard, P., Le Corre, M., Cosson, R. P. and Bustamante, P. 2008. Effects of lipid extraction on delta $\mathrm{C}-13$ and delta $\mathrm{N}-15$ values in seabird muscle, liver and feathers. Waterbirds 31: 169-178.

Krasnov, B. R., Morand. S., Hawlena. H., Khokhlova, I. S. and Shenbrot, G. I. 2005. Sexbiased parasitism, seasonality and sexual size dimorphism in desert rodents. Oecologia 146: 209-217. 
Kvach, Y. and Stepien, C. A. 2008. Metazoan parasites of introduced round and tubenose gobies in the Great Lakes: Support for the "enemy release hypothesis". Journal of Great Lakes Research 34: 23-35.

Lafferty, K. D. 1997. Environmental parasitology: What can parasites tell us about human impacts on the environment? Parasitology Today 13: 251-255.

Lajeunesse, M. J. and Forbes, M. R. 2002. Host range and local parasite adaptation. Proceedings of the Royal Society of London, Series B 269: 703-710.

Landis, W. G. and Yu. M. 2004. Introduction to environmental toxicology: Impacts of chemicals upon ecological systems. Boca Raton, Lewis Publishers.

Leonzio, C., Bianchi, N., Gustin. M., Sorace, A. and Ancora, S. 2009. Mercury, lead and copper in feathers and excreta of small passerine species in relation to foraging guilds and age of feathers. Bulletin of Environmental Contamination and Toxicology 83: 693-697.

Lewis, S., Benvenuti, S., Dall'Antonia, L., Griffiths, R., Money, L., Sherrat, T. N., Wanless, S. and Hamer, K. C. 2002. Sex-specific foraging behaviour in a monomorphic seabird. Proceedings of the Royal Society of London Series B 269: 1687-1693. 
Lewis, S. A., Becker, P. H. and Furness. R. W. 1993. Mercury levels in eggs, tissues, and feathers of herring gulls Larts argentatus from the German Wadden sea coast. Environmental Pollution 80: 293-299.

Luebke, R. W., Copeland. C. B., Diliberto, J. J., Akubue, P. I., Andrews, D. L., Riddle, M. M.. Williams, W. C. and Birnbaum, L. S. 1994. Assessment of host-resistance to Trichinella spiralss in mice following preinfection exposure to $2,3,7,8-\mathrm{TCDD}$. Toxicology and Applied Pharmacology 125: 7-16.

Mackiewicz, J. S. 1988. Cestode transmission patterns. Journal of Parasitology 74: 60-71.

Mallory, M. L., McLaughlin, J. D. and Forbes, M. R. 2007. Breeding status, contaminant burden and helminth parasites of northern fulmars Fulmarus glacialis from the Canadian high arctic. Ibis 149: 338-344.

Marcogliese, D. J. 2002. Food webs and the transmission of parasites to marine fish. Parasitology 124: S83-S99.

Martinez del Rio, C., Wolf, B. O.. Carleton, S. A. and Gannes, L. Z. 2009. Isotopic ecology ten years after a call for more laboratory experiments. Biological Reviews 84: $91-111$

Martinez del Rio, C., Wolf, B. O.. Starck, J. M. and Wang, T. 2005. Mass-balance models for animal isotopic ecology. Physiological and Ecological Adaptations to Feeding in Vertebrates. 141-174. 
Mason, R. P., Fitzgerald, W. F. and Morel, F. M. M. 1994. The biogeochemical cycling of elemental mercury - anthropogenic influences. Geochimica Et Cosmochimica Acta 58: 3191-3198.

McConnaughey, T. and McRoy, C. P. 1979. Food-web structure and the fractionation of carbon isotopes in the Bering Sea. Marine Biology 53: 257-262.

McCurdy, D. G., Shutler, D., Mullie. A. and Forbes, M. R. 1998. Sex-biased parasitism of avian hosts: Relations to blood parasite taxon and mating system. Oikos 82: 303312.

Merkel, F. R., Jamieson, S. E., Falk, K. and Mosbech, A. 2007. The diet of common eiders wintering in Nuuk, southwest Greenland. Polar Biology 30: 227-234.

Minagawa, M. and Wada. E. 1984. Stepwise enrichment of N-15 along food-chains further evidence and the relation between delta-N-15 and animal age. Geochimica $\mathrm{Et}$ Cosmochimica Acta 48: 1135-1140.

Minchella, D. J. and Scott, M. E. 1991. Parasitism - a cryptic determinant of animal community structure. Trends in Ecology \& Evolution 6: 250-254.

Mitro, M. G., Evers, D. C., Meyer, M. W. and Piper, W. H. 2008. Common loon survival rates and mercury in New England and Wisconsin. Journal of Wildlife Management 72: $665-673$. 
Monteiro. L. R. and Furness. R. W. 2001. Kinetics, dose-response and excretion of methylmercury in free-living adult Cory's shearwaters. Environmental Science \& Technology 35: 739-746.

Moore, S. L. and Wilson, K. 2002. Parasites as a viability cost of sexual selection in natural populations of mammals. Science 297: 2015-2018.

Morales-Montor, J., Chavarria. A., De Leon, M. A., Del Castillo, L. I., Escobedo, E. G., Sanchez, E. N., Vargas, J. A., Hernandez-Flores, M., Romo-Gonzalez, T. and Larralde, C. 2004. Host gender in parasitic infections of mammals: An evaluation of the female host supremacy paradigm. Journal of Parasitology 90: 531-546.

Moser, M. E. 1986. Prey profitability for adult gray herons Ardea cinerea and the constraints on prey size when feeding young nestlings. Ibis 128: 392-405.

Nevins HM. 2004. Diet, demography, and diving behaviour of the common murre (Uria aalge) in central California. Moss Landing. California: Moss Landing Marine Laboratories and San Francisco State University. 69-102 p.

Newton, I. 1998. Population limitation in birds. London, Academic Press.

Nisbet, I. C. T., Montoya, J. P., Burger. J. and Hatch, J. J. 2002. Use of stable isotopes to investigate individual differences in diets and mercury exposures among common terns Sterna hirundo in breeding and wintering grounds. Marine Ecology-Progress Series 242: $267-274$. 
Norseth, T. and Clarkson, T. W. 1970. Studies on biotransformation of Hg-203-labeled methyl mercury chloride in rats. Archives of Environmental Health 21: 717-719.

Pacyna, E. G. and Pacyna, J. M. 2002. Global emission of mercury from anthropogenic sources in 1995. Water Air and Soil Pollution 137: 149-165.

Pacyna, E. G., Pacyna, J. M., Steenhuisen, F. and Wilson, S. 2006. Global anthropogenic mercury emission inventory for 2000. Atmospheric Environment 40: 4048-4063.

Palikova, M. and Barus, V. 2003. Mercury content in Anguillicola crassus (Nematoda) and its host Anguilla anguilla. Acta Veterinaria Brno 72: 289-294.

Persson, M. E., Larsson, P. and Stenroth. P. 2007. Fractionation of delta N-15 and delta C-13 for Atlantic salmon and its intestinal cestode Eubothtium crassum. Journal of Fish Biology $71: 441-452$.

Pinnegar, J. K., Campbell, N. and Polunin, N. V. C. 2001. Unusual stable isotope, fractionation patterns observed for fish host-parasite trophic relationships. Journal of Fish Biology 59: 494-503.

Platteeuw, M., Vaneerden, M. R. and Vandeguchte, K. 1995. Variation in contaminant content of livers from cormorants Phalacrocorax carbo sinensis living nearby a polluted sedimentation area in Lake Ijsselmeer, the Netherlands. Ardea 83: 315-324. 
Post, D. M. 2002. Using stable isotopes to estimate trophic position: models, methods and assumptions. Ecology 83: 703-718.

Poulin. R. 1996. Sexual inequalities in helminth infections: A cost of being a male? The American Naturalist 147: 287-295.

Power, M. and Klein, G. M. 2004. Fish host-cestode parasite stable isotope enrichment patterns in marine, estuarine and freshwater fishes from northern Canada. Isotopes in Environmental and Health Studies 40: 257-266.

Price, I. M. and Weseloh, D. V. 1986. Increased numbers and productivity of doublecrested cormorants, Phalacrocorax anritus, on Lake Ontario. The Canadian FieldNaturalist 100: 474-482.

Price, P. W. 1980. Evolutionary biology of parasites. Princeton, New Jersey, Princeton University Press.

Quinn, G. P. and Keough, M. J. 2002. Experimental design and data analysis for biologists. Cambridge, United Kingdom, Cambridge University Press.

Ramos, R., Gonzalez-Solis, J., Forero, M. G., Moreno, R., Gomez-Diaz, E., Ruiz, X. and Hobson, K. A. 2009. The influence of breeding colony and sex on mercury, selenium and lead levels and carbon and nitrogen stable isotope signatures in summer and winter feathers of Calonectris shearwaters. Oecologia 159: 345-354. 
Rausch, R. L. 1983. The biology of avian parasites: Helminths. In: Farmer, D. S., King, J. R. and Parkes, K. C. (eds.) Avian biology. Academic Press, New York, pp. 367-442.

Reed, T. E., Daunt. F., Hall, M. E.. Phillips, R. A., Wanless, S. and Cunningham, E. J. A. 2008. Parasite treatment affects maternal investment in sons. Science 321: 16811682.

Rennie. M. D., Sprules, W. G. and Johnson, T. B. 2009. Resource switching in fish following a major food web disruption. Oecologia 159:789-802.

Ricca, M. A.. Miles, A. K. and Anthony, R. G. 2008. Sources of organochlorine contaminants and mercury in seabirds from the Aleutian archipelago of Alaska: Inferences from spatial and trophic variation. Science of the Total Environment 406 : $308-323$

Ricklefs, R. E. 1967. A graphical method of fitting equations to growth curves. Ecology 48: $978-\&$.

Roberts, L. S. and Janovy, J. J. 2005. Foundations of parasitology. Toronto, McGraw Hill Higher Education.

Roff, D. A. 1992. The evolution of life histories. New York, Chapman \& Hall. 
Ryman. J. E., Van Walleghem, J. L. A. and Blanchfield, P. J. 2008. Methylmercury levels in a parasite (Apophallus brevis metacercariae) and its host. yellow perch (Perca flavescens). Aquatic Ecology 42: 495-501.

Sagerup, K., Henriksen, E. O., Skorping, A., Skaare, J. U. and Gabrielsen, G. W. 2000. Intensity of parasitic nematodes increases with organochlorine levels in glaucous gull. The Journal of Applied Ecology 37: 532-539.

Sagerup, K., Henriksen, E. O., Skaare, J. U. and Gabrielsen, G. W. 2002. Intraspecific variation in trophic feeding levels and organochlorine concentrations in glaucous gulls (Larus hyperboreus) from Bjornoya, the Barents Sea. Ecotoxicology 11: 119125.

Sagerup, K., Helgason, L. B., Polder, A., Strom, H., Josefsen, T. D., Skare, J. U. and Gabrielsen, G. W. 2009. Persistent organic pollutants and mercury in dead and dying glaucous gulls (Larus hyperboreus) at Bjornoya (Svalbard). Science of the Total Environment 407: 6009-6016.

Salgado-Maldonando, G. and Kennedy, C. R. 1997. Richness and similarity of helminth communities in the tropical cichlid fish Cichlasoma urophthalmus from the Yucatan peninsula, Mexico. Parasitology 114: 581-590.

SAS Institute Inc. 1989-2000. JMP. [computer program]. Version 4. Cary, North Carolina. 
Saumier, M. D.. Rau, M. E. and Bird, D. M. 1986. The effect of Trichenella psetdospiralis on the reproductive success of captive American kestrels (Falco spanerius). Canadian Journal of Zoology 64: 2123-2125.

Schalk, G. and Forbes, M. R. 1997. Male biases in parasitism of mammals: Effects of study type, host age, and parasite taxon. Oikos 78: 67-74.

Scheuhammer, A. M. 1987. The chronic toxicity of aluminum, cadmium, mercury, and lead in birds - a review. Environmental Pollution 46: 263-295.

Scheuhammer, A. M., Meyer. M. W., Sandheinrich, M. B. and Murray, M. W. 2007. Effects of environmental methylmercury on the health of wild birds, mammals. and fish. Ambio 36: 12-18.

Scheuhammer, A. M., Wong, A. H. K. and Bond, D. 1998b. Mercury and selenium accumulation in common loons (Gavia immer) and common mergansers (Mergus' merganser) from eastern Canada. Environmental Toxicology and Chemistry 17: 197-201.

Scheuhammer, A. M., Atchison, C. M., Wong, A. H. K. and Evers, D. C. 1998a. Mercury exposure in breeding common loons (Gavia immer) in central Ontario, Canada. Environmental Toxicology and Chemistry 17: 191-196. 
Scheuhammer, A. M.. Basu, N., Burgess, N. M., Elliott, J. E., Campbell, G. D., Wayland, M., Champoux, L. and Rodrigue, J. 2008. Relationships among mercury, selenium. and neurochemical parameters in common loons (fiavia immer) and bald eagles (Haliceetus leucocephalus). Ecotoxicology 17: 93-101.

Scott, W. B. and Crossman. E. J. 1998. Freshwater fishes of Canada. Oakville, Galt House Publications Ltd.

Sears, J., Hatch, S. A. and O'Brien, D. M. 2009. Disentangling effects of growth and nutritional status on seabird stable isotope ratios. Oecologia 159: 41-48.

Sheldon, B. C. and Verhulst, S. 1996. Ecological immunology: Costly parasite defences and trade-offs in evolutionary ecology. Trends in Ecology and Evolution 11: 317 321.

Shutler, D.. Alisauskas, R. T. and McLaughlin, J. D. 1999. Mass dynamics of the spleen and other organs in geese: Measures of immune relationships to helminths? Canadian Journal of Zoology 77: 351-359.

Sih, A., Bell, A. M. and Kerby, J. L. 2004. Two stressors are far deadlier than one. Trends in Ecology \& Evolution 19: 274-276.

Slagsvold, T. and Wiebe, K. L. 2007. Hatching asynchrony and early nestling mortality: The feeding constraint hypothesis. Animal Behaviour 73: 691-700. 
Sol, D., Szekely, T., Liker, A. and Lefebvre, L. 2007. Big-brained birds survive better in nature. Proceedings of the Royal Society B-Biological Sciences 274: 763-769.

Somers, C. M., Lozer, M. N., Kjoss, V. A. and Quinn, J. S. 2003. The invasive round goby (Neogobins melanostomus) in the diet of nestling double-crested cormorants (Phalacrocorax auritus) in Hamilton harbour. Lake Ontario. Journal of Great Lakes Research 29: 392-399.

Sturkie, P. D. 1986. Avian physiology. New York, Springer-Verlag.

Sures, B. 2004. Environmental parasitology: Relevancy of parasites in monitoring environmental pollution. TRENDS in Parasitology 20: 170-177.

Sures, B. 2003. Accumulation of heavy metals by intestinal helminths in fish: An overview and perspective. Parasitology 126: S53-S60.

Sures, B. 2001 . The use of fish parasites as bioindicators of heavy metals in aquatic ecosystems: A review. Aquatic Ecology 35: 245-255.

Sures, B. and Siddall, R. 1999. Pomphorhynchus laevis: The intestinal acanthocephalan as a lead sink for its fish host, chub (Leuciscus cephalus). Experimental Parasitology 93: $66-72$. 
Sures, B., Dezfuli, B. S. and Krug, H. F. 2003. The intestinal parasite Pomphorhynchus laevis (Acanthocephala) interferes with the uptake and accumulation of lead $\left({ }^{210} \mathrm{~Pb}\right.$ ) in its fish host chub (Leusciscus cephalus). International Journal for Parasitology 33: 1617-1622.

Sures, B., Siddall, R. and Taraschewski, H. 1999. Parasites as accumulation indicators of heavy metal pollution. Parasitology Today 15: 16-21.

Sures, B., Jurges, G. and Taraschewski, H. 1998. Relative concentrations of heavy metals in the parasites Ascaris smm (Nematoda) and Fasciola hepatica (Digenea) and their respective porcine and bovine definitive hosts. International Journal for Parasitology 28: $1173-1178$.

Thomas, J. D. 2002. The ecology of fish parasites with particular reference to helminth parasites and their salmonid fish hosts in Welsh rivers: A review of some of the central questions. Advances in Parasitology 52: 1-154.

Thompson. D. R. and Furness, R. W. 1989a. The chemical form of mercury stored in south-Atlantic seabirds. Environmental Pollution 60: 305-317.

Thompson, D. R. and Furness, R. W. 1989b. Comparison of the levels of total and organic mercury in seabird feathers. Marine Pollution Bulletin 20: 577-579. 
Thompson, D. R., Hamer, K. C. and Furness. R. W. 1991. Mercury accumulation in Great Skuas Catharacta skua of known age and sex, and its effect upon breeding and survival. Journal of Applied Ecology 28: 672-684.

Thompson, E., Makarewicz, J. C. and Lewis, T. W. 2005. Additional link in the food web does not biomagnify a persistent contaminant in Lake Ontario: The case of Cercopagis pengoi. Journal of Great Lakes Research 31: 210-218.

Tobin, M. E., King, D. T., Dorr, B. S., Werner, S. J. and Reinhold, D. S. 2002. Effect of roost harassment on the cormorant movements and roosting in the delta region of Mississippi. Waterbirds 25: 44-51.

Torres, P., Ortega, J. and Schlatter, R. 2005. Nematode parasites of the digestive tract in neotropic cormorant chicks (Phalacrocorax brasilianus) from the river Cruces Ramsar site in southern Chile. Parasitology Research 97: 103-107.

Trueman, C. N., McGill. R. A. R. and Guyard, P. H. 2005. The effect of growth rate on tissue-diet isotopic spacing in rapidly growing animals. an experimental study with Atlantic salmon (Salmo salar). Rapid Communications in Mass Spectrometry 19: $3239-3247$.

Tsao, D. C., Miles, A. K.. Takekawa. J. Y. and Woo, I. 2009. Potential effects of mercury on threatened California black rails. Archives of Environmental Contamination and Toxicology 56: 292-301. 
Vanderklift, M. A. and Ponsard, S. 2003. Sources of variation in consumer-diet delta N15 enrichment: A meta-analysis. Oecologia 136: 169-182.

Vest, J. L.. Conover, M. R., Perschon, C., Luft, J. and Hall. J. O. 2009. Trace element concentrations in wintering waterfowl from the Great Salt Lake, Utah. Archives of Environmental Contamination and Toxicology 56:302-316.

Vidal-Martinez, V. M., Pech, D., Sures, B., Purucker, S. T. and Poulin. R. 2010. Can parasites really reveal environmental impact? Trends in Parasitology 26: 44-51.

Watanuki, Y., Kato, A. and Naito, Y. 1996. Diving performance of male and female Japanese cormorants. Canadian Journal of Zoology 74: 1098-1109.

Wayland, M., Gilchrist, H. G., Dickson, D. L., Bollinger, T., James, C., Carreno, R. A. and Keating, J. 2001. Trace elements in king eiders and common eiders in the Canadian arctic. Archives of Environmental Contamination and Toxicology 41: 491 500.

Weimerskirch, H. and Lys, P. 2000. Seasonal changes in the provisioning behaviour and mass of male and female wandering albatrosses in relation to the growth of their chick. Polar Biology 23: 733-744.

Weimerskirch, H., Barbraud, C. and Lys, P. 2000. Sex differences in parental investment and chick growth in wandering albatrosses: Fitness consequences. Ecology $81: 309$ 318. 
Weiner, J. G., Krabbenhoft. D. P., Heinz, G. H. and Scheuhammer, A. M. 2003.

Ecotoxicology of mercury. In: Hoffman. D. J., Rattner, B. A., Burton, J. G. A. and Cairns. J. J. (eds.) Handbook of ecotoxicology. CRC Press, Boca Raton, FL, pp. 409463.

Weseloh, D. V.. Ewins, P. J., Struger, J., Mineau, P., Bishop, C. A., Postupalsky, S. and Ludwig, J. P. 1995. Double-crested cormorants of the Great Lakes: Changes in population size, breeding distribution and reproductive output between $1913 \mathrm{ad}$ 1991. Colonial Waterbirds 18: 48-59.

Weseloh, D. V., Teeple, S. M. and Gilbertson. M. 1983. Double-crested cormorants of the Great Lakes - egg-laying parameters, reproductive failure, and contaminant residues in eggs, Lake Huron 1972-1973. Canadian Journal of Zoology 61: 427-436.

Weseloh, D. V. C. and Ewins. P. J. 1994. Characteristics of a rapidly increasing colony of double-crested cormorants (Phalacrocorax aurthis) in Lake Ontario - populationsize, reproductive parameters and band recoveries. Journal of Great Lakes Research 20: 443-456.

Wiebe, K. L. and Slagstold. T. 2009. Parental sex differences in food allocation to junior brood members as mediated by prey size. Ethology 115: 49-58. 
Wiemeyer, S. N., Schmeling, S. K. and Anderson, A. 1987. Environmental-pollutant and necropsy data for ospreys from the eastern-united-states, 1975-1982. Journal of Wildlife Diseases 23: 279-291.

Williams, C. T., Buck, C. L., Sears, J. and Kitaysky, A. S. 2007. Effects of nutritional restriction on nitrogen and carbon stable isotopes in growing seabirds. Oecologia 153: $11-18$.

Williamson, C. E. 1991. Copepoda. In: Thorp, J. H. and Covich, A. P. (eds.) Ecology and classification of North American freshwater invertebrates. Academic Press, New York, pp. 787-813.

Wilson, K., Bjornstad, O. N., Dobson, A. P., Merler, S., Poglayen, G., Randolph, S. E., Read, A. F. and Skorping, A. 2002. Heterogeneities in macroparasite infections: Patterns and processes. In: Hudson, P. J., Rizzoli, A., Grenfell, B. T., Heesterbeek, H. and Dobson, A. P. (eds.) The ecology of wildlife diseases. Oxford University Press. Oxford. New York, pp. 6-44.

Wilson, H. M., Petersen. M. R. and Troy, D. 2004. Concentrations of metals and trace elements in blood of spectacled and king eiders in northern Alaska, USA. Environmental Toxicology and Chemistry 23: 408-414. 
Withers, K. and Brooks, T. S. 2004. Diet of double-crested cormorants (Phalacrocorax anritus) wintering on the central Texas coast. The Southwestern Naturalist 49; 48 53.

Wolfe, M. F., Schwarzbach, S. and Sulaiman, R. A. 1998. Effects of mercury on wildlife: A comprehensive review. Environmental Toxicology and Chemistry 17: 146-160.

Yang, D. Y., Ye, X., Chen, Y. W. and Belzile, N. 2010. Inverse relationships between selenium and mercury in tissues of young walleye (Stizosedion vitreum) from Canadian boreal lakes. Science of the Total Environment 408: 1676-1683.

Zar, J. H. 1999. Biostatistical analysis. Upper Saddle River, Prentice-Hall.

Zuk, M. and McKean, K. A. 1996. Sex differences in parasite infections: Patterns and processes. International Journal for Parasitology 26: 1009-1024. 
Appendix A: Operational definitions of terms bolded in the text.

\begin{tabular}{|c|c|}
\hline Term & Operational Definition \\
\hline Abundance & $\begin{array}{l}\text { A term used to describe the total number of parasites within } \\
\text { all hosts inspected (including uninfected hosts); mean } \\
\text { abundance is the average number of parasites per host } \\
\text { (infected and uninfected host) (Bush et al. 1997) }\end{array}$ \\
\hline Acanthocephalan & $\begin{array}{l}\text { Commonly called a thorny-headed worm: in the Phylum } \\
\text { Acanthocephala: uses at least two hosts in life cycle; found } \\
\text { in several classes of vertebrates (Bush et al. 2001) }\end{array}$ \\
\hline Bioaccumulation & $\begin{array}{l}\text { The increase in concentration of a contaminant in an } \\
\text { organism compared to the environment (Landis \& Yu 2004) }\end{array}$ \\
\hline Biodegradable & $\begin{array}{l}\text { Substance can be decomposed or broken down to simpler } \\
\text { and less harmful components by bacteria or other living } \\
\text { organisms (Landis \& Yu 2004) }\end{array}$ \\
\hline Biomagnify & $\begin{array}{l}\text { Progressive buildup or transfer of substances with increasing } \\
\text { trophic level (Landis \& Yu 2004) }\end{array}$ \\
\hline Cestode & $\begin{array}{l}\text { Commonly called a flatworm; in the Phylum Platyhelminthes } \\
\text { and Class Cestoidea. All parasitic, common in almost all } \\
\text { classes of vertebrates (except agnathan classes); intermediate } \\
\text { host required for most species (Roberts \& Janovy 2005) }\end{array}$ \\
\hline Definitive host & $\begin{array}{l}\text { The host in which a parasite achieves sexual maturity } \\
\text { (Roberts \& Janovy 2005) }\end{array}$ \\
\hline Helminth & A parasitic worm that lives inside the host \\
\hline Immunity & $\begin{array}{l}\text { The state in which a host is more or less resistant to an } \\
\text { infective agent (Roberts \& Janovy 2005) }\end{array}$ \\
\hline Immunosuppression & Reduction in an organisms immune function \\
\hline Indirect life cycle & $\begin{array}{l}\text { The use of successive hosts for growth and reproduction } \\
\text { (Roberts \& Janovy 2005) }\end{array}$ \\
\hline Intensity & $\begin{array}{l}\text { A term used to describe the total number of parasites in hosts } \\
\text { that were infected (excluding uninfected hosts); mean } \\
\text { intensity is the average number of parasites per infected host } \\
\text { (Bush et al. 1997) }\end{array}$ \\
\hline Intermediate host & $\begin{array}{l}\text { A host of a parasite for which the parasite develops to some } \\
\text { extent but does not achieve sexual maturity (Roberts \& } \\
\text { Janovy 2005) }\end{array}$ \\
\hline Life history traits & $\begin{array}{l}\text { Prime determinants of fitness; set of rules and choices } \\
\text { pertaining to an individual's schedule of reproduction, } \\
\text { survival and survival of offspring (e.g., development time, } \\
\text { body size and fecundity; Roff 1992) }\end{array}$ \\
\hline Nematode & $\begin{array}{l}\text { Commonly called a roundworm; in the Phylum Nematoda; } \\
\text { parasitic to variety of vertebrates; massive variability in life } \\
\text { cycles (Bush et al. 2001) }\end{array}$ \\
\hline
\end{tabular}


Appendix $A$

Appendix A. Continued

\begin{tabular}{|l|l|}
\hline Term & Operational Definition \\
\hline Pathogenicity & $\begin{array}{l}\text { Capability of an agent to produce disease (Roberts \& Janovy } \\
\text { 2005) }\end{array}$ \\
\hline Prevalence & $\begin{array}{l}\text { Percentage of all hosts infected from all hosts inspected } \\
\text { (Bush } \text { et al. } \text { 1997) }\end{array}$ \\
\hline $\begin{array}{l}\text { Sexual size } \\
\text { dimorphism }\end{array}$ & $\begin{array}{l}\text { The occurrence of morphological differences between males } \\
\text { and females relating to overall size (Fairbairn 1997) }\end{array}$ \\
\hline Stressor & $\begin{array}{l}\text { An external factor that might limit an organism's rate of } \\
\text { resource acquisition, growth and reproduction (Grime 1989) }\end{array}$ \\
\hline $\begin{array}{l}\text { Transmitted } \\
\text { trophically }\end{array}$ & $\begin{array}{l}\text { A method by which a parasite can reach its definitive host; } \\
\text { pertains to the parasite exploiting predator-prey relationships } \\
\text { to reach the next host in their life cycle (Bush et al. 2001) }\end{array}$ \\
\hline Trematode & $\begin{array}{l}\text { Commonly called a flatworm (or fluke); in the Phylum } \\
\text { Platyhelminthes and Class Trematoda: all parasitic, common } \\
\text { in all classes of vertebrates; Subclass Digenea uses at least } \\
\text { two hosts in life cycle and is the only Subclass that uses } \\
\text { birds as one of its hosts (Roberts \& Janovy 2005) }\end{array}$ \\
\hline Trophic levels & $\begin{array}{l}\text { Steps in a food chain; for example, primary producers are at } \\
\text { a lower trophic level than top consumers, such as piscivorous } \\
\text { birds }\end{array}$ \\
\hline
\end{tabular}

